\title{
THESIS
}

\section{A SPATIO-TEMPORAL CORRELATION TECHNIQUE TO IMPROVE SATELLITE \\ RAINFALL ACCUMULATION}

\author{
Submitted by \\ Veljko Petković \\ Department of Atmospheric Science
}

\author{
In partial fulfillment of the requirements \\ For the Degree of Master of Science \\ Colorado State University \\ Fort Collins, Colorado
}

Summer 2011

Master's Committee:

Advisor: Christian D. Kummerow

Thomas H. Vonder Haar

Jorge A. Ramírez 
Copyright by Veljko Petković 2011

All Rights Reserved 
ABSTRACT

\section{A SPATIO-TEMPORAL CORRELATION TECHNIQUE TO IMPROVE SATELLITE}

\section{RAINFALL ACCUMULATION}

A spatio-temporal correlation technique has been developed to combine satellite rainfall measurements using the spatial and temporal correlation of the rainfall fields to overcome problems of sparse and infrequent measurements, while at the same time accounting for the measurements' accuracies. This technique estimates instantaneous rainfall with desired temporal sampling using only currently available satellite measurements with the goal of estimating 3-hour total rainfall accumulations at various spatial scales.

The technique uses weighted mean to combine the measurements, adjusting the weights to the temporal correlation length of the measured rainfall field, and to the instrument accuracies. The relationship between the temporal and spatial correlation of the rainfall field is exploited to provide information about rainfall beyond instantaneous measurements. This information, depending on the nature of the rainfall field, can be accurate for prolonged time periods. It is shown that slow changing rainfall fields (i.e. stratiform-like rain) have high values of spatial correlation coefficients, and temporal correlation lengths as long as $60 \mathrm{~min}$. While, 
on the other hand, fast changing rainfall fields (i.e. convective-like rain) tend to have low spatial correlations, and temporal correlation lengths as short as $20 \mathrm{~min}$.

This technique is developed using synthetic radar data. Nine months of the Operational Program for the Exchange of weather RAdar (OPERA) data is used on grid sizes of $100 \mathrm{~km}, 250 \mathrm{~km}$ and $500 \mathrm{~km}$ with pixel resolutions of $8 \mathrm{~km}, 12 \mathrm{~km}$ and $24 \mathrm{~km}$ to simulate satellite FOVs, and then applied to the real satellite data over the Southwest region of USA to calculate 3-hour rainfall accumulations. The results are then compared to the simple averaging technique, which takes a simple mean of the measurements as a constant rainfall rate over the entire accumulation period. The comparison is presented as improvements of the total absolute and RMS errors. Using synthetic data, depending on the time separation of the measurements and their accuracy, the technique has shown the potential to bring improvements of up to $40 \%$ in absolute, and up to $25 \%$ in RMS error. When applied to the real satellite data over the SE-USA, the technique has shown less skill, only $2 \%$ to $6 \%$ error improvement, which can be explained by the poor temporal sampling of the reference measurements.

This technique is computationally inexpensive and easily applicable to currently used rainfall accumulation methods with linear interpolation between measurements such as CMORPH (Climate Prediction Center's Morphing Technique) and TMPA (The Tropical Rainfall Measuring Mission Multi-satellite Precipitation Analysis). 


\section{ACKNOWLEDGMENTS}

I would like to thank my advisor, Professor Christian Kummerow, for giving me an opportunity to work and study at the prestigious Department of Atmospheric Science at Colorado State University. I would also like to thank my committee members, Professors Thomas Vonder Haar and Jorge Ramirez, for their helpful comments and for taking time out of their schedules to serve on my committee. Also, thanks to all the amazing people I've met in Professor Kummerow's research group for all their help and encouragement, especially Amariah Lebsock for helping me to improve my writing skills. And last, but certainly not least, thank you to my lovely wife Biljana Orescanin for all her love and support.

Veljko Petkovic

Department of Atmospheric Science

Colorado State University

Fort Collins, CO 80523

Summer 2011 


\section{TABLE OF CONTENTS}

Chapter

Page

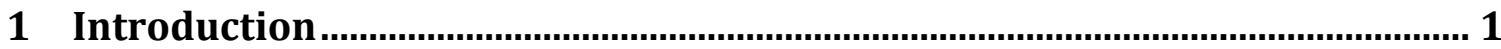

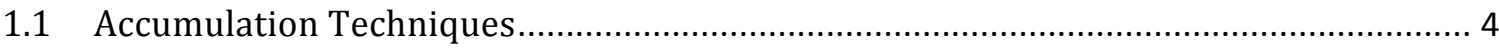

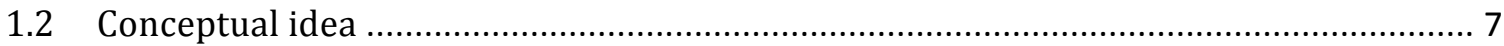

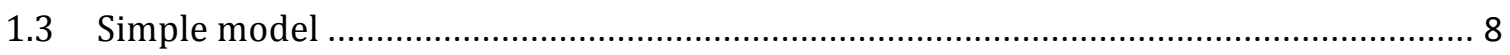

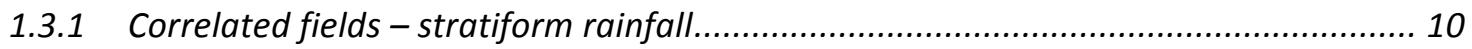

1.3.2 Uncorrelated fields - convective rainfall............................................................ 12

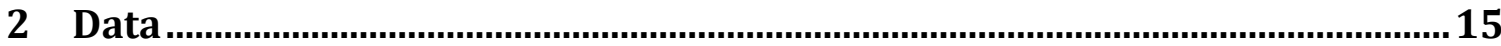

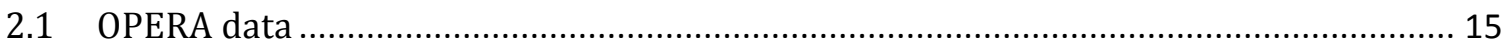

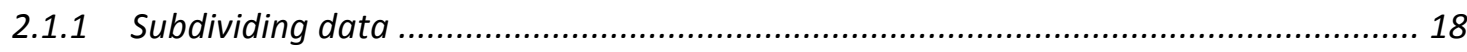

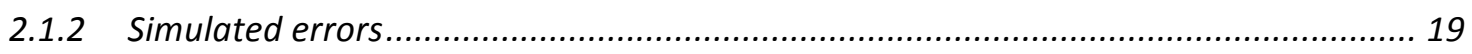

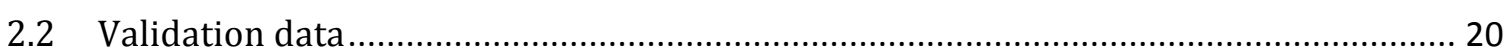

3 Temporal variability and spatial correlation of rainfall .............................24

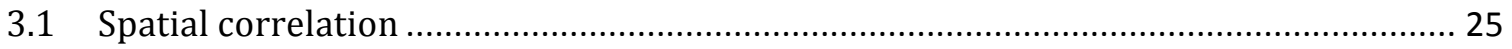

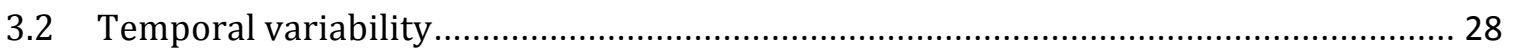

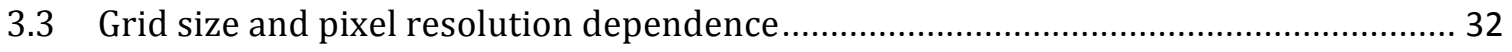

3.4 Temporal variability dependence on spatial correlation coefficient............................ 35

4 Spatio-temporal correlation technique

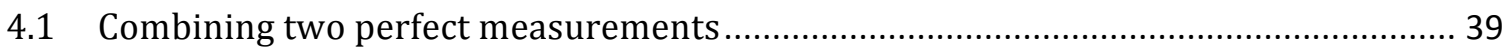

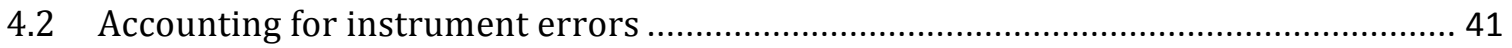

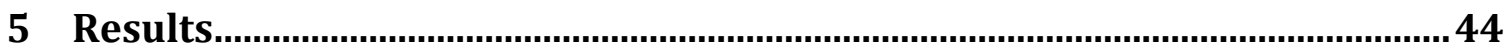

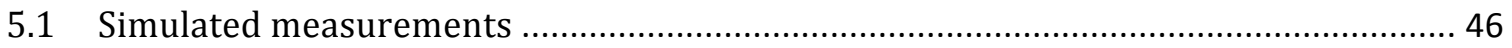

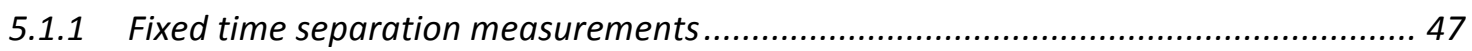

5.1.2 Random time separation measurements ............................................................... 49

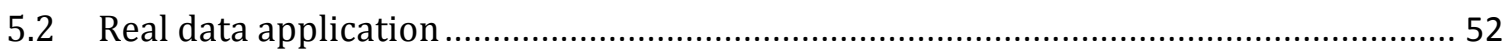

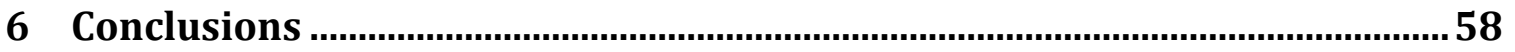

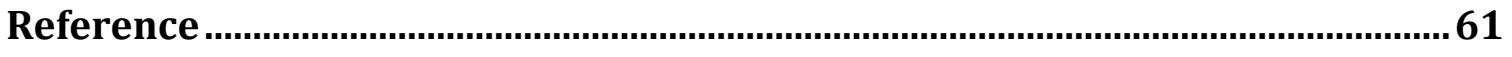

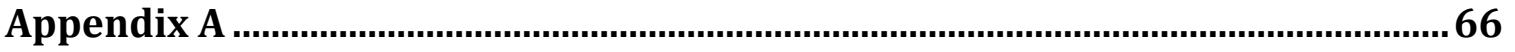

Appendix B

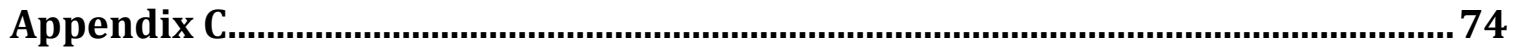




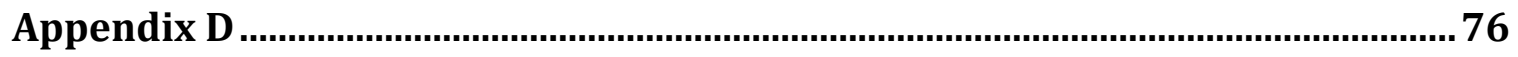

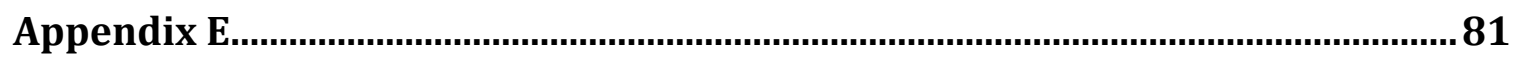




\section{LIST OF TABLES}

$\underline{\text { Table }}$

Page

Average spatial correlation coefficient for grid size of $100 \times 100 \mathrm{~km}$............................. 27

Temporal variability time dependence shown in Figure 12 ............................................. 31

Temporal variability time dependence shown in Figure 13 ........................................... 32

Averaged spatial correlation coefficient for different grid sizes and pixel resolutions

Average temporal variability (\%) for different grid sizes and pixel resolutions for time separations of $30 \mathrm{~min}$ and $45 \mathrm{~min}$ 35

Look up table of temporal variability for a grid size of $250 \mathrm{~km}$ and a $12 \mathrm{~km}$ pixel resolution 41

Instantaneous grid average rainfall estimates given by the correlation technique .. 45 Instantaneous grid rainfall estimates given by simple averaging technique ............... 45

Instantaneous grid rainfall estimates given by OPERA data (the truth) ........................ 46 Comparing the results of two technique estimates .......................................................... 46

Error improvement (\%) for various time separations; grid size $250 \mathrm{~km}$; pixel

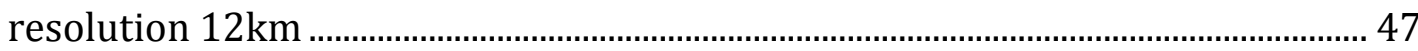

Absolute error improvement (\%); $120 \mathrm{~min}$ separation time; Grid size $250 \mathrm{~km}$; pixel

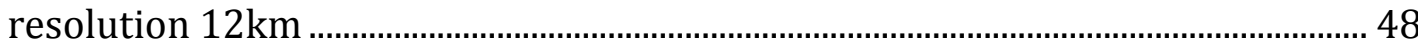

RMS error improvement (\%); 120min separation time; Grid size 250km; pixel resolution $12 \mathrm{~km}$

Error improvement; random separation time; grid size $250 \mathrm{~km}$ pixel resolution $12 \mathrm{~km}$ 50

Absolute error improvement (\%); random separation time; grid size $250 \mathrm{~km}$ pixel resolution $12 \mathrm{~km}$

RMS error improvement (\%); random separation time; grid size $250 \mathrm{~km}$ pixel resolution $12 \mathrm{~km}$

Absolute error improvement for sensors uncertainty of 30\%; various grid sizes and

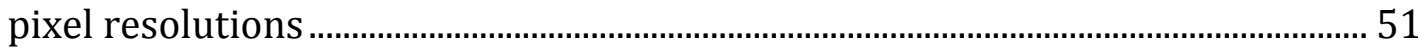

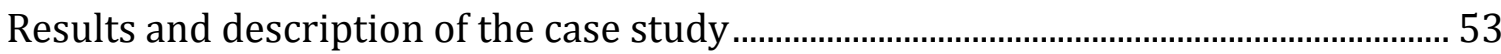

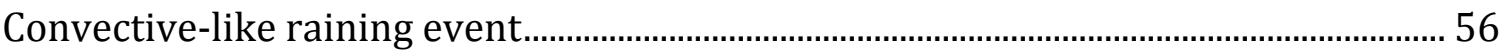

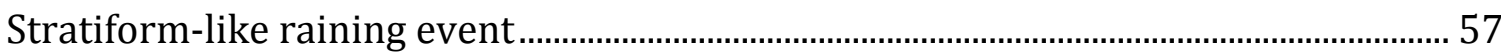

Spatial correlation coefficient and length for a grid size of $100 \times 100 \mathrm{~km}$..................... 66 
Correlation length vs. correlation coefficient.............................................................. 67

temporal correaltion coefficient for separation times of 30 and $45 \mathrm{~min}$........................ 68

Spatial-Temporal length (grid size 250km; pixel resolution 12km) ……………...... 69

Spatial correlation coefficient correction (grid size $250 \mathrm{~km} ; 12 \mathrm{~km}$ pixel resolution) 


\section{LIST OF FIGURES}

Figure

$\underline{\text { Page }}$

Radar rainfall rates over Europe (OPERA image on 2nd May 2009)..... 9

Evolution of the uniform rainfall field over 3-hour time interval in 15min snapshots

Evolution of the non-uniform rainfall field over 3 hour time interval in 15min snapshots. 13

OPERA data scene 16

OPERA network (map provided from OPERA web documentation) 18

Case study area (grey rectangle) and NEXRAD radar sites (yellow pins) ..................... 21

NEXRAD Stage IV data scene (hourly rainfall accumulation). 22

NEXRAD Stage IV radar data zoomed into the case study area (hourly rainfall

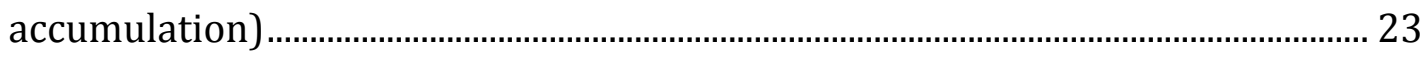

Calculation of the spatial correlation coefficient ........................................................... 26

Rainfall rate distribution of non-uniform vs. uniform type of rain................................ 28

Calculation of temporal variability ............................................................................................ 29

Time line of temporal variability for stratiform raining event shown in Figure 2.... 30

Time line of temporal variability for non-uniform raining event shown in Figure 332 Temporal variability vs. spatial correlation coefficient (grid size: $250 \mathrm{~km}$, pixel

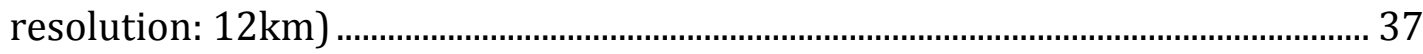

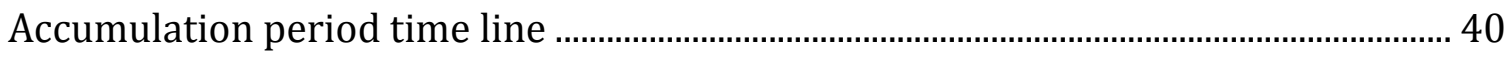

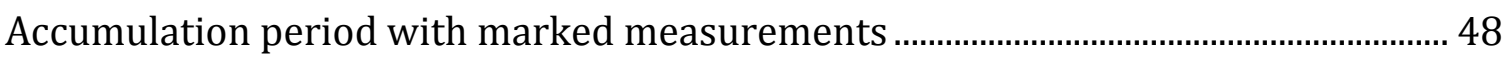

Convective-like raining event (NEXRAD stage IV hourly rainfall accumulations) ..... 54

Stratiform-like raining event (NEXRAD stage IV hourly rainfall accumulations) ...... 55 Spatial correlation coefficient vs. length (grid size $100 \mathrm{~km}$; $8 \mathrm{~km}$ pixel resolution) ... 67 Spatial-Temporal length (grid size 250km; pixel resolution $12 \mathrm{~km}$ )............................... 69 


\section{CHAPTER 1}

\section{Introduction}

Demands on water resources have been increasing since the early days of human kind. Today, more than one billion people-almost one-fifth of the world's population-still lack access to safe drinking water according to the $3^{\text {rd }}$ United Nations World Water Development Report (2009). Precipitation variability dominates both water supply and the occurrence of droughts and floods, thus exerting great pressure on agriculture, as well as economic and social activities. This was and still is the basic motivation for precipitation measurements from early records in China dating as far back as two thousand years B. C. (Wand and Zhang 1988). Today's motives are still the same with perhaps an added interest related to recent climate change science. Understanding the hydrologic balance on a global scale requires accurate precipitation information available at a high temporal resolution. Atmospheric energy sources are highly influenced by spatial and temporal distribution of the precipitation. An important part of the global hydrology cycle is the interaction between its small and large-scale components. Both climate and weather forecasts suffer from insufficient information about rainfall reflected in their inability to correctly represent raining processes. All of this points to the importance of precipitation measurements. Occurrence, intensity, amount, time and 
place of a rain event is information that is always in high demand. Of those parameters, rainfall accumulation is typically the most complex measurement. To provide one, either dense frequent measurements or perfect knowledge about the nature of rain is required.

For hundreds of years rainfall has been measured by the conventional method of rain gauges, which provide good temporal coverage but no spatial distribution. Today, with the ground radar networks and satellite remote-sensing technology, rainfall accumulation estimates have improved dramatically. However, even with the latest improvements there is still not enough accuracy to satisfy all the needs of hydrology and meteorology. Research areas such as radiation, climate and flash floods are still lacking in temporal and spatial coverage.

Spatial scales requirements can be as small as $1 \mathrm{~km} \times 1 \mathrm{~km}$ for purposes of nowcasting flash flood events (Huff 1993 and Yates et al. 2000), and as large as $250 \mathrm{~km} \times 250 \mathrm{~km}$ for global climate analysis and forecasting (ref. GEWEX). At the same time, requirements on temporal sampling varies from $5 \mathrm{~min}$ (flash floods) to a week or month (climatology means). There is also a demand for high accuracy at large scales. For example, although they correspond to very large spatial and temporal scales, calculations of global or regional rainfall trends require very small errors.

Currently the best areal rainfall accumulations are provided by systems such as the Weather Surveillance Radar 1988 Doppler (WSR-88D) system in the United States (Crum et al. 1998). Unfortunately, the majority of the World does not have 
such systems and is limited to satellite estimates. Using all currently available space based measurements even three-hour and 0.25 degree space resolution remains a challenge (Joyce et al. 2004, Huffman et al. 2007). The primary objective of this study is to assess if spatial correlation patterns observed in rain systems can be exploited to improve three-hour accumulations that would result from simple averaging of sensor data.

Current rainfall accumulation products are based on measurements provided by Infrared (IR), microwave and sometimes model results to compensate for poor temporal and spatial samplings over some areas. Certainly for convective rain, studies have shown that radars and spaceborn microwave sensors have the highest skill scores (Ebert et al. 2007). However, these sensors suffer from temporal sampling limitations.

Currently, temporal coverage of rainfall measurements from passive microwave sensors varies from about 30-minute at high latitudes to about 6 hours at low and mid-latitudes. It is expected that three-hour time sampling (the goal set by the Global Precipitation Climatology Project) over all latitudes become available for the first time once the Global Precipitation Mission (GPM) is in place (http://gpm.gsfc.nasa.gov). To achieve this 3-hour global coverage goal, this project plans to launch a core satellite to be used as a reference standard to a constellation of partner radiometers. Measurements from all available satellites, regardless of their capabilities, will be integrated to provide one global rainfall product. There is no doubt that a planned increase in the number of orbiting satellites itself will 
dramatically improve the quality of current rainfall products. However, in order to provide the best possible results, the measurements from all sensors need to be combined in such a manner that the most accurate ones are exploited to its maxima.

A number of techniques for combining the information from different instruments have been developed. Currently, techniques such as TMPA (Huffman et al. 2007) and CMORPH (Joyce et al. 2004) are able to provide rainfall estimates based on the combination of IR, microwave, radar and gauge measurements from both space and the ground (when available). These techniques use different methods to overcome poor temporal-spatial sampling. However, there are still some basic problems that if solved in a more quantitative manner can improve rainfall estimates from combined measurements. Before discussing these problems, they are introduced through a brief description of what are currently considered to be state of the art rainfall accumulation techniques.

\section{$1.1 \quad$ Accumulation Techniques}

The method called CMORPH (Climate Prediction Center's Morphing Technique: Joyce et al. 2004) is based on tracking the rain system using information from geostationary satellites (Griffith et al. 1978). CMORPH uses motion vectors derived from half-hourly interval geostationary satellite IR imagery to propagate the relatively high quality precipitation estimates derived from passive microwave data. In addition, the shape and intensity of the precipitation features are modified (morphed) during the time between microwave sensor's scans by performing a 
time-weighted linear interpolation. This process yields spatially and temporally complete microwave-derived precipitation analyses, independent of the infrared temperature field. CMORPH showed substantial improvements over both the simple averaging of the microwave estimates and over the techniques that blend microwave and infrared information but that derive estimates of precipitation from infrared data when passive microwave information is unavailable. However, CMORPH does not account for the differences in accuracy of microwave sensors or the length of time that a passive microwave estimate might be valid for. For example, if two measurements taken at the same time by two microwave sensors of different accuracies are available, CMORPH will simply use the average value since time weighting does not apply in this scenario. This is clearly not the best of what two measurements can provide. This study offers a relatively simple solution for this and similar accuracy related issues that can be easily implemented into interpolation process.

The Tropical Rainfall Measuring Mission (TRMM) Multi-satellite Precipitation Analysis (TMPA), is another method which provides a calibration-based sequential scheme for combining precipitation estimates from multiple satellites, at fine scales (0.25 × 0.25 and 3hourly: Huffman et al. 2007). This method calibrates the measurements from multi-satellite sensors using probability matching of precipitation rate histograms of coincident data similar to the probability-matched method suggested by Miller (1972) and used, for example, by Krajewski and Smith (1991). Estimates are produced in four stages: 1) the microwave precipitation estimates are calibrated and combined, 2) infrared precipitation estimates are 
created using the calibrated microwave precipitation, 3) the microwave and IR estimates are combined, and 4) rain gauge data are incorporated. The data source used in this process is TRMM combined instrument estimate, which employs data from both TRMM microwave imager and TRMM precipitation radar (TRMM product 2B31; Haddad et al. 1997a,b). In essence, when the measurement is provided by one of lower quality sensors this method uses measurements of higher quality instruments as a reference for calibrating. However in this process the method uses relatively simple technique to form the best estimate of microwave input. For example, when there are multiple overpasses in the 3-hour window for a given grid box, data are simply averaged.

TMPA and CMORPH accumulations are ultimately both based on simple averages of individual observations with no weight on the temporal correlation of potentially superior estimate at some time step in the averaging window. This study explores this topic providing a relatively simple method to exploit the temporal correlation of rain to improve rainfall accumulation of techniques such as those.

The goal of this study is to investigate the nature of the rainfall fields and, based on the findings, to develop a method that is capable of combining instantaneous rainfall estimates into a rainfall accumulation. Rather than taking a simple average of the measurements to represent the whole accumulation period, the method will recognize when one measurement should be trusted for longer periods. This solution can form a basis for improving accumulation techniques currently in use. 


\subsection{Conceptual idea}

When measurements from two sensors are combined, their accuracies are often quite different. In such cases they should be weighted according to their accuracy. Simply, measurements of higher accuracy should be trusted more. The example of such an application is satellite-gauge-model (SGM: Huffman et al. 1995). SGM combines satellite and gauge measurements with model results, weighting them by their accuracy. In this study, the focus is on a 3-hour accumulation window sampled by two radiometers. Rather than simply averaging two satellites overpasses in the grid box to form a 3-hour accumulation, the technique will look at both the accuracy and the temporal correlation of the observed field to develop an optimal accumulation strategy for each grid box.

If successfully designed, this method will improve the accuracy of combined rainfall rate measurements. To verify the results the rainfall accumulation will be compared to the "simple mean technique" results. This technique simply uses an average of two measurements to form a combined estimate.

Similar to the SGM, the basis of this concept is using a weighted mean. If two measurements are made at times different than the time at which the estimate based on them is made, then it is important to consider the expected change in the rainfall field from the time of observation, as well as the accuracy of each measurement. A larger weight should be assigned if the rain is expected to change little and accuracy is high. The method, however, also has to be capable of 
recognizing a point at which temporal decorrelation dominates over measurement accuracy error and vice versa. Using a simple model, the basic idea of the method is presented in the following section, while a detailed description can be found in Chapter 4 .

\subsection{Simple model}

Figure 1 depicts the radar image over Europe on May $2^{\text {nd }}$ 2009. This is a product of the OPERA radar network system which is further described in Chapter

2. The blue and green rectangles in the figure indicate the approximate locations of the areas where two raining systems, subjectively classified as non-uniform and uniform, respectively, have occurred. The sizes of the marked areas are about $150 \times 150 \mathrm{~km}$. 


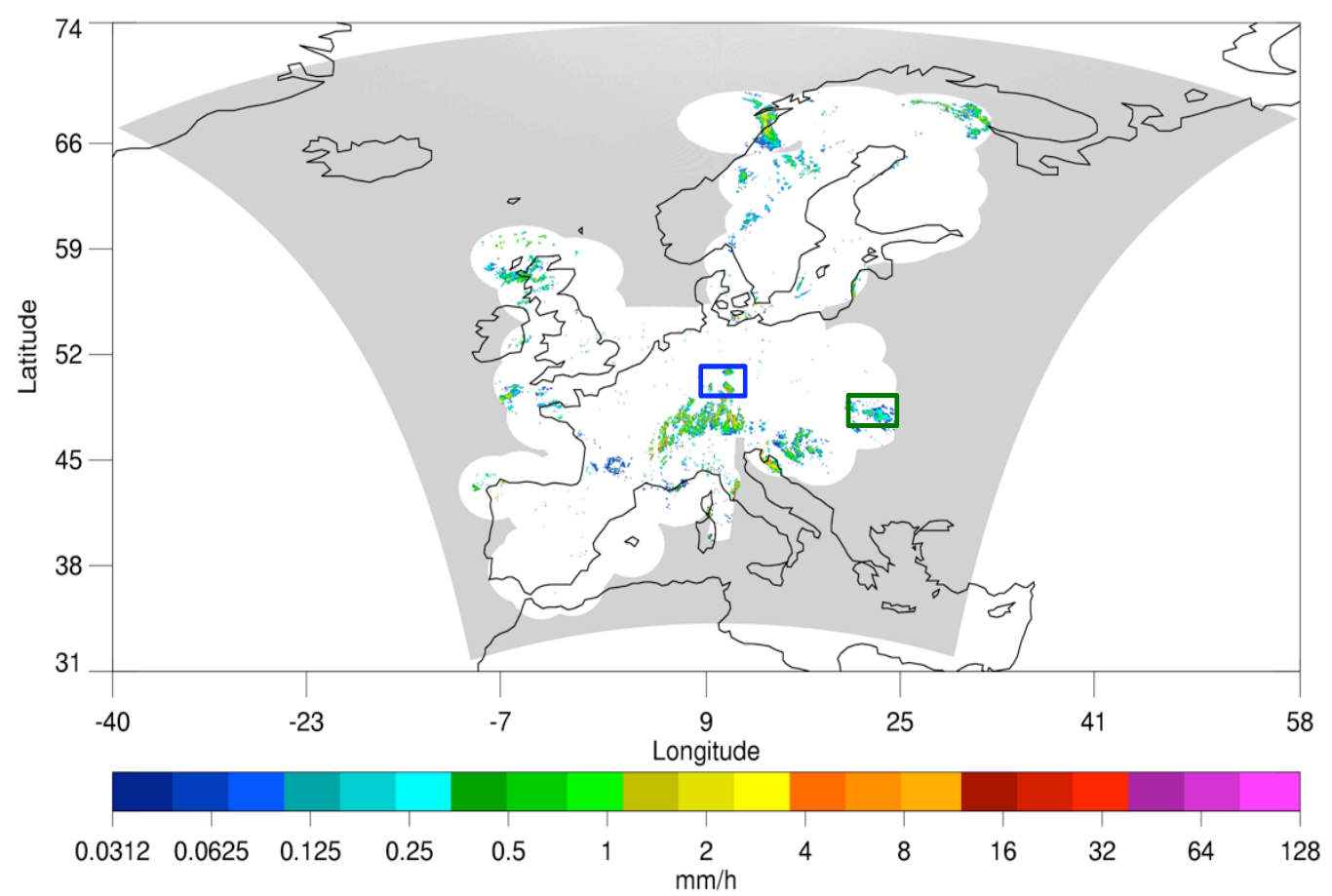

Figure 1. Radar rainfall rates over Europe (OPERA image on $2^{\text {nd }}$ May 2009)

Both areas, the green and the blue, are shown in Figure 2 and Figure 3, respectively, as sets of radar snapshots taken over the three-hour time interval. These two events, one more convective and one more stratiform, are used to illustrate how the nature of the measured raining system can be used as a criterion for assigning the weights to the measurements before they are combined.

To conceptually introduce the method, imagine that for the 3-hour time interval, shown in Figure 2, two measurements are given by the first and last snapshots only. Based on these two measurements a 3-hour accumulation must be estimated. This can be done in two steps. In the first step, each of the measurements is used to create a set of the "best guesses" of the precipitation at a set of fixed time points along the accumulation period. In the second step, the estimates derived from 
each of the measurements are weighted and combined based upon the expected accuracy of each estimate. Here and throughout this study, the field's states are estimated at 15-minute time increments in order to match OPERA data sampling and to make the method verification process easier. Chapter 4 describes in detail the second of the two steps. This section will only focus on the first one, where the instantaneous rain measurements and knowledge of the rain system characteristic are used to estimate the rainfall at intermediate time steps.

We define a quantity called temporal variability to provide the uncertainty of the estimate at some time, $\boldsymbol{t}$, before or after the actual observation. The definition and detailed description of temporal variability is given in Chapter 3. From a rain system's perspective, the more uniform the system, the less it will change in time. Small changes imply small temporal variability, while greater changes imply grater temporal variability. Temporal variability, while unique to each raining system, nonetheless do have some general characteristic. This is presented in Chapter 3. The next two examples illustrate how the nature of a raining system can be quantified.

\subsubsection{Correlated fields - stratiform rainfall}

Figure 2 shows a set of consecutive 15-minute snapshots over a zoomed-in

area marked by the green rectangle in Figure 1. By tracking the change (in time) of the rainfall system's shape and intensity, it can be observed that the shape changes relatively slowly while the rainfall rates remain more or less constant. In other words, a stratiform rain system as shown in Figure 2, is likely to keep its shape and intensity for prolonged time periods. Mathematically, time change of the system can 
be presented through a temporal correlation coefficient or temporal variability (both defined later). If calculated between the initial and each of the latter states, the value of this coefficient will slowly decrease, while the value of the temporal variability will slowly increase.

Besides this slow change in time, another important property of the stratiform system shown in Figure 2 is the absence of large changes in rainfall rates. Mathematically, the uniformity of the system can be presented by a spatial correlation coefficient. If calculated, this coefficient would have a high value for any of the field states shown in Figure 2. The mathematics of this is also presented in Chapter 3. 


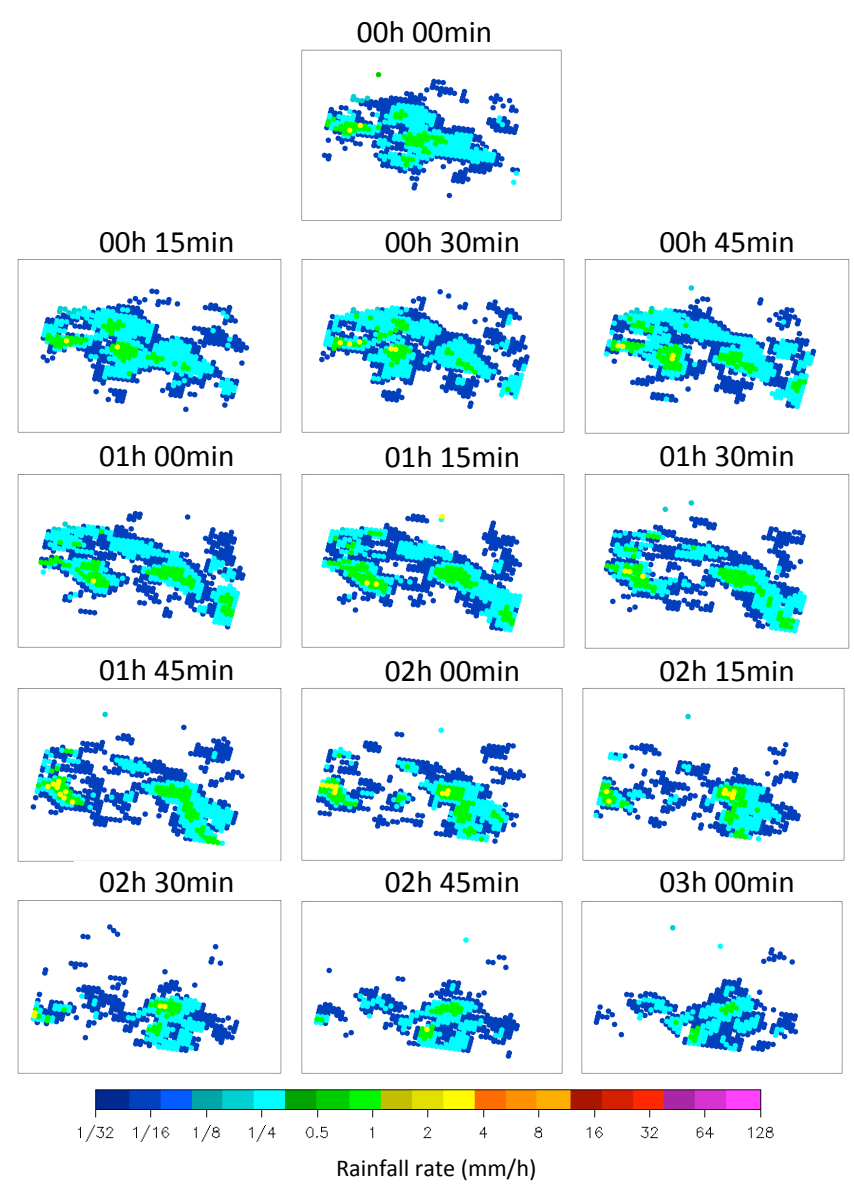

Figure 2. Evolution of the uniform rainfall field over 3-hour time interval in 15min snapshots

\subsubsection{Uncorrelated fields - convective rainfall}

Another rain event (the one marked by the blue rectangle in Figure 1) is shown in Figure 3. Again, focusing on the temporal and spatial change of the distribution of the rain, it is noticeable that the rainfall field at the time of 15minutes is already quite different form the initial one, especially in rain intensity. Mathematically speaking, this means that the temporal variability between the two field states is large or, the temporal correlation coefficient is low. At the same time, due to high spatial variability in the rainfall rates, this is an example of a non- 
uniform system, typically associated with convective types of clouds. If calculated, the spatial correlation coefficient of any of the states shown in Figure 3 would have a low value.

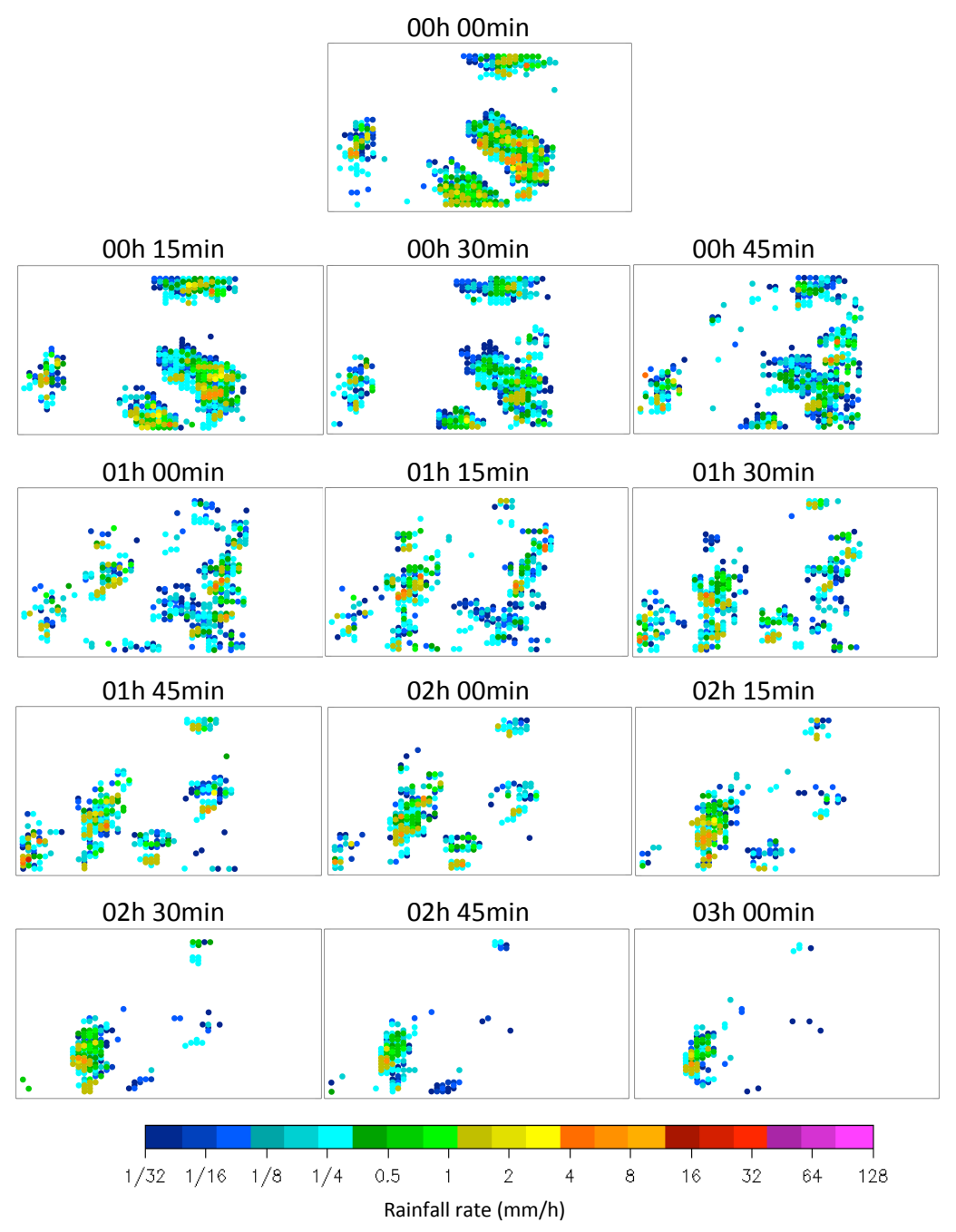

Figure 3. Evolution of the non-uniform rainfall field over 3 hour time interval in $15 \mathrm{~min}$ snapshots

It is important to note that for two completely different types of raining systems seen in these two examples, stratiform and convective, the relationship between temporal variability and spatial correlation coefficient is preserved. Temporal variability appears inversely proportional to the spatial correlation 
coefficient. This relation will be exploited to say something about the temporal evolution of the rain field based upon the spatial correlation coefficient at any given time. This sets the basis for this study, namely that the spatial correlation computed at the time of rainfall observation is generally related to the temporal correlation of the rainfall and therefore can be exploited to improve the estimated rain between actual observations. 


\section{CHAPTER 2}

\section{Data}

\subsection{OPERA data}

The primary goal of this study was to design a rainfall accumulation method that is based on any two, or more, instantaneous rainfall measurements. To accomplish this, the data from the Operational Program for the Exchange of weather RAdar (OPERA) were employed. The OPERA program (Huuskonen, 2006) is the Weather Radar program of GIE/EIG (Economic Interest Group) EUMETNET, the Network of the European Meteorological Services. The objective of OPERA is to harmonize and improve the operational exchange of weather radar information between national meteorological services. It is a joint effort of 30 European countries, and it is designed to firmly establish the host of the European Weather Radar Network. Currently OPERA is in its $3^{\text {rd }}$ stage (OPERA 3). The program will run from 2007 through 2012 with the Royal Netherlands Meteorological Institute as the Coordinating Member. OPERA 3 radar data are available at 15-minute time resolution over the majority of Europe (see Figure 4) at a spatial resolution (here referred to as pixel resolution) of $4 \mathrm{~km} \times 4 \mathrm{~km}$. This makes OPERA data well suited for studying spatial and temporal properties of precipitating systems. This study 
uses OPERA 3 data from the beginning of September 2008 to the end May 2009 over its entire available domain.

Figure 4 presents a randomly chosen OPERA data scene. Scenes like this one are available every 15 minutes, except for intermittent problems affecting individual radars and for a dominant period during January and February 2009 when no data are available due to archiving.

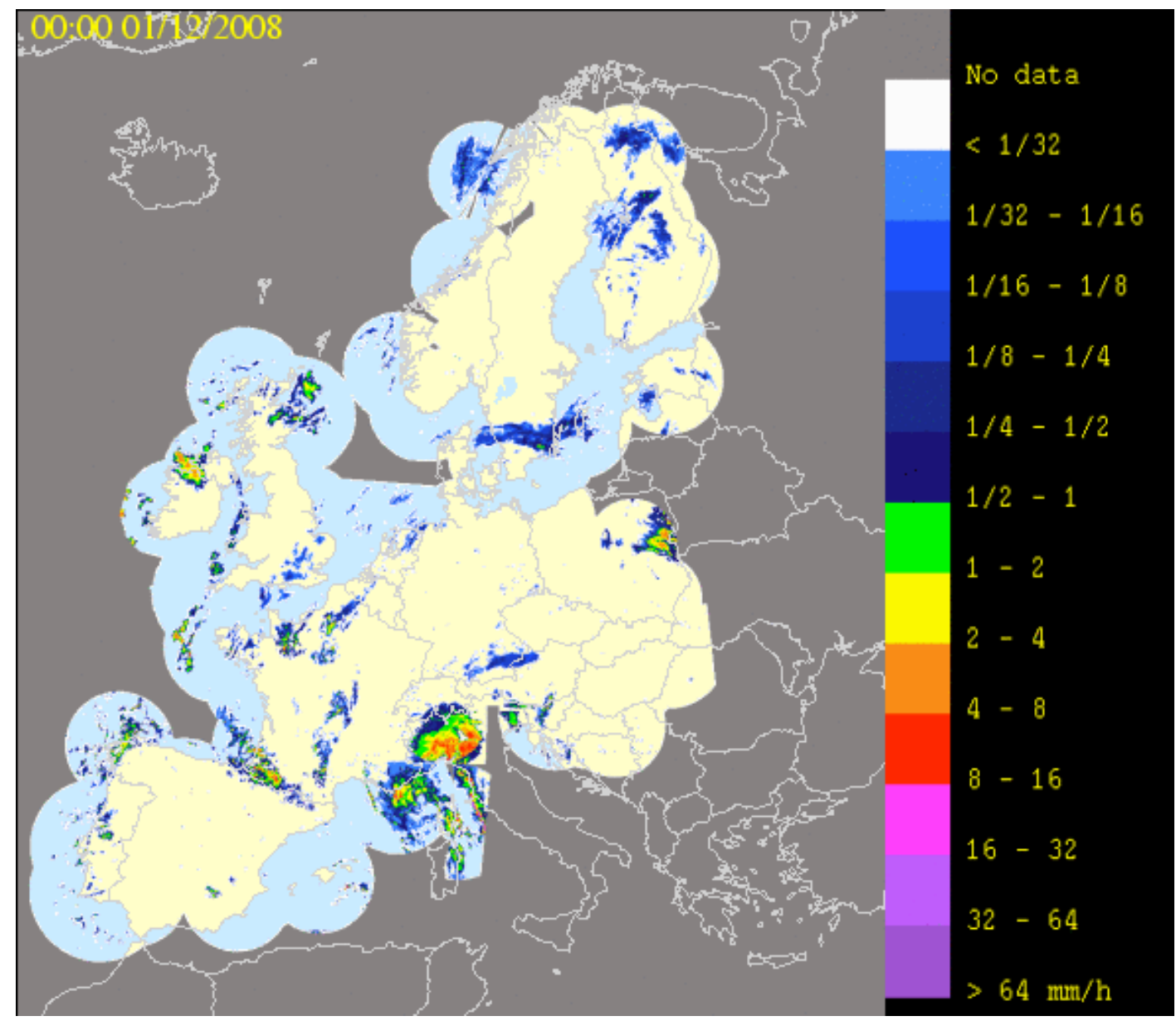

Figure 4. OPERA data scene

The current spatial distribution and radar types in the OPERA network system are shown in Figure 5. Data from Iceland, Bulgaria, Romania, Serbia, Greece, 
Lithuania, and the eastern part of Italy were not used in the study since these data became available in the OPERA network only in late 2009 and 2010. A total of approximately 100 radars are used, all of which operate at S, C or X band in either Doppler or non-Doppler mode. About $5-10 \%$ of radars are polarimetric radars. All data are assumed to be accurate with no qualitative differences between different types of radars. The data is used here only to develop and test the techniques so that uncertainties in the rain rates themselves would have little or no impact on the results. No time or space interpolation is made at times when missing data has occurred. 


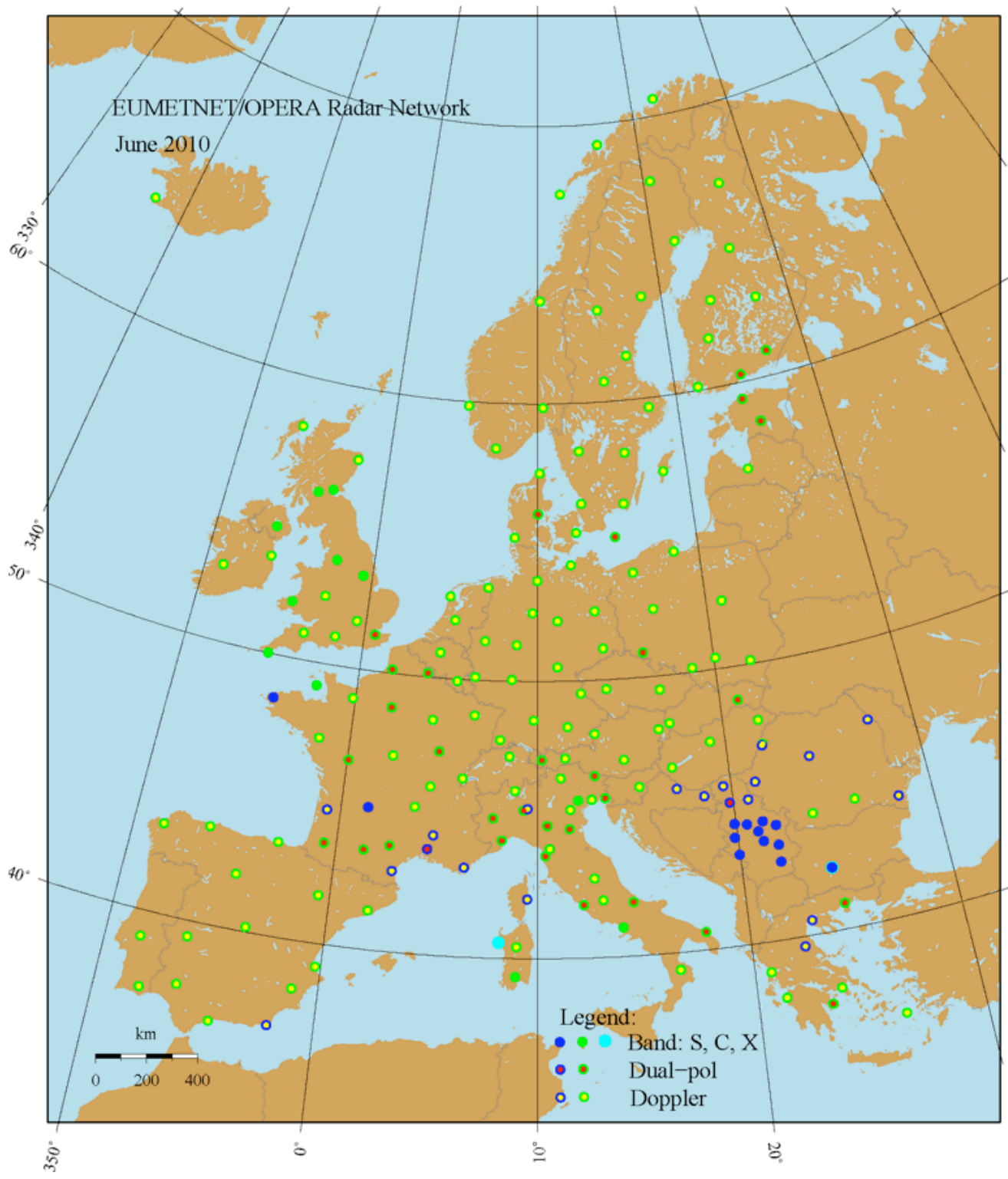

Figure 5. OPERA network (map provided from OPERA web documentation)

\subsubsection{Subdividing data}

All scenes are divided into a number of square, equally spaced sub-scenes, referred to as grids. In this study, the following three grid sizes are used: $100 \mathrm{~km}$, $250 \mathrm{~km}$ and $500 \mathrm{~km}$. These grids are intended to correspond to typical accumulation grids used in satellite studies. For a grid size of a $100 \mathrm{~km}$, for instance, the entire 
radar coverage area is divided into approximately 400 sub-scenes. Throughout the study, only fully covered sub-scenes containing at least one raining pixel are used as grids. Each grid contains a certain number of pixels. Beside the original $4 \mathrm{~km}$ radar resolution, three lower pixel resolutions are formed $(8 \mathrm{~km}, 12 \mathrm{~km}$ and $24 \mathrm{~km}$ ). Averaging the number of neighboring pixels reduces the original resolution. These pixels resolutions are again intended to represent typical satellite fields of view (FOVs).

A grid size of $100 \mathrm{~km}$ provides approximately 1.5 million grids over the 6 months of available OPERA data. For $500 \mathrm{~km}$ grids, the number of grids is approximately 100 000, still providing a relatively large database.

\subsubsection{Simulated errors}

The methodology developed in this study is intended for satellite data application, which, unlike the OPERA data, has a broad range of uncertainties. Therefore, the methodology must be tested on inaccurate data. Rather than using sparse, scattered, real satellite data where the accuracy is often difficult to estimate, inaccurate data are simulated by the OPERA data itself.

Random errors are introduced in a controlled manner. Normally distributed random perturbations are added to the prescribed pixel rain rates. This is done following

$$
r=r_{\text {OPERA }}\left(1+e_{r} n\right)
$$


where $\boldsymbol{r}$ denotes the rainfall rate having some uncertainty, $\boldsymbol{e}_{\boldsymbol{r}}, \boldsymbol{r}_{\text {opfRA }}$ is the original rainfall value provided by OPERA, $\boldsymbol{n}$ in normally distributed random number, and $\boldsymbol{e}_{\boldsymbol{r}}$ is the assigned error. The product $\boldsymbol{e}_{\boldsymbol{r}} \boldsymbol{n}$ represents a perturbation that has been added to the original data. The value of $\boldsymbol{e}_{\boldsymbol{r}}$ is allowed to vary from 0.1 to 0.9 (in increments of 0.1 ) corresponding to errors from $10 \%$ to $90 \%$.

\subsection{Validation data}

While the methods are developed using OPERA data, the methodology is tested using real data in a case study over the Southeastern US. Satellite data are provided from currently available sensors consisting of the TRMM Microwave Imager (TMI: Kummerow et al. 1998), the Advanced Microwave Scanning Radiometer for EOS (AMSR-E) onboard the NASA Aqua satellite (Lobl 2001, NSIDC 2007b), and the Special Sensor Microwave Imagers (SSM/I: Weng, and Grody, 1994) carried aboard the Defense Meteorological Satellite Program's (DMSP) satellites F13, F14 and F15. The data covers a 10 day time period from April $20^{\text {th }}$ to April $30^{\text {th }}$ 2006. The area used in the case study is $10^{\circ}$ by $5^{\circ}$, placed in the South-Eastern USA $\left(83^{\circ} \mathrm{W}-93^{\circ} \mathrm{W}, 31^{\circ} \mathrm{N}-36^{\circ} \mathrm{N}\right)$ marked in Figure 6 as a grey rectangle. 


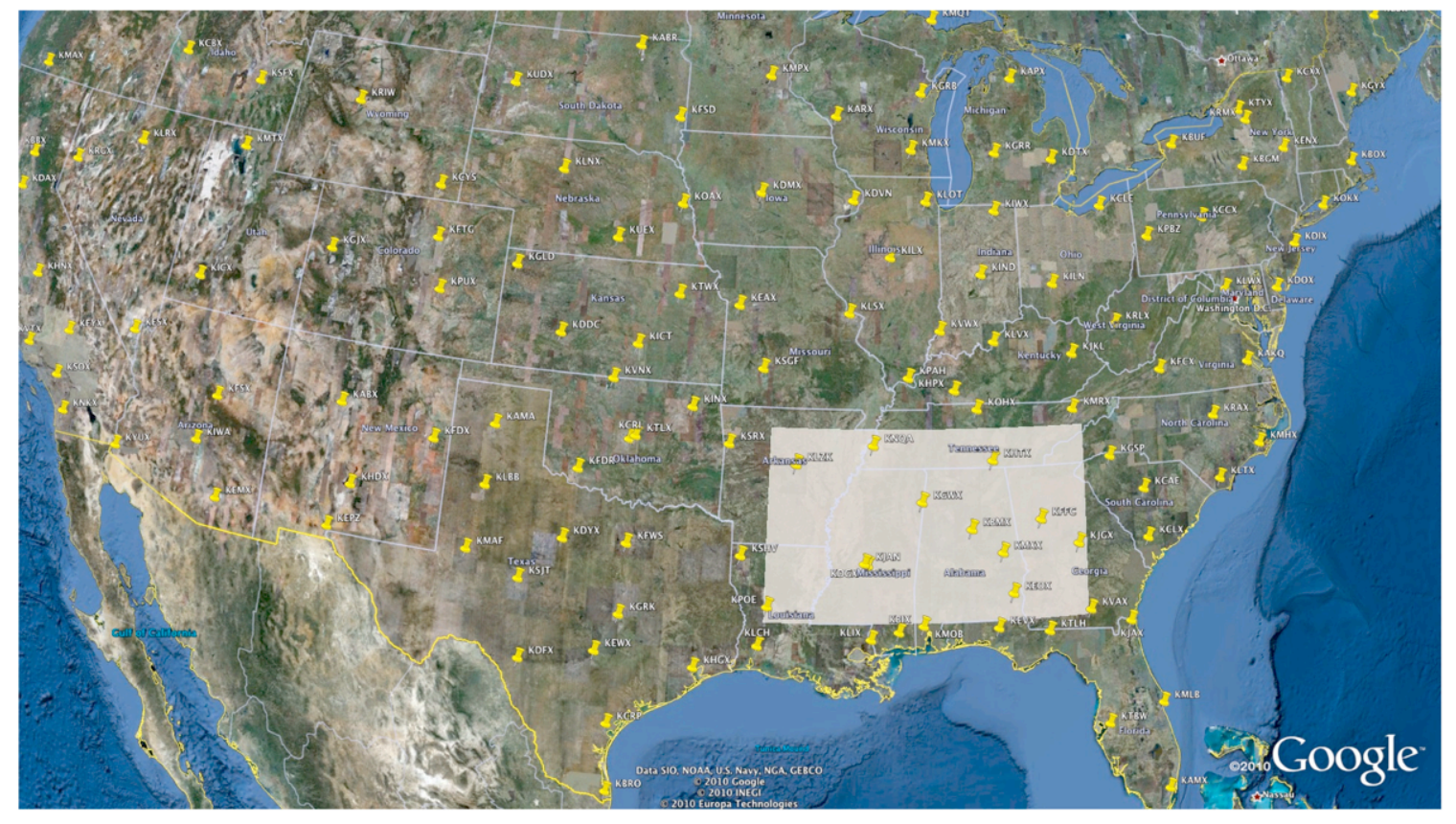

Figure 6. Case study area (grey rectangle) and NEXRAD radar sites (yellow pins)

On average, each satellite passes over the area twice a day leading to an average sampling interval of 140 minutes. Spatial coverage of the area is also relatively poor. Satellites' swats are 700 to $1400 \mathrm{~km}$ which corresponds to about half of the area. On the other hand, data resolution is relatively high at roughly $25 \mathrm{~km}$. Due to its low inclination TRMM has slightly more overpasses than the other satellites. 


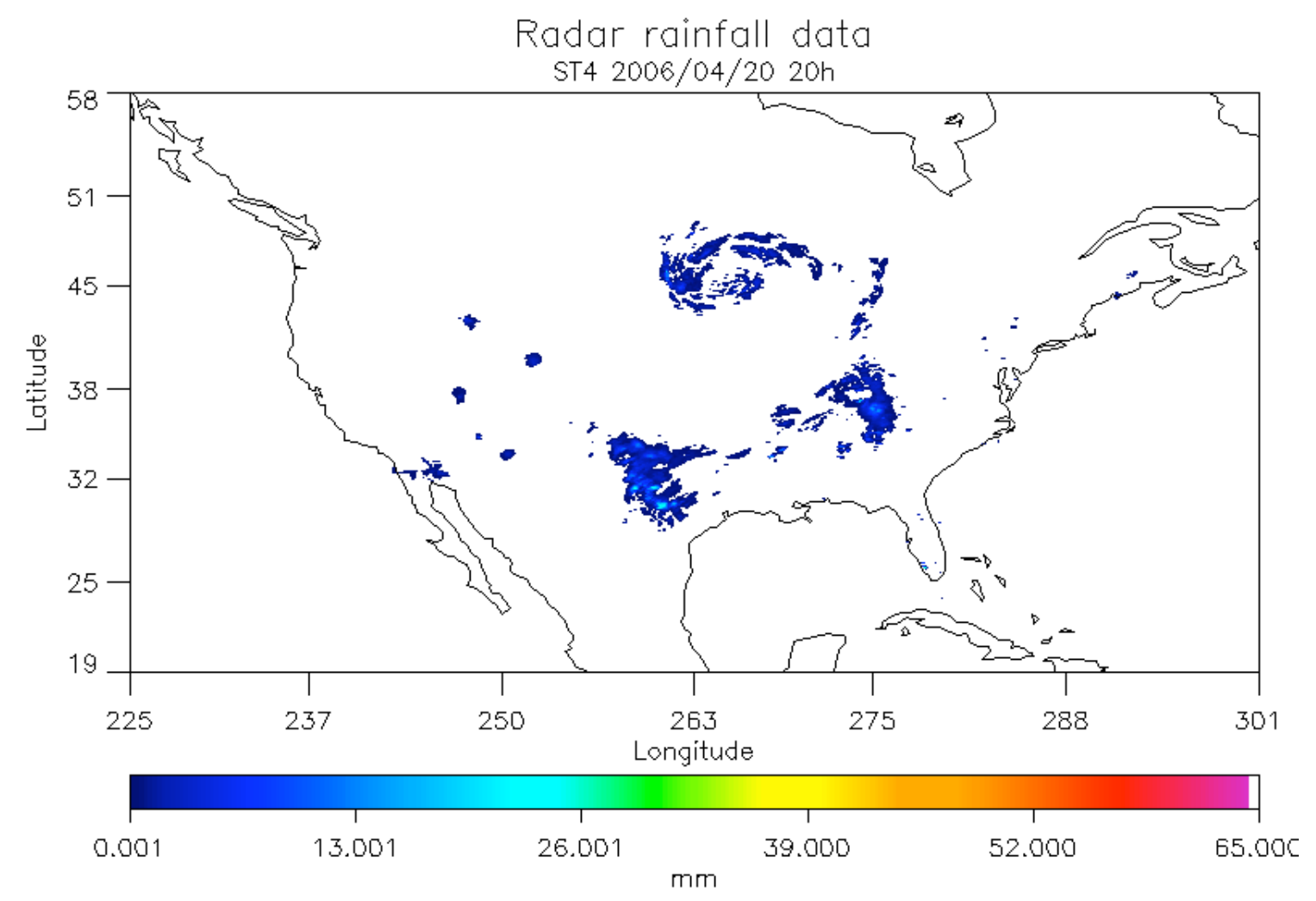

Figure 7. NEXRAD Stage IV data scene (hourly rainfall accumulation)

"Truth" for the case study over the SE US is provided by the NEXRAD stage IV radar data (Lin and Mitchell 2005, Baldwin and Mitchell 1998). The NEXRAD stage IV data represent the best estimate of rainfall accumulation where currently available, considering spatial and temporal coverage. Stage IV data are radar data mosaicked into a national product at the National Centers for Environmental Prediction (NCEP), from the regional hourly/6-hourly multi-sensor (radar and gauges) precipitation analyses produced by the 12 River Forecast Centers over conterminous United States (CONUS). Data are available hourly on a $4 \mathrm{~km}$ grid, from Jan $1^{\text {st }} 2002$ to the present. Figure 7 shows a randomly chosen stage IV scene which took place on $20^{\text {th }}$ April 2006 at 20h UTC. Figure 8 shows the part of that scene that corresponds to the area of the case study (gray rectangle in Figure 6). 


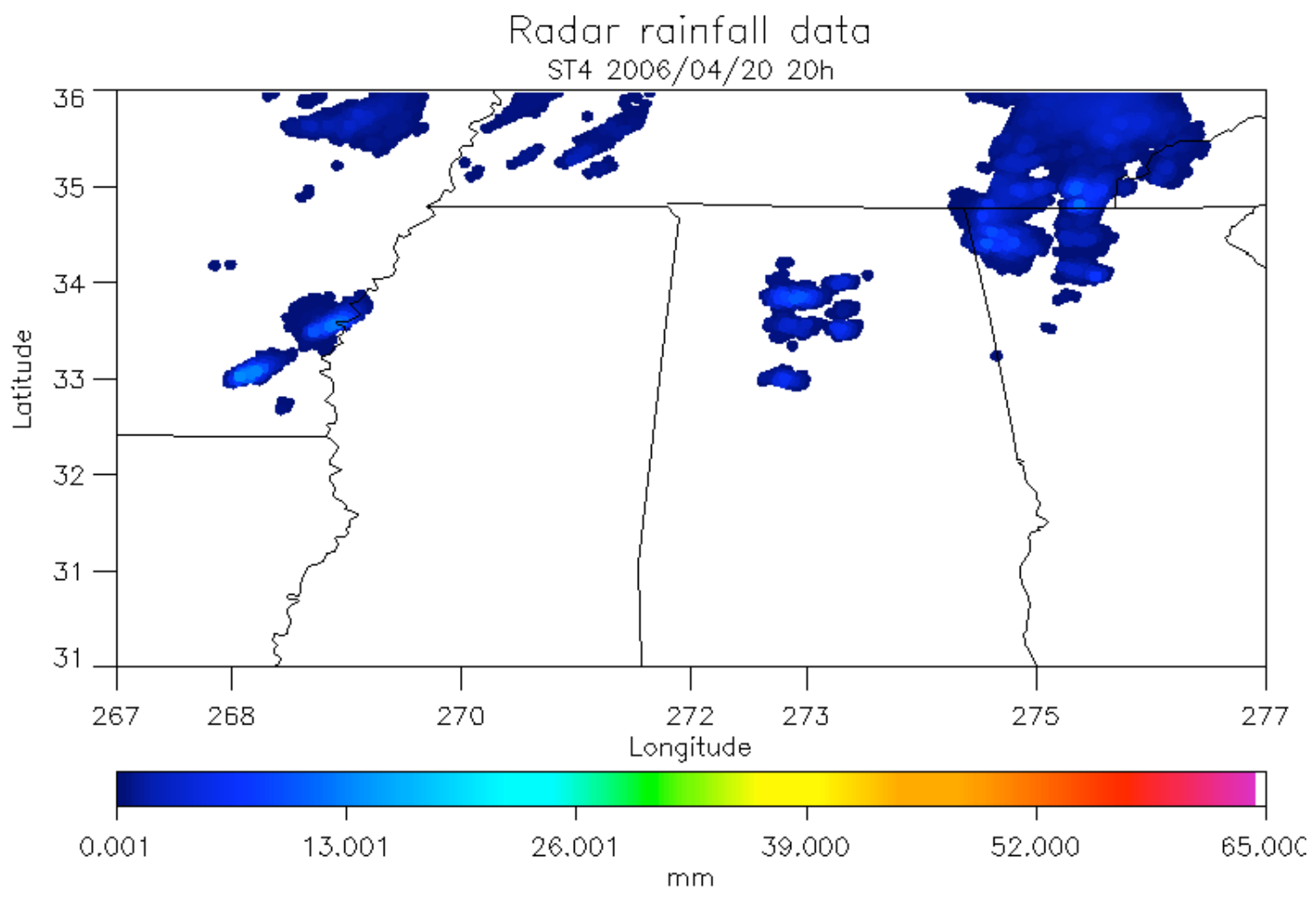

Figure 8. NEXRAD Stage IV radar data zoomed into the case study area (hourly rainfall accumulation) 


\section{CHAPTER 3}

\section{Temporal variability and spatial correlation of rainfall}

In Chapter 1, the concept of using temporal variability and spatial correlation was introduced. This Chapter explains these two quantities and their dependence on grid size and pixel resolution. Results presented here are extended in Chapter 4 to give a full understanding of their role in the rainfall accumulation estimation process. Before proceeding, terms used in this study such as rainfall grid and pixel resolution are defined more precisely.

A pixel refers to a single rainfall rate measurement that is taken over an area and defines the resolution of the data. The original size of the "OPERA" pixel is $4 \times 4 \mathrm{~km}$. All areas used in this study are square. The $4 \times 4 \mathrm{~km}$ pixel is therefore referred to simply as a pixel of $4 \mathrm{~km}$ resolution. A pixel of $8 \mathrm{~km}$ resolution would imply an average of four $4 \mathrm{~km}$ pixels to a pixel of $8 \times 8 \mathrm{~km}$.

A rainfall grid is an area that is at least the size of the pixel though typically larger over which the rainfall is being accumulated. The size of the grid can vary, usually depending on the users' needs. For modeling purposes, grids can be as small as $1 \times 1 \mathrm{~km}$ in mesoscale or flash flood models, or as large as $500 \times 500 \mathrm{~km}$ in Global Circulation Models. Here the size of the grid varies from $100 \times 100 \mathrm{~km}$ to $500 \times 500 \mathrm{~km}$, 
which corresponds to the grid sizes used in GPCP (Global Precipitation Climatology Project).

A series of consecutive raining grids over a given area describes a rain event. A grid is considered to be raining if it has at least one raining pixel. As previously mentioned, grids with missing data are excluded from this study. If the excluded grid is part of a rain event, that event is excluded as well. This causes a reduction of $10-12 \%$ of the available data, leaving $3,500-15,000$ fully described rain events, depending on the size of the grid.

\subsection{Spatial correlation}

Polar orbiting satellites often have highly accurate rain estimates and good spatial resolution but suffer from poor temporal coverage. By linking the spatial correlation of the measured grid to its temporal variability (defined in Section 3.2), these instantaneous measurements can be used to determine the expected temporal variability.

There are a variety of techniques used to calculate the spatial correlation or the spatial auto-correlation of one entity. The correct technique depends on the purpose of the calculation and on the definition of the entity. The entity used here is rainfall grid. Mathematically, spatial auto-correlation quantifies the similarity between the distributions of the values of two vector's elements. In this case, the elements of two vectors are the grid's pixels, while their values are rainfall rates 
(see Figure 9). Therefore, the correlation coefficient represents the "uniformity" of the rainfall field enclosed by the grid.

Figure 9 depicts one grid with its pixels. Both the left and the right panels represent the same grid at the same time point $\left(\mathbf{t}_{\mathbf{0}}\right)$. The labels are applied to provide a physical explanation of Equation 2.
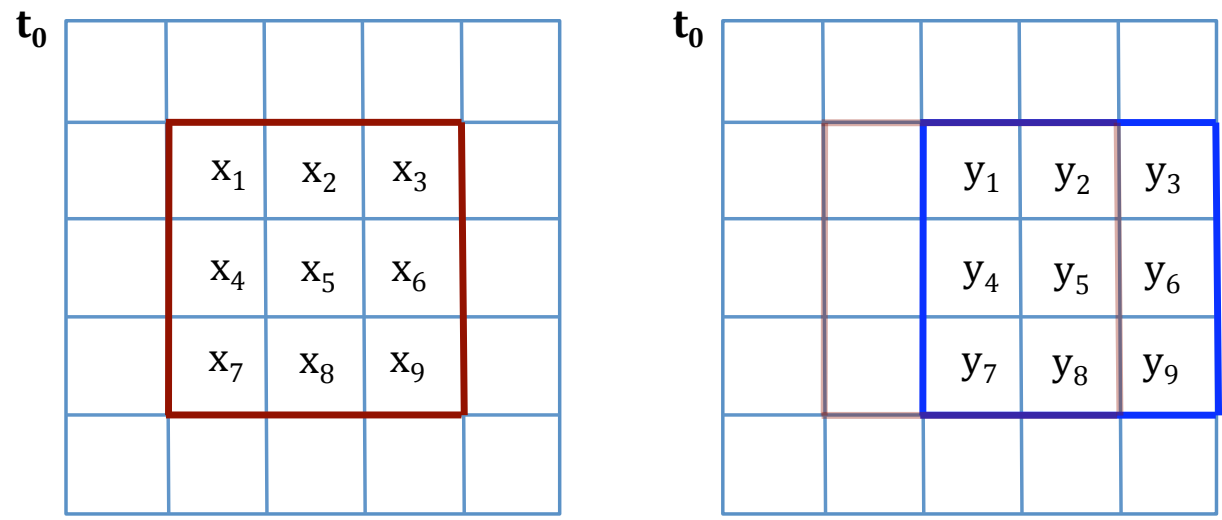

Figure 9. Calculation of the spatial correlation coefficient

The spatial correlation coefficient, $\mathbf{r}_{x y}$, of a rainfall field is calculated using:

$$
r_{x y}=\frac{n \sum x_{i} y_{i}-\sum x_{i} \sum y_{i}}{\sqrt{n \sum x_{i}^{2}-\left(\sum x_{i}\right)^{2}} \sqrt{n \sum y_{i}^{2}-\left(\sum y_{i}\right)^{2}}}=\frac{\sum_{i=1}^{n}\left(x_{i}-\bar{x}\right)\left(y_{i}-\bar{y}\right)}{(n-1) S_{x} S_{y}}
$$

where $\boldsymbol{x}$ and $\boldsymbol{y}$ are two vectors: $\boldsymbol{x}=\left(x_{1}, x_{2}, x_{3}, \ldots, x_{n}\right)$ is the vector that contains the grid's pixels as marked in the left panel in Figure 9, and $\boldsymbol{y}=\left(y_{1}, y_{2}, y_{3}, \ldots, y_{n}\right)$ is the vector that contains the corresponding neighboring pixels shifted by one pixel to the right, and $\boldsymbol{n}$ represents the number of pixels. $\boldsymbol{S}_{\boldsymbol{x}}$ and $\boldsymbol{S}_{\boldsymbol{y}}$ are standard deviations of the vectors $\boldsymbol{x}$ and $\boldsymbol{y}$ respectively. Equation 2 can be applied to any or all directions. The example in Figure 9 illustrates only the shift in the westerly direction. If more than 
one direction is used, then for each additional direction $\mathbf{x}$ vector is extended by repeating its elements while vector $\mathbf{y}$ will contain sets of corresponding neighboring pixels in that direction. Results presented in this study are based on the spatial correlation being calculated using the four directions, West, East, North and South.

Spatial correlation (referred to here as "uniformity") has high values for highly uniform raining systems. Average spatial correlations for OPERA data for three different pixel sizes $(8,12,24 \mathrm{~km})$ and a grid size of $100 \mathrm{~km}$ are shown in Table 1 .

Table 1. Average spatial correlation coefficient for grid size of $100 \times 100 \mathrm{~km}$

\begin{tabular}{|c|c|c|c|}
\hline Pixel resolution $(\mathrm{km})$ & $\mathbf{2 4}$ & $\mathbf{1 2}$ & $\mathbf{8}$ \\
\hline Spatial correlation coefficient & 0.599 & 0.624 & 0.635 \\
\hline
\end{tabular}

Table 1 suggests that the lower the pixel resolution is, the smaller the correlation coefficient will be. Since spatial correlation describes the uniformity of the rainfall field within a grid, the higher the coefficient is, the more uniform the field is. However, it would be wrong to conclude that the spatial correlation coefficients in Table 1 suggest that an increase of the resolution increases the uniformity of the field. On the contrary, a decrease in pixel resolution always results in an increase in uniformity. The technique presented in Figure 9 implies that the lower the resolution is, the larger the shifts of the pixels in space will be. This causes the correlation coefficient values in Table 1 to decrease with a decrease in pixel resolution, since in general, rainfall rates between further points differ more than between close ones. Being aware of this, the more appropriate conclusion from Table 1 is: the lower the pixel resolution is, the less of the uniformity is captured. 
Spatial correlation coefficients calculated for various field sizes and resolutions are shown and discussed in Section 3.3. Here, an example of this calculation for two different types of raining events is shown. The purpose of this example is to demonstrate that different distributions of the rainfall rates over the grid result in different spatial correlation coefficients of the grid. The red box on the right panel side of Figure 10 corresponds to a uniform (stratiform) type of rain, while the box shown on the left is placed over a non-uniform (convective) type of rain. These are the same fields that were previously discussed in Chapter 1 . In this example the non-uniform rain has a spatial correlation of 0.529 , while the uniform type of rain has a spatial correlation of 0.682 . Calculations for both grids were done for resolutions of $4 \mathrm{~km}$ and grids of $150 \mathrm{~km}$ by $150 \mathrm{~km}$.
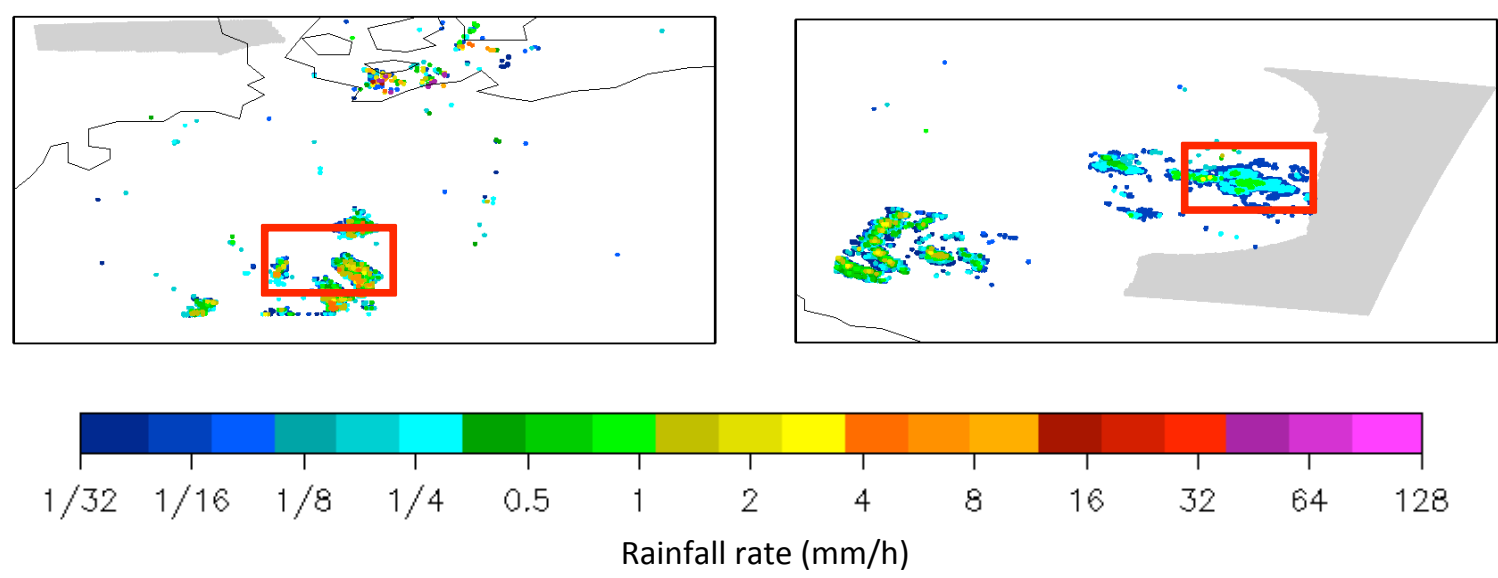

Figure 10. Rainfall rate distribution of non-uniform vs. uniform type of rain

\subsection{Temporal variability}

The previous section explained how spatial correlation coefficients could be used to quantify the homogeneity of rainfall. This section will define the temporal variability of the rainfall field. 
Using the same concept as in Figure 9, Figure 11 helps to understand the mathematical definition of temporal variability $\mathbf{e}_{\boldsymbol{x}}$ given by Equation 3:

$$
e_{x}=\frac{\sum_{i=1}^{n} x_{i}-\sum_{i=1}^{n} y_{i}}{\sum_{i=1}^{n} x_{i}}
$$

where $\mathbf{x}$ and $\mathbf{y}$ have the same meanings as in Eqauton 2, except that now the vector $\mathbf{y}$ corresponds to same pixels as vector $\mathbf{x}$ just at some later time $\mathbf{t}_{\mathbf{1}}$. Since vectors $\mathbf{x}$ and $\mathbf{y}$ are made of instantaneous rainfall rate values, their totals are instantaneous totals. Therefore, the temporal variability of a raining grid corresponds to the change of rainfall during a time interval $\Delta t$. This change is presented as a ratio between the average instantaneous rain of the initial state, and the difference in the average instantaneous rain between the initial and final state. The temporal variability also can be defined as a temporal sampling error, implying the error that would be introduced to the estimate based on the assumption that the initial rainfall is constant in time.
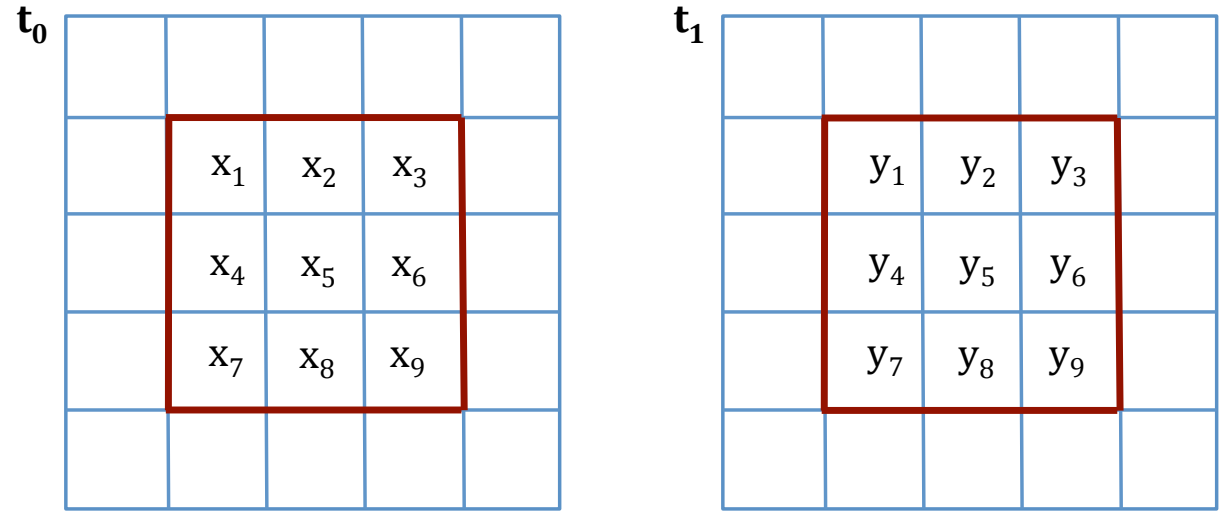

Figure 11. Calculation of temporal variability 
The temporal variability must be defined relative to a time separation $\left(\mathbf{t}_{\mathbf{1}}-\mathbf{t}_{\mathbf{0}}\right)$. Each measurement time of the OPERA data defines one state of the raining event, so for $\mathbf{m}$ consecutive measurements (states of the raining event) this would result in $\mathbf{m}$ temporal variability $\left(\boldsymbol{e}_{\boldsymbol{x} 1}, \ldots, \boldsymbol{e}_{\boldsymbol{x} m}\right)$. An example is shown in Figure 12 and the values used are given in Table 2. Temporal variability in this figure are calculated directly from the 15min OPERA data for a single stratiform raining event, which occurred on May $2^{\text {nd }} 2009$, and plotted as a function of time. Negative values of temporal variability indicate increase in the rainfall compared to its initial value at 0 -minute.

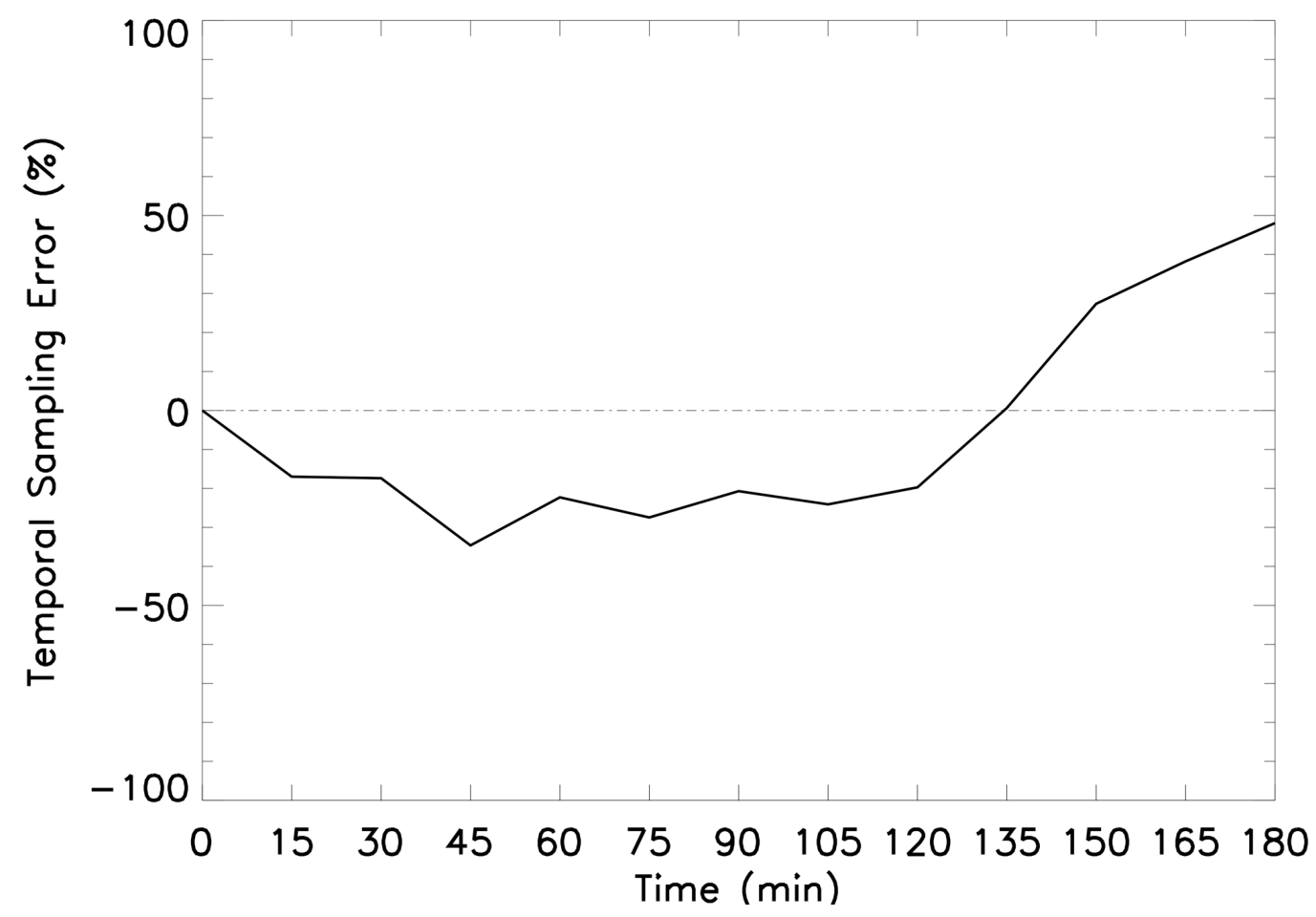

Figure 12. Time line of temporal variability for stratiform raining event shown in Figure 2 
Table 2. Temporal variability time dependence shown in Figure 12

\begin{tabular}{|c|c|c|c|c|c|c|c|c|c|c|c|c|c|}
\hline Time (min) & 0 & 15 & 30 & 45 & 60 & 75 & 90 & 105 & 120 & 135 & 150 & 165 & 180 \\
\hline Temporal variability (\%) & 0 & -17 & -17 & -34 & -22 & -27 & -20 & -24 & -19 & 1 & 27 & 38 & 48 \\
\hline
\end{tabular}

Another example, for a single non-uniform raining event (the one presented in Figures 1 and 3), is shown in Figure 13 followed by Table 3. It is easy to notice that the temporal variability in Figure 13 has larger amplitude and more rapid change than in Figure 12. This supports the hypothesis that grids of higher spatial correlations, or uniformity, have temporal variability that change at a slower rate and are more or less monotonical, as compared to less uniform ones. More detailed results supporting this are presented in Chapter 3.

A number of factors influence the change in temporal variability. Aside from the rainfall type, temporal variability behavior depends largely on the size of the chosen grid. Rainfall moving in and out of the grid, it will be seen, affects the temporal variability considerably. 


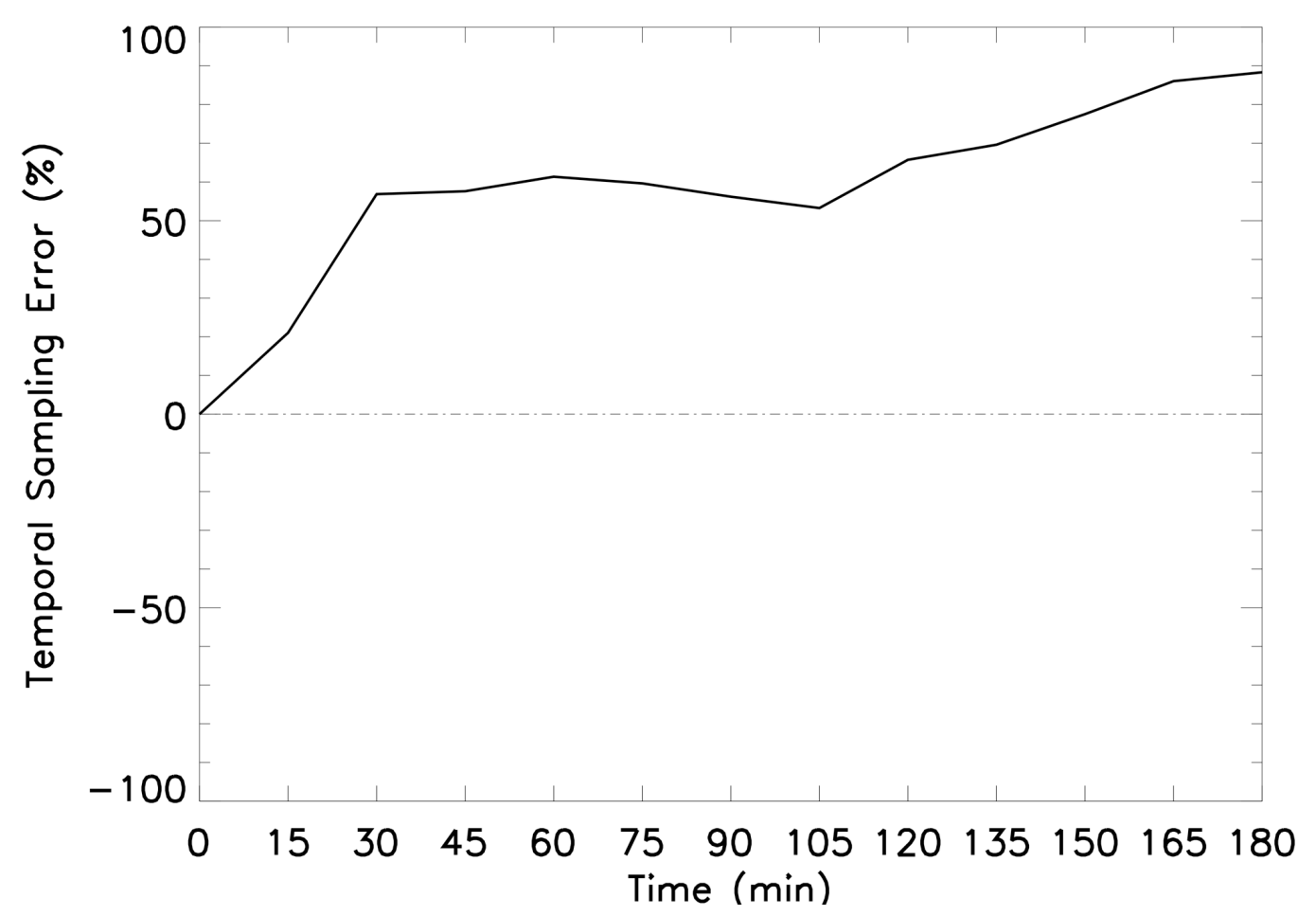

Figure 13. Time line of temporal variability for non-uniform raining event shown in Figure 3

Table 3. Temporal variability time dependence shown in Figure 13

\begin{tabular}{|c|c|c|c|c|c|c|c|c|c|c|c|c|c|}
\hline Time (min) & 0 & 15 & 30 & 45 & 60 & 75 & 90 & 105 & 120 & 135 & 150 & 165 & 180 \\
\hline Temporal variability (\%) & 0 & 21 & 57 & 58 & 61 & 60 & 56 & 53 & 66 & 70 & 78 & 86 & 88 \\
\hline
\end{tabular}

\subsection{Grid size and pixel resolution dependence}

The results illustrated in the previous section depend upon the grid and pixel sizes. The results presented here are based on the OPERA data domain. The 
following grid sizes and pixel resolutions are used to simulate typical grid sizes and satellite FOV:

○ 500x500km grid for pixel resolutions of: 8,12 and $24 \mathrm{~km}$

○ 250x250km grid for pixel resolutions of: 8,12 and $24 \mathrm{~km}$

○ 100x100km grid for pixel resolutions of: 8,12 and $24 \mathrm{~km}$

On average, approximately 100,000 raining events are used in calculation. Results shown in this section are average values.

Table 4 enumerates the values of the spatial correlation coefficient for different grid sizes and pixel resolutions.

Table 4. Averaged spatial correlation coefficient for different grid sizes and pixel resolutions

\begin{tabular}{|c|c|c|c|}
\hline \multirow{2}{*}{ Grid size (km) } & \multicolumn{3}{|c|}{ Pixel Resolution (km) } \\
\cline { 2 - 4 } & $\mathbf{2 4}$ & $\mathbf{1 2}$ & $\mathbf{8}$ \\
\hline $\mathbf{5 0 0} \times \mathbf{5 0 0}$ & 0.406 & 0.454 & 0.469 \\
\hline $\mathbf{2 5 0} \times \mathbf{2 5 0}$ & 0.385 & 0.418 & 0.438 \\
\hline $\mathbf{1 0 0} \times \mathbf{1 0 0}$ & 0.599 & 0.624 & 0.635 \\
\hline
\end{tabular}

By looking at any of the rows in Table 4, one can see that the correlation coefficient increases with finer pixel resolution. As previously explained, this is brought about simply because grids are shifted by one pixel to compute the spatial correlation. The spatial shift of the $8 \mathrm{~km}$ pixel is therefore only $1 / 3$ of the shift used to compute the correlation when the pixel size is $24 \mathrm{~km}$.

Calculations (not shown here) are made for some smaller grid sizes (75km and $50 \mathrm{~km})$. Results show the same trend of increasing correlation coefficients with 
decreasing grid size. This can be explained by the fact that smaller grids have fewer raining systems. Rain systems over smaller areas increase the probability of uniform raining systems. Generally, rainfall rates change gradually within a raining system, implying that smaller portions of a system are generally more uniform. However, this is not the case when the $500 \mathrm{~km}$ grid is compared to the $250 \mathrm{~km}$ grid. This is caused by the definition of raining grids requiring at least one raining pixel. Very large grids have a higher chance of containing isolated rain pixels, which appears highly correlated because of the large number of zeros in those grids. The minimum around $250 \mathrm{mk}$ grids appears to be related to synoptic scales. That is, there is usually some rain at these scales but not always at the smaller scales considered in this study.

Similar behavior can be seen in the temporal variability results. Table 5 shows the average variability for the same grid sizes and pixel resolutions as are shown in Table 4. The same data are used, choosing 180-minute long raining events to start at $00,06,12$, and 18 UTC. A raining event is defined as the time period during which all of the grids are raining. Grids without continuous rain were not considered.

Table 5 shows only two time separations (30-minute and 45-minute). Similar behavior is seen for both longer and shorter separations. For all grid sizes and pixel resolutions, increased time separation results in increased temporal variability. Simply, the longer it has been, the more the precipitation will change. By looking at any of the columns in Table 5 one can conclude that smaller grids experience larger changes in instantaneous accumulations. This is plausible since raining systems 
need less time to move over smaller grids. Table 5 also confirms that the temporal variability is not dependent on pixel resolution. This is expected since changes in the average rain within the grid are constant no matter what the pixel resolution is, as long as the grid captures the same area.

Table 5. Average temporal variability (\%) for different grid sizes and pixel resolutions for time separations of $30 \mathrm{~min}$ and $45 \mathrm{~min}$

\begin{tabular}{|c|c|c|c|c|}
\hline \multirow{2}{*}{ Grid size (km) } & \multirow{2}{*}{ Time separation (min) } & \multicolumn{3}{|c|}{ Pixel resolution (km) } \\
\cline { 2 - 5 } & & $\mathbf{2 4}$ & $\mathbf{1 2}$ & $\mathbf{8}$ \\
\hline \multirow{2}{*}{$\mathbf{5 0 0} \times \mathbf{5 0 0}$} & $\mathbf{3 0}$ & 24 & 24 & 24 \\
\cline { 2 - 5 } & $\mathbf{4 5}$ & 34 & 34 & 34 \\
\hline \multirow{2}{*}{$\mathbf{2 5 0} \times \mathbf{2 5 0}$} & $\mathbf{3 0}$ & 74 & 74 & 74 \\
\cline { 2 - 5 } & $\mathbf{4 5}$ & 109 & 109 & 109 \\
\hline \multirow{2}{*}{$\mathbf{1 0 0} \times \mathbf{1 0 0}$} & $\mathbf{3 0}$ & 252 & 252 & 252 \\
\cline { 2 - 5 } & $\mathbf{4 5}$ & 287 & 287 & 287 \\
\hline
\end{tabular}

Similar results, as seen here for spatial correlations and temporal variability, can be found in the works of Bell et al. 1990 and Habib et al. 2001a. In these two studies the correlation length is used instead of the correlation coefficient (see Appendix A). Additionally, rather than using temporal variability to describe the change of the rainfall field in time, these authors used temporal correlation, which is related to the temporal variability.

\subsection{Temporal variability dependence on spatial correlation \\ coefficient}

The fundamental hypothesis of this study is that the correlation coefficient, or rainfall homogeneity that can be observed by a satellite snapshot, is closely related to the temporal variability. Linking these two allows instantaneous rainfall 
measurement to propagate its information through time, providing a basis for rainfall estimates along the period of propagation (see Chapter 4). The idea of using the link between the spatial and temporal properties of the rainfall field comes from studies such as Bell et al. 1990 and Habib et al. 2001a. These two studies present the dependence of spatial and temporal correlation coefficients on separation distances and separation time, respectively. The calculations are repeated here using the OPERA data set to confirm those results as well as the present methodology (see Appendix A).

Figure 14 shows the average absolute values of temporal variability and their standard deviations, as a function of spatial correlation coefficient for 6 separation times. The sample size used in this calculation is depicted as the green curve in Figure 14. This result is based on the full OPERA data domain for a grid size of $250 \mathrm{~km}$ and pixel resolution of $12 \mathrm{~km}$. Other combinations of grid sizes and pixel resolutions (not shown here) show the same trends. It is clear that as the separation time increases the temporal variability increase as well. Also, for any given separation time, higher values of the spatial correlation coefficient correspond to lower temporal variability. Variability for separation time of 0 -minute are equal to zero since they correspond to the difference of the initial state of the grid to itself.

The relationship shown in Figure 14 is the basis of the spatio-temporal correlation technique used to accumulate rainfall from multiple satellites. 

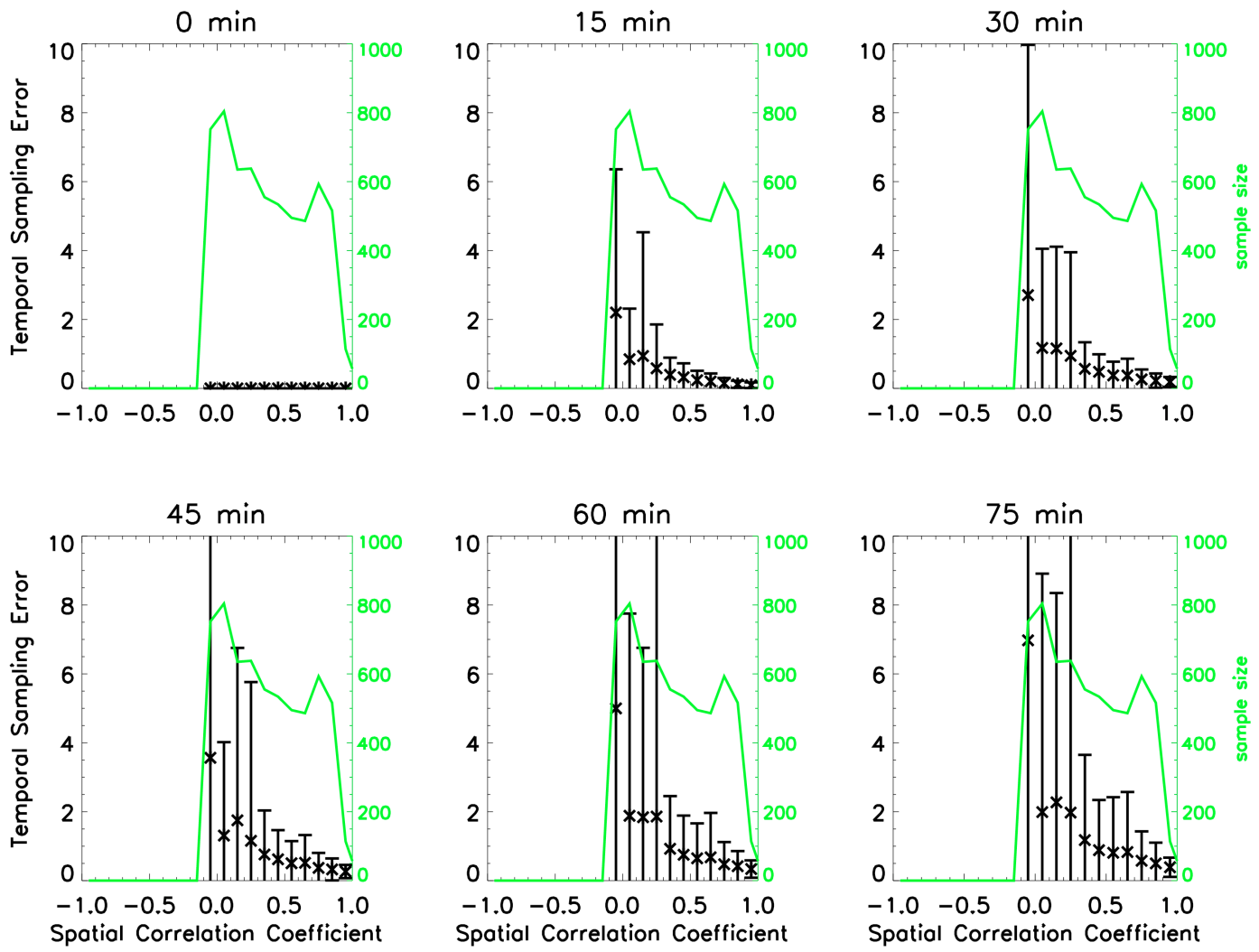

Figure 14. Temporal variability vs. spatial correlation coefficient (grid size: $250 \mathrm{~km}$, pixel resolution: 12km) 


\section{CHAPTER 4}

\section{Spatio-temporal correlation technique}

The spatio-temporal correlation technique is a statistical method that combines rainfall rate measurements from sensors on different satellites, with the goal of estimating 3-hour total rainfall accumulations at various spatial scales.

The total rainfall accumulation is computed by weighting the available measurements based on both the measurements accuracies and the temporal variability of the measurements. The calculation of total rainfall accumulation is presented in two parts in this section. The first part (i) introduces the technique assuming that the sensors are $100 \%$ accurate, focusing only on temporal variability. The second part (ii) deals with measurement accuracies only. Finally, both parts are combined to provide an estimate of instantaneous grid average rainfall and its uncertainty.

The spatio-temporal correlation technique is introduced here with the assumption that there are only two available measurements within the accumulation interval. The technique can be modified to use a larger number of measurements, but that does not change the principles discussed here. Each 
measurement provides an instantaneous grid average rainfall, $\boldsymbol{r}$, and the spatial correlation coefficient of the grid, $\boldsymbol{\lambda}$.

Figure 15 shows an example that is used in this chapter to introduce the spatio-temporal correlation technique. In this example, the accumulation time period is chosen to be 3 hours with a 15 -minute sampling rate. The accumulation interval is chosen to match the GPCP products (described in Chapter 1), while the time sampling matches the OPERA sampling. To estimate the total rainfall accumulation during this period, instantaneous grid average rainfall must be known. For 15minute time intervals without measurements, the instantaneous grid average rainfall must be calculated first.

\subsection{Combining two perfect measurements}

Figure 15 shows a timeline of the accumulation period. An instantaneous grid average rainfall for any specified time is estimated by a weighted mean (Rabinovich, 2005) of the two measured instantaneous grid average rainfalls. The weighted mean, $\mathbf{r}$, is given by:

$$
r=\left(r_{1} w_{1}+r_{2} w_{2}\right) \frac{1}{w_{1}+w_{2}}
$$

where $\mathbf{r}_{1}$ and $\mathbf{r}_{\mathbf{2}}$ are measured instantaneous grid average rainfalls at times $\mathbf{t}_{\mathbf{1}}$ and $\mathbf{t}_{2}$, while $\mathbf{w}_{1}$ and $\mathbf{w}_{\mathbf{2}}$ are the corresponding weights. The weighting accounts for a temporal variability using weights given by: 


$$
w_{i}=\frac{1}{e_{i, j}^{2}}
$$

where $\boldsymbol{e}_{\boldsymbol{i}, \boldsymbol{j}}$ is the temporal variability, $\boldsymbol{i}$ is the measurement index corresponding to one of the two measurements used in this study, and $\boldsymbol{j}$ is the separation time between the measured and the estimated instantaneous grid average rainfall. The derivation of the weighted mean is given in Appendix B.

In Figure 15, the green points mark the times $\mathbf{t}_{1}=45 \mathrm{~min}$ and $\mathbf{t}_{2}=150 \mathrm{~min}$ when two measurements of instantaneous grid average rainfall are made, while the red point marks the time of the instantaneous grid average rainfall estimate. In this scenario subscript $\boldsymbol{j}$ in $\boldsymbol{e}_{1, j}$ has the value of 45 , since there is $45 \mathrm{~min}$ separation time between the measurement at $\mathbf{t}_{\mathbf{1}}$ and the estimate. Similarly, subscript $\boldsymbol{j}$ in $\boldsymbol{e}_{2, \boldsymbol{j}}$ has a value of 60 .

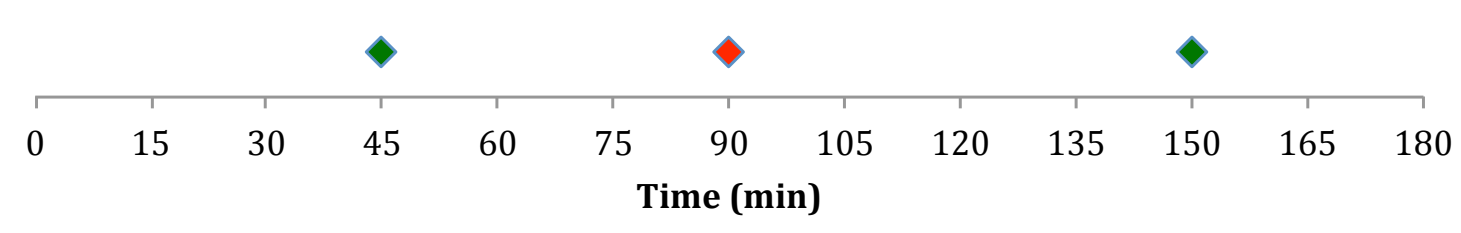

Figure 15. Accumulation period time line

Temporal variability, $\boldsymbol{e}$, that is used to form the weights are pre-calculated based on large sets of data, as described in Chapter 3, and stored in look-up tables.

Table 6 gives an example of a look-up table corresponding to values shown in Figure 14 where temporal variability are given as a function of the spatial correlation coefficient for a grid size of $250 \mathrm{~km}$ and $12 \mathrm{~km}$ pixel resolution. Once the measurement is made, the grid size, the pixel resolution, and the spatial correlation 
coefficient are known. A corresponding look-up table provides a temporal variability value for any chosen time separation.

Table 6. Look up table of temporal variability for a grid size of $250 \mathrm{~km}$ and a $12 \mathrm{~km}$ pixel resolution

\begin{tabular}{|c|c|c|c|c|c|c|c|c|c|c|c|c|}
\hline & \multicolumn{11}{|c|}{ Spatial correlation coefficient } \\
\hline & & -0.1 & 0 & 0.1 & 0.2 & 0.3 & 0.4 & 0.5 & 0.6 & 0.7 & 0.8 & 0.9 \\
\hline \multirow{12}{*}{ 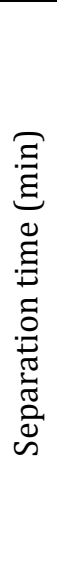 } & 0 & 0 & 0 & 0 & 0 & 0 & 0 & 0 & 0 & 0 & 0 & 0 \\
\hline & 15 & 3.04 & 0.89 & 0.82 & 0.66 & 0.42 & 0.3 & 0.22 & 0.17 & 0.14 & 0.12 & 0.11 \\
\hline & 30 & 4.14 & 1.2 & 1.13 & 1.02 & 0.61 & 0.45 & 0.36 & 0.3 & 0.25 & 0.22 & 0.21 \\
\hline & 45 & 5.65 & 1.5 & 1.48 & 1.24 & 0.79 & 0.63 & 0.5 & 0.42 & 0.35 & 0.32 & 0.31 \\
\hline & 60 & 8.91 & 1.97 & 1.95 & 1.69 & 1.08 & 0.79 & 0.64 & 0.53 & 0.44 & 0.39 & 0.4 \\
\hline & 75 & 8.82 & 2.4 & 2.27 & 2.02 & 1.42 & 0.98 & 0.79 & 0.65 & 0.53 & 0.47 & 0.44 \\
\hline & 90 & 12.43 & 3.09 & 2.88 & 2.58 & 1.71 & 1.16 & 0.92 & 0.75 & 0.61 & 0.54 & 0.49 \\
\hline & 105 & 16.94 & 3.56 & 3.47 & 3.1 & 2.12 & 1.4 & 1.11 & 0.86 & 0.69 & 0.61 & 0.56 \\
\hline & 120 & 21.87 & 4.33 & 4.31 & 3.75 & 2.56 & 1.61 & 1.27 & 0.96 & 0.76 & 0.67 & 0.62 \\
\hline & 135 & 28.39 & 5.1 & 5.19 & 4.39 & 2.98 & 1.79 & 1.46 & 1.06 & 0.83 & 0.73 & 0.66 \\
\hline & 150 & 35.53 & 6.27 & 5.85 & 5.41 & 3.53 & 2.03 & 1.6 & 1.15 & 0.89 & 0.77 & 0.7 \\
\hline & 165 & 43.66 & 7.57 & 6.71 & 6.75 & 4.11 & 2.31 & 1.78 & 1.25 & 0.95 & 0.82 & 0.75 \\
\hline
\end{tabular}

\subsection{Accounting for instrument errors}

Using weights given by Equation 5 , the rain can be estimated at $\mathbf{t}=90 \mathrm{~min}$ from rain and its spatial correlation at $\mathbf{t}_{\mathbf{1}}=45 \mathrm{~min}$ and $\mathbf{t}_{\mathbf{2}}=150 \mathrm{~min}$. However, perfect measurements are rarely available, if ever. If two imperfect measurements are combined according to the previous method, the error of any of them can easily bias the estimate, making it worse than if a simple mean had been used. Therefore, the weights that are defined in Equation 5 must be modified according to well established techniques (e.g. Xie and Arikin 1996) to account for measurement errors. However, when the weights are adjusted for measurement errors, temporal variability must be preserved. Before the two adjustments are combined, the weight for the measurement error adjustment alone is presented: 


$$
w_{i}=\frac{1}{a_{i}^{2}}
$$

where $\boldsymbol{a}_{\boldsymbol{i}}$ is the uncertainty of the instrument $\boldsymbol{i}$, given in a form of a positive decimal number. For example, $10 \%$ uncertainty is given by $\boldsymbol{a}=0.1$. Since the weight is an inverse of uncertainty, less accurate measurements are weighted less. If there was no temporal variability involved, the weighted mean of two uncertain measurements, defined using Equation 6, would provide the best estimate of instantaneous grid average rainfall.

Appendix B explains how to combine two independent errors of a measurement. Since measurement error and temporal variability are independent, and Section 3.2 defines temporal variability as temporal sampling error, the method described in Appendix B can be used to combine them and form the weights as shown in Equation 7:

$$
w_{i}=\frac{1}{e_{i, j}^{2}+a_{i}^{2}}
$$

where the symbols are the same as previously explained. Using the weighted mean with weights as defined in Equation 7, one can estimate $\boldsymbol{r}$ at any time in Figure 15. Summing the instantaneous grid average rainfalls within the accumulation period forms the estimate of the total rainfall accumulation.

Before proceeding to the results presented in Chapter 5, it should be noted that if the measurement is not $100 \%$ accurate, the spatial correlation coefficient provided by such a measurement is also imperfect. The measurement error thus 
affects the temporal variability as well. Therefore, correlation coefficients are corrected to compensate for measurement inaccuracy. Monte Carlo methods are used to define the corrections (see Appendix C). Once known, corrections are added to the measured correlation coefficient, which are then used to find the corresponding temporal variability. 


\section{CHAPTER 5}

\section{$5 \quad$ Results}

The goal of this study was to provide potential improvement to rainfall accumulation estimates by implementing the spatio-temporal correlation technique into currently used state of the art rainfall accumulation methods as described in Chapter 1. To achieve this goal, the spatio-temporal correlation technique must provide a foundation for those methods that is better than the one currently being used. Since most of them use linearly interpolated raw measurements, simulations of those are used to define a baseline against which improvements can be gauged.

A randomly chosen rain event from the OPERA data is used (the same one was shown in Figure 2 to illustrate the methodology). The accumulation period is as defined in Figure 15. Both the spatio-temporal correlation technique and the simple average technique base their instantaneous grid average rainfall estimates on using only two grids marked by times $\mathbf{t}_{\mathbf{1}}$ and $\mathbf{t}_{\mathbf{2}}$. This simulates a scenario when only two measurements are available for the entire accumulation interval. For simplicity, both measurements are $100 \%$ accurate in this example. 
The spatio-temporal correlation technique uses Equation 4 with weights $\mathbf{w}_{\mathbf{1}}$ and $\mathbf{w}_{2}$ defined for $100 \%$ accurate instruments $\left(\mathbf{a}_{1}=\mathbf{a}_{2}=0\right)$. Estimates of instantaneous grid average rainfall are made at 15-minute intervals along the accumulation period. The results are given in Table 7 with the estimate of the total rainfall accumulation of $280.2 \times 10^{-3} \mathrm{~mm} / 3 \mathrm{~h}$ (of the $150 \times 150 \mathrm{~km}$ box shown in Figure 2), which is simply the sum of all instantaneous grid average rainfalls (IGARs).

Table 7. Instantaneous grid average rainfall estimates given by the correlation technique

\begin{tabular}{|c|c|c|c|c|c|c|c|c|c|c|c|c|c|}
\hline Time (min) & 0 & 15 & 30 & $\mathbf{4 5}$ & 60 & 75 & 90 & 105 & 120 & 135 & $\mathbf{1 5 0}$ & 165 & 180 \\
\hline IGARs (mm10 $\left.^{-3} / \mathbf{h}\right)$ & 113 & 115 & 117 & $\mathbf{1 1 9}$ & 116 & 109 & 98 & 85 & 76 & 67 & $\mathbf{6 4}$ & 66 & 69 \\
\hline
\end{tabular}

The simple averaging technique uses the same equation 4 to make an instantaneous grid average rainfall estimate, but rather than weighting the measurements according to their temporal variability, it forms their simple mean by setting $\mathbf{w}_{\mathbf{1}}=\mathbf{w}_{2}$. This simple mean is taken to be instantaneous grid average rainfall at all time points of an accumulation interval where no measurement is available. Results are given in Table 8 with the estimate of the total rainfall accumulation of $275.7 \times 10^{-3} \mathrm{~mm} / 3 \mathrm{~h}$.

Table 8. Instantaneous grid rainfall estimates given by simple averaging technique

\begin{tabular}{|c|c|c|c|c|c|c|c|c|c|c|c|c|c|}
\hline Time (min) & 0 & 15 & 30 & $\mathbf{4 5}$ & 60 & 75 & 90 & 105 & 120 & 135 & $\mathbf{1 5 0}$ & 165 & 180 \\
\hline IGARs (mm10 $\left.^{-5} / \mathbf{h}\right)$ & 92 & 91 & 92 & $\mathbf{1 1 9}$ & 92 & 92 & 92 & 92 & 92 & 92 & $\mathbf{6 4}$ & 92 & 92 \\
\hline
\end{tabular}

The true total rainfall accumulation of $279.7 \times 10^{-3} \mathrm{~mm} / 3 \mathrm{~h}$ is calculated by summing all of the instantaneous grid average rainfalls given by the OPERA data set for this raining event. This is shown in Table 9. 
Table 9. Instantaneous grid rainfall estimates given by OPERA data (the truth)

\begin{tabular}{|c|c|c|c|c|c|c|c|c|c|c|c|c|c|}
\hline Time (min) & 0 & 15 & 30 & $\mathbf{4 5}$ & 60 & 75 & 90 & 105 & 120 & 135 & $\mathbf{1 5 0}$ & 165 & 180 \\
\hline IGARs (mm 10 $\left.^{-5} / \mathbf{h}\right)$ & 89 & 104 & 104 & 119 & 108 & 113 & 107 & 110 & 106 & 88 & 64 & 54 & 46 \\
\hline
\end{tabular}

Table 10 shows the differences between the true value of total rainfall accumulation (given in Table 9) and the values estimated by the two techniques. The last column of Table 10, labeled as "improvement", quantifies both the absolute and the Root Mean Square (RMS) error improvement over simple averages. Positive values of these numbers indicate that improvement has been made, while negative values indicate a decrease in skill from the spatio-temporal correlation technique.

Table 10. Comparing the results of two technique estimates

\begin{tabular}{|c|c|c|c|c|c|}
\hline & \multicolumn{2}{|c|}{$\begin{array}{c}\text { Total Rainfall } \\
\text { Accumulation } \\
\left(\mathrm{mm}^{*} 10^{-3} / 3 \mathrm{~h}\right)\end{array}$} & \multicolumn{2}{|c|}{$\begin{array}{c}\text { Error } \\
\left(\mathrm{mm}^{*} 10^{-3} / 3 \mathrm{~h}\right)\end{array}$} & \multicolumn{2}{|c|}{$\begin{array}{c}\text { Improvement } \\
\text { (\%) }\end{array}$} \\
\hline $\begin{array}{c}\text { OPERA data } \\
\text { the truth) }\end{array}$ & 279.7 & $\begin{array}{c}\text { Absolute } \\
\text { error }\end{array}$ & $\begin{array}{c}\text { RMS } \\
\text { error }\end{array}$ & $\begin{array}{c}\text { Absolute } \\
\text { error }\end{array}$ & $\begin{array}{c}\text { RMS } \\
\text { error }\end{array}$ \\
\hline $\begin{array}{c}\text { Simple averaging } \\
\text { Technique }\end{array}$ & 275.7 & 4.0 & $\mathbf{2 0 . 2}$ & \multicolumn{2}{|c}{-} \\
\hline $\begin{array}{c}\text { Spatio-temporal } \\
\text { correlation technique }\end{array}$ & 280.2 & 0.5 & $\mathbf{1 6 . 8}$ & 88 & 17 \\
\hline
\end{tabular}

In this particular example, it is clear that the spatio-temporal correlation technique has smaller errors. If used, these instantaneous grid average rainfalls could potentially improve total rainfall accumulation estimates significantly.

\subsection{Simulated measurements}

To depict the characteristics of the spatio-temporal correlation technique, two cases are examined. In the first one, the time separation of the two measurements is 
kept constant, while in the second case, the time separations are randomly distributed over the accumulation period. The first case provides more insight into the improvements that are dependent on data accuracy and temporal decorrelation, while the latter simulates more realistic scenarios, but is more difficult to interpret.

The results indicate that there are improvements in total rainfall accumulation estimates made by applying the spatio-temporal correlation technique to approximately 15,000 raining events over the entire OPERA space/time domain.

\subsubsection{Fixed time separation measurements}

Table 11 gives the absolute and the RMS error improvements for the grid size of $250 \mathrm{~km}$ with $12 \mathrm{~km}$ pixels. The time steps and the resulting temporal separations are shown in Figure 16. The color markers correspond to the markers displayed in Table 11. Measurement errors are set to be $0 \%$ for both of the instruments.

Table 11. Error improvement (\%) for various time separations; grid size $250 \mathrm{~km}$; pixel resolution $12 \mathrm{~km}$

\begin{tabular}{|c|c|c|c|c|}
\hline \multirow{2}{*}{ Error improvement (\%) } & \multicolumn{4}{|c|}{ Separation time (min) } \\
\hline & $\diamond$ & $\begin{array}{l}4 \\
\quad 6\end{array}$ & $\bullet \quad 1$ & 180 \\
\hline Absolute & 0.00 & 33.03 & 47.54 & .00 \\
\hline RMS & 0.00 & 26.04 & 45.30 & .10 \\
\hline
\end{tabular}

Both the absolute and the RMS error improvements behave the same. Since both instruments are assumed perfect (i.e. 0\% measurement error), weighting is based only on the temporal variability. The maximum improvement occurs when the correlation times (related to spatial correlation) of the two measurements cover as much of the accumulation period as possible. Typically the length of the 
correlation time is not longer than 60-minute. If measurements are too close to each other their correlation times could overlap, potentially leaving portions of the accumulation period uncovered. This lowers the impact of improvement. The time separations of 0 -minute and 60-minute in Table 11 correspond to overlapping correlation time lengths. The ideal scenario is to have measurements that are about twice the mean temporal correlation length apart. A separation of 120-minute is an example of this scenario, clearly having the greatest improvement among all of the time separations.

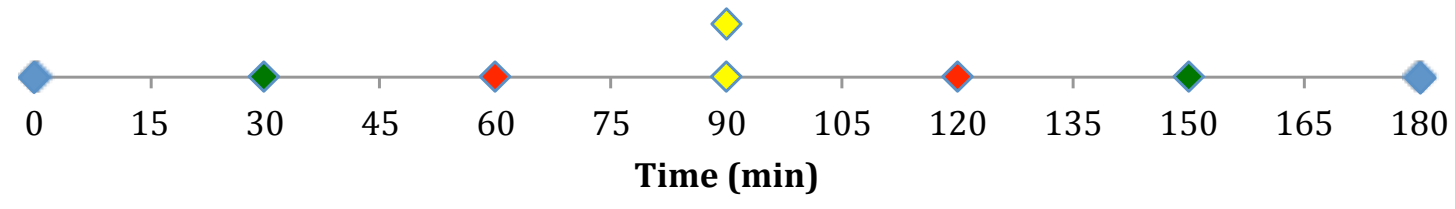

Figure 16. Accumulation period with marked measurements

In Table 12 and Table 13 error improvements are given for combinations of 3 different sensor's accuracies while the time separation is fixed at 120 -minute to provide simpler analysis.

Table 12. Absolute error improvement (\%); 120min separation time; Grid size 250km; pixel resolution $12 \mathrm{~km}$

\begin{tabular}{|c|c|c|c|c|}
\hline \multicolumn{2}{|c|}{} & \multicolumn{3}{|c|}{ Uncertainty of sensor \#1 (\%) } \\
\cline { 3 - 5 } \multicolumn{2}{|c|}{} & 10 & 30 & 60 \\
\hline \multirow{2}{*}{$\begin{array}{l}\text { Uncertainty of } \\
\text { sensor \#2 (\%) }\end{array}$} & 10 & 46.62 & 42.47 & 25.16 \\
\cline { 2 - 5 } & 30 & 42.47 & 43.46 & 32.77 \\
\cline { 2 - 5 } & 60 & 25.16 & 32.77 & 39.69 \\
\hline
\end{tabular}

It is clear from the tables that the best results are obtained if two measurements have the same accuracy. This is expected, since any inequality in the measurement error will lead to more weight being given to a single sensor. This is 
the case even if the instantaneous grid average rainfall estimate corresponds to the times beyond the correlation time of the more accurate measurement. Temporal variability that corresponds to extended time separations of accurate measurements is larger than variability that corresponds to short time separations of less accurate measurements. It is important to note that this does not mean that a pair of two instruments of equal accuracies produces a better instantaneous grid average rainfall estimate than the same pair after the accuracy of one of them is increased. It simply means that in this case, the improvement compared to the simple average technique, is lower.

Table 13. RMS error improvement (\%); 120min separation time; Grid size 250km; pixel resolution $12 \mathrm{~km}$

\begin{tabular}{|l|c|c|c|c|}
\hline \multicolumn{2}{|c|}{} & \multicolumn{3}{c|}{ Uncertainty of sensor \#1 (\%) } \\
\cline { 3 - 5 } \multicolumn{2}{|c|}{} & 10 & 30 & 60 \\
\hline \multirow{2}{*}{$\begin{array}{l}\text { Uncertainty of } \\
\text { sensor \#2 (\%) }\end{array}$} & 10 & 45.24 & 41.75 & 20.32 \\
\cline { 2 - 5 } & 30 & 41.75 & 44.15 & 30.94 \\
\cline { 2 - 5 } & 60 & 20.32 & 30.94 & 40.81 \\
\hline
\end{tabular}

Additional details on these results are shown in Appendix D.

\subsubsection{Random time separation measurements}

Table 14 presents absolute and RMS error improvements for the grid size of $250 \mathrm{~km}$ with $12 \mathrm{~km}$ pixels. The measurements are randomly distributed over a 3hour accumulation periods. The distribution is uniform, allowing any time separation within the 3-hour interval to occur, including the case of no-separation (i.e. measurements taken at same time). Measurement errors are set equal for both instruments. 
Table 14. Error improvement; random separation time; grid size $250 \mathrm{~km}$ pixel resolution $12 \mathrm{~km}$

\begin{tabular}{|c|c|c|c|c|c|c|c|c|c|c|c|}
\hline \multicolumn{2}{|c|}{ Measurement error (\%) } & 0 & 10 & 20 & 30 & 40 & 50 & 60 & 70 & 80 & 90 \\
\hline $\begin{array}{c}\text { Error } \\
\text { Improvement } \\
(\%)\end{array}$ & Absolute & 22.94 & 21.74 & 19.81 & 18.49 & 17.13 & 16.64 & 15.93 & 15.86 & 15.14 & 15.41 \\
\cline { 2 - 11 } & RMS & 15.26 & 15.15 & 14.54 & 14.16 & 13.74 & 13.67 & 13.33 & 13.26 & 12.96 & 12.39 \\
\hline
\end{tabular}

In general, Table 14 indicates that a decrease in sensor accuracy leads to a decrease in error improvements. It is worth mentioning that the spatio-temporal correlation technique applied to measurements with $90 \%$ uncertainty still provide an absolute error improvement of $15 \%$ and RMS error improvement of more than $10 \%$. This implies that the spatio-temporal correlation technique has skill even when applied to unreliable instrument measurements. Even more important is the fact that the technique can deal effectively with inaccurate measurements, which was the primary mission of this study. Error improvements for various spatial resolutions are shown in Appendix E.

In Tables 15 and 16, error improvements are given for 3 combinations of different sensor's accuracies. These results mirror those seen in the fixed time separation scenario, except that the improvements are lower. This is expected, since time separation is not set to be at its optimum value (120-minute in Table 12). Again, different spatial resolutions for the grid and pixel resolutions are found in Appendix E. 
Table 15. Absolute error improvement (\%); random separation time; grid size $250 \mathrm{~km}$ pixel resolution $12 \mathrm{~km}$

\begin{tabular}{|c|c|c|c|}
\hline \multirow{2}{*}{ Uncertainty of sensor \#2 } & \multicolumn{3}{|c|}{ Uncertainty of sensor \#1 } \\
\cline { 2 - 4 } & 10 & 30 & 60 \\
\hline 10 & 21.74 & 18.16 & 9.57 \\
\hline 30 & 18.16 & 18.49 & 12.94 \\
\hline 60 & 9.57 & 12.94 & 15.93 \\
\hline
\end{tabular}

Table 16. RMS error improvement (\%); random separation time; grid size $250 \mathrm{~km}$ pixel resolution $12 \mathrm{~km}$

\begin{tabular}{|c|c|c|c|}
\hline \multirow{2}{*}{ Uncertainty of sensor \#2 } & \multicolumn{3}{|c|}{ Uncertainty of sensor \#1 } \\
\cline { 2 - 4 } & 10 & 30 & 60 \\
\hline 10 & 15.15 & 13.42 & 5.93 \\
\hline 30 & 13.42 & 14.16 & 9.59 \\
\hline 60 & 5.93 & 9.59 & 13.33 \\
\hline
\end{tabular}

Finally, Table 17 shows how the absolute error improvement is dependent on the grid size and pixel resolution. Both of the measurement errors are equal to $30 \%$.

Table 17. Absolute error improvement for sensors uncertainty of $30 \%$; various grid sizes and pixel resolutions

\begin{tabular}{|c|c|c|c|c|}
\hline \multicolumn{2}{|c|}{ Uncertainty of sensors $30 \%$} & \multicolumn{3}{|c|}{ Grid Size $(\mathrm{km})$} \\
\cline { 3 - 5 } & & $\mathbf{1 0 0}$ & $\mathbf{2 5 0}$ & $\mathbf{5 0 0}$ \\
\hline \multirow{2}{*}{$\begin{array}{c}\text { Pixel resolution } \\
(\mathrm{km})\end{array}$} & $\mathbf{8}$ & 18.69 & 18.77 & 15.10 \\
\cline { 2 - 5 } & $\mathbf{1 2}$ & 17.69 & 18.49 & 15.56 \\
\cline { 2 - 5 } & $\mathbf{2 4}$ & 18.57 & 16.32 & 18.62 \\
\hline
\end{tabular}

No particular pattern is evident from Table 17. The same is the case for other combinations of measurement errors as well as for RMS error. Thus, the conclusion is that improvements do not show well-defined dependency on the grid size or the pixel resolution. However, they do remain reasonably high, keeping their values in the range of $15 \%$ to $20 \%$ for absolute error improvements. 


\subsection{Real data application}

To test its methodology with real data, the spatio-temporal correlation technique was applied to satellite data observed over the Southeastern US for a period of 10 consecutive days, as described in Chapter 2. The results and basic information regarding the case study are given in Table 18 .

Measurements from five satellite sensors are used. Sensors' biases are calculated by comparing satellite instantaneous grid average rainfall measurements to the ground based instantaneous grid average rainfalls for the 10-day period. After removing the bias, instrument errors are determined by comparing satellite instantaneous pixel rainfall estimates to the true instantaneous pixel rainfall estimates, for each sensor over the study area. Measurement errors are given in Table 18.

The satellite pixel resolution was approximately $0.25^{\circ}$, currently among the highest resolutions available. The grid size is defined by $4 \times 4$ pixels resulting in grids of about $100 \mathrm{~km}$ in size. Across the 10-day period, two or more instruments have detected 42 raining events having a time separation shorter than 3 hours.

The true total rainfall accumulation is estimated using the NEXRAD stage IV data. As described in Chapter 2, these data are hourly accumulation estimates. In order to calculate the improvement of spatio-temporal correlation technique over simple averages, 15-minute estimates made from the spatio-temporal correlation technique are aggregated to 1-hour period and compared to NEXRAD's accumulation. Results are shown in Table 18. Results are not as good as those predicted with synthetic data 
(shown in brackets) but this is often the case when using real data. The total rainfall accumulations shown in Table 18 correspond only to the area where rain has been detected by satellites.

Table 18. Results and description of the case study

\begin{tabular}{|c|c|}
\hline Number of satellites & 5 \\
\hline Satellites' instruments & TMI, AMSR-E, SSMI13, SSMI14, SSMI15 \\
\hline Instrument error (\%) & $30,30,40,30,30$ \\
\hline Number of raining events & 42 \\
\hline Accumulation Grid Size & $100 \mathrm{~km}$ \\
\hline Pixel resolution & $24 \mathrm{~km}$ \\
\hline Accumulation intervals & 3 hours \\
\hline Total accumulation time & 10 days \\
\hline Total accumulation area & $5^{\circ} \times 10^{\circ}$ \\
\hline True TRA (radar) & $159 \mathrm{~mm} / 10$ days \\
\hline Estimated TRA & $164 \mathrm{~mm} / 10$ days \\
\hline Absolute error improvement & $6 \%(18 \%)$ \\
\hline RMS error improvement & $2 \%(13 \%)$ \\
\hline
\end{tabular}




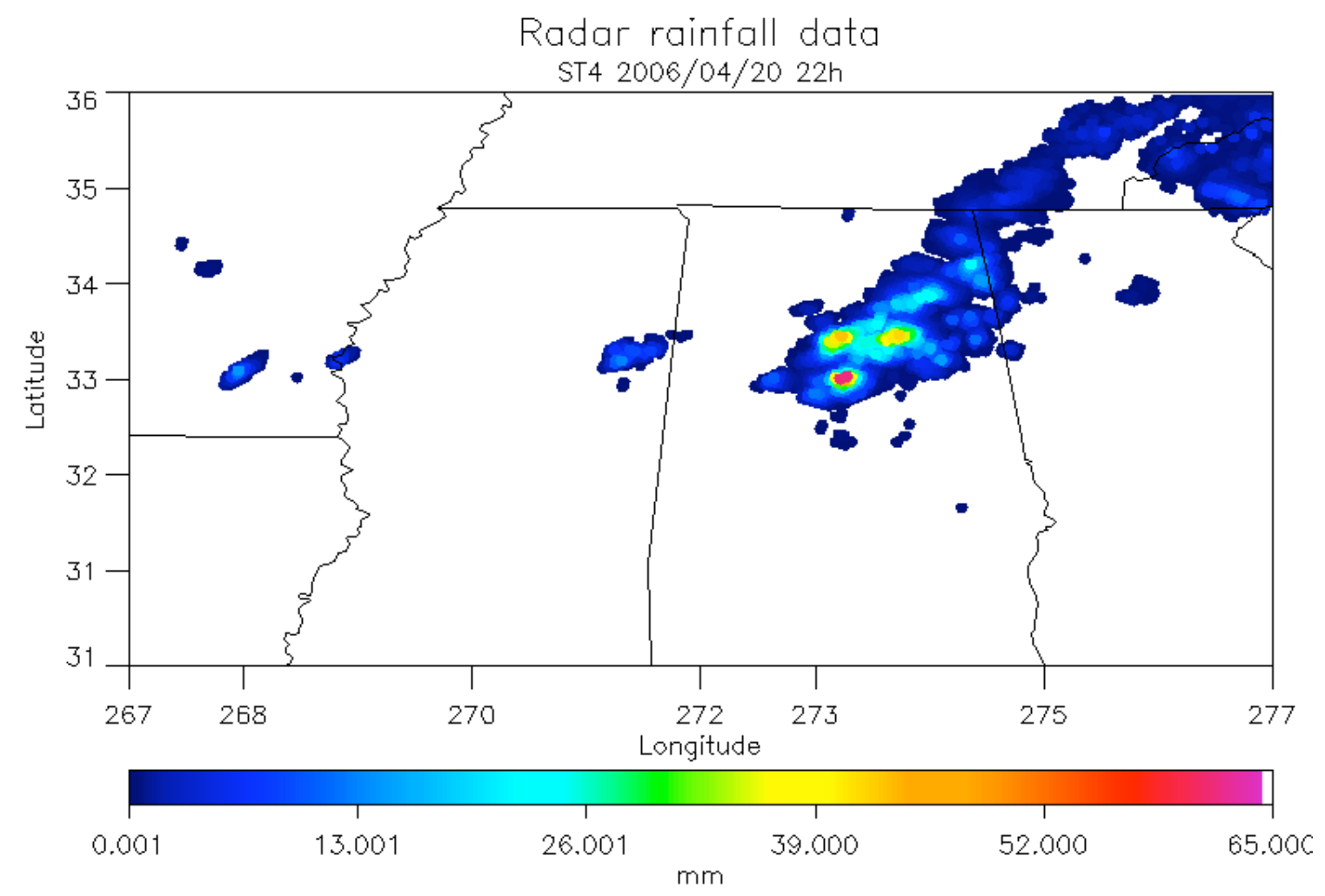

Figure 17. Convective-like raining event (NEXRAD stage IV hourly rainfall accumulations)

Details of two selected rain events are shown in Table 19 and Table 20, while events are shown in Figure 17 and Figure 18. Similar to Chapter 1, the two events are used to present two different raining types. One of the events has fields with high spatial correlation coefficients, indicating uniform rain (Table 20); while the other event containing low coefficients, implies more convective-like raining fields (Table 19). 


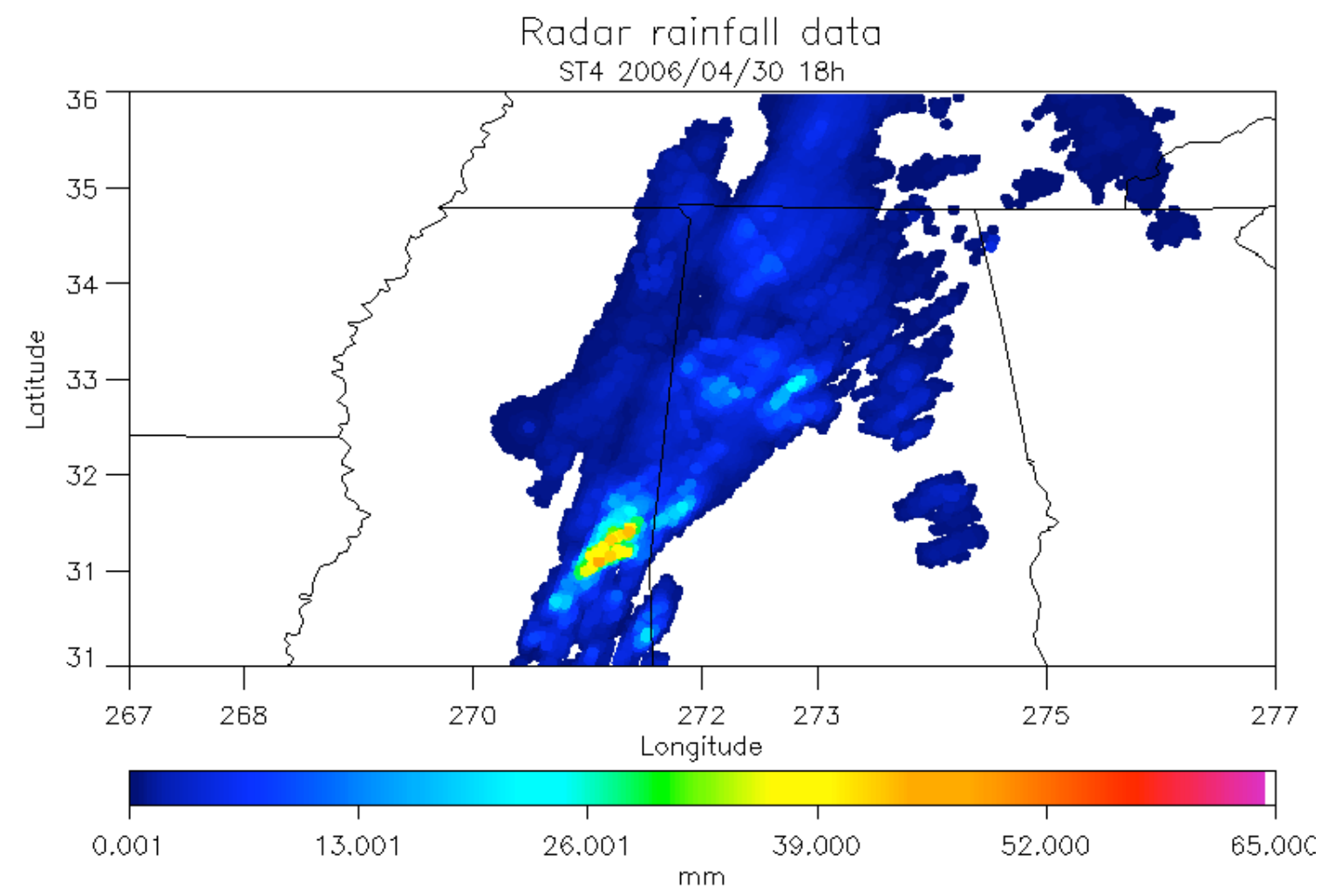

Figure 18. Stratiform-like raining event (NEXRAD stage IV hourly rainfall accumulations)

A time separation happened to be at the minimum in the convective type event. Table 19 shows small $\Delta t$. Instantaneous rain, and rain accumulation for this event are shown in Table 19. This 3-hour accumulation period started on April $20^{\text {th }}$ 2006 at 21:45 UTC. Two satellite instantaneous grid average rainfall measurements, made by the SSMI13 and SSMI14 sensors, at approximately 23:30 and 23:45 UTC, respectively, are $6.060 \mathrm{~mm} / \mathrm{h}$ and $6.236 \mathrm{~mm} / \mathrm{h}$. The times of measurements are marked as 105-minute and 120-minute (relative to the beginning of the accumulation interval) in Table 19. A spatial correlation coefficient of the field measured by SSMI13 was 0.181 , while 15 minutes later and with the same field, the SSMI14 had estimated a spatial correlation coefficient of 0.258 . Both of the 
techniques have overestimated the radar accumulation. Also, the simple averaging technique has a slightly better result than the spatio-temporal correlation technique. The absolute error improvement made by the spatio-temporal correlation technique is negative and equal to $-0.9 \%$. In other words, the spatio-temporal correlation technique has made a $0.9 \%$ larger absolute error than the simple averaging technique. Table 19 supports findings of previous section, that low values of spatial correlation coefficients and/or short time separations, result in small improvements, or even in slight aggravations.

Table 19. Convective-like raining event

\begin{tabular}{|c|c|c|c|c|c|}
\hline Time (min) & \multicolumn{5}{|c|}{ Accumulation $(\mathrm{mm} / \mathrm{h})$} \\
\hline & \multicolumn{2}{|c|}{$\begin{array}{c}\text { Spatio-temporal } \\
\text { correlation technique }\end{array}$} & \multicolumn{2}{|c|}{$\begin{array}{c}\text { Simple } \\
\text { averaging technique }\end{array}$} & Radar \\
\hline 15 & 6.196 & \multirow{4}{*}{6.184} & 6.148 & \multirow{4}{*}{6.148} & \multirow{4}{*}{4.165} \\
\hline 30 & 6.184 & & 6.148 & & \\
\hline 45 & 6.180 & & 6.148 & & \\
\hline 60 & 6.176 & & 6.148 & & \\
\hline 75 & 6.176 & \multirow{4}{*}{6.168} & 6.148 & \multirow{4}{*}{6.148} & \multirow{4}{*}{5.554} \\
\hline 90 & 6.180 & & 6.148 & & \\
\hline 105 & 6.188 & & 6.060 & & \\
\hline 120 & 6.128 & & 6.236 & & \\
\hline 135 & 6.124 & \multirow{4}{*}{6.131} & 6.148 & \multirow{4}{*}{6.148} & \multirow{4}{*}{4.450} \\
\hline 150 & 6.132 & & 6.148 & & \\
\hline 165 & 6.132 & & 6.148 & & \\
\hline 180 & 6.136 & & 6.148 & & \\
\hline $\begin{array}{c}\text { Total } \\
(\mathrm{mm} / 3 \mathrm{~h})\end{array}$ & \multicolumn{2}{|c|}{18.483} & \multicolumn{2}{|c|}{18.444} & 14.169 \\
\hline
\end{tabular}

Another raining event that occurred on April $30^{\text {th }} 2006$ was detected by the TMI sensor. The 3-hour rainfall accumulation period, starting at 18:00 UTC, with satellite measurements of the instantaneous grid average rainfall at approximately 19:00 UTC and 20:45 UTC is shown in Table 20. Instantaneous grid average rainfall 
measurements had values of $1.992 \mathrm{~mm} / \mathrm{h}$ and $0.144 \mathrm{~mm} / \mathrm{h}$. Two measured fields had spatial correlation coefficients of 0.422 and 0.239 , respectively, implying a higher uniformity than the fields presented in Table 19. Here, both techniques have underestimated the radar accumulation, except that the spatio-temporal correlation technique made a $0.847 \mathrm{~mm}$ smaller absolute error than the simple averaging technique, providing improvement of $41 \%$.

Clearly, higher spatial correlation coefficients and longer time separations resulted in an increased skill of the spatio-temporal correlation technique. Also, from comparing hourly rainfall accumulations of the two techniques, Table 20 shows that having the second measurement at the end of the accumulation period decreases the skill of the spatio-temporal correlation technique.

Table 20. Stratiform-like raining event

\begin{tabular}{|c|c|c|c|c|c|}
\hline Time (min) & \multicolumn{5}{|c|}{ Accumulation $(\mathrm{mm} / \mathrm{h})$} \\
\hline & \multicolumn{2}{|c|}{$\begin{array}{c}\text { Spatio-temporal } \\
\text { correlation technique }\end{array}$} & \multicolumn{2}{|c|}{$\begin{array}{c}\text { Simple } \\
\text { averaging technique }\end{array}$} & Radar \\
\hline 15 & 1.872 & \multirow{4}{*}{1.906} & 1.068 & \multirow{4}{*}{1.068} & \multirow{4}{*}{3.146} \\
\hline 30 & 1.884 & & 1.068 & & \\
\hline 45 & 1.920 & & 1.068 & & \\
\hline 60 & 1.948 & & 1.068 & & \\
\hline 75 & 1.964 & \multirow{4}{*}{1.720} & 1.992 & \multirow{4}{*}{1.299} & \multirow{4}{*}{1.341} \\
\hline 90 & 1.888 & & 1.068 & & \\
\hline 105 & 1.708 & & 1.068 & & \\
\hline 120 & 1.320 & & 1.068 & & \\
\hline 135 & 0.888 & \multirow{4}{*}{0.469} & 1.068 & \multirow{4}{*}{1.837} & \multirow{4}{*}{0.885} \\
\hline 150 & 0.520 & & 1.068 & & \\
\hline 165 & 0.292 & & 1.068 & & \\
\hline 180 & 0.176 & & 0.144 & & \\
\hline $\begin{array}{c}\text { Total } \\
(\mathrm{mm} / 3 \mathrm{~h})\end{array}$ & \multicolumn{2}{|c|}{4.095} & \multicolumn{2}{|c|}{3.204} & 5.372 \\
\hline
\end{tabular}




\section{CHAPTER 6}

\section{Conclusions}

The spatio-temporal correlation technique has been developed to improve estimations of 3-hour satellite rainfall accumulations. Statistical properties of rain and technical properties of instruments have been combined to assign the weights to sparse and rare instantaneous rainfall measurements. When weighted, they were first combined to form the estimates of the rainfall at the times between the measurements, and then used to estimate a 3-hour total rainfall accumulation. The results were then compared to the simple averaging technique, which takes a simple mean of the measurements as a constant rainfall rate over the entire accumulation period. The comparison was presented as improvements of the absolute and the RMS errors. The results implied a potential improvement of the total rainfall accumulations of currently used accumulation methods, such as CMORPH and TMPA, if the technique would be implemented into their estimates.

This new technique has showed skill in combining both inaccurate and sparse measurements. Rainfall fields have characteristic temporal and spatial correlations, which if used, can assist in making estimates between satellite overpasses. It was shown that more uniform rainfall fields have longer time correlations than less uniform fields. It was also shown that the temporal 
correlation length, or the time that the information from a single measurement is still useful, can be as long as 60 minutes. This greatly overcomes the temporal sparseness of the measurements, provided that the measurements are properly spaced over the accumulation period.

The best results are seen when the measurements are 120min apart, and of equal accuracies. The prior is consequence of having temporal correlation length of both measurements entirely covering the accumulation period, leaving no gaps in information about rainfall no matter which of the two measurements this information originates from. The letter is based on the fact that when one measurement is trusted less the other one is trusted even beyond its temporal correlation length. This results in lower improvements since temporal variability that corresponds to extended time separations of accurate measurements is larger than variability that corresponds to short time separations of less accurate measurements.

In addition to time separation dependence, the proficiency of the spatiotemporal correlation technique depends on the accuracy of the measurements. This technique has shown the capability of combining the measurements of different accuracy, although the most valuable results tend to occur if the measurements are of the similar accuracies.

The results indicate that when the spatio-temporal correlation technique is compared to the simple averaging technique, it creates improvement of $0 \%-50 \%$ in absolute error, and $0 \%-40 \%$ in RMS error, depending on the time separation and 
the measurement accuracy. Additionally, the spatio-temporal correlation technique rarely results in a deterioration of quality.

It is certain that the time separation between the measurements cannot be chosen or forced to its ideal length of 120 minutes. However, the results obtained by simulating the realistic scenario of having the length of time separation randomly distributed between 0 and 180 minutes are promising. They imply that the spatiotemporal correlation technique is capable of making up to $25 \%$ improvement in absolute error and up to 15\% improvement in RMS error when compared to the simple averaging technique. This is non-negligible, especially since the spatiotemporal correlation technique is computationally inexpensive. 


\section{Reference}

Babak, 0.; Deutsch, C. 2009. Statistical approach to inverse distance interpolation, Stoch Environ Res Risk Assess 23(5): 543-553. doi:10.1007/s00477-008-02266

Baldwin, M.E., and K.E. Mitchell, 1998: Progress on the NCEP hourly multi-sensor U.S. precipitation analysis for operations and GCIP research. Preprints, 2nd Symposium on Integrated Observing Systems, 78th AMS Annual Meeting, 10-11.

Bell, T. L., A. Abdullah, R. L. Martin, and G. R. North, 1990b: Sampling errors for satellite-derived tropical rainfall: Monte Carlo study using a space-time stochastic model. J. Geophys. Res., 95, 2195-2205

Dorman, C. E., and R. H. Bourke, 1979: Precipitation over the Pacific Ocean, 308 S to 608N. Mon. Wea. Rev., 107, 896-910.

Ebert, E. E., J. E. Janowiak, and C. Kidd, 2007: Comparison of near-realtime precipitation estimates from satellite observations and numerical models. Bull. Amer. Meteor. Soc., 88, 47-64.

Eric A. Smith and group of authors; 2004. Draft: International Global Precipitation Measurement (GPM) Program and Mission: An Overview, For Publication in Measuring Precipitation from Space: EURAINSAT and the Future. 
Griffith, C. G., W. L. Woodley, P. G. Grube, D. W. Martin, J. Stout, and D. N. Sikdar, 1978: Rain estimation from geosynchronous satellite imagery - Visible and infrared studies. Mon. Wea. Rev., 106, 1153-1171.J. Appl. Meteor., 42, 12181226.

Habib, E., W. F. Krajewski, and G. J. Ciach, 2001a: Estimation of rainfall interstation correlation. J. Hydrometeor., 2:621-629

Haddad, Z. S., D. A. Short, S. L. Durden, E. Im, S. Hensley, M. B. Grable, and R. A. Black, 1997a: A new parameterization of the rain drop size distribution. IEEE Trans. Geosci. Remote Sens., 35, 532-539.

Haddad, Z. S., E. A. Smith, C. D. Kummerow, T. Iguchi, M. R. Farrar, S. L. Durden, M. Alves, and W. S. Olson, 1997b: The TRMM "day-1" radar/radiometer combined rain-profiling algorithm. J. Meteor. Soc. Japan, 75, 799-809

Hong, Y., K. L. Hsu, S. Sorooshian, and X. Gao (2004), Precipitation estimation from remotely sensed information using artificial neural network cloud classification system, J. Appl. Meteorol., 43(12), 1834 - 1853.

Hsu, K., X. Gao, S. Sorooshian, and H. V. Gupta (1997), Precipitation estimation from remotely sensed information using artificial neural networks, J. Appl. Meteorol., $36,1176-1190$.

Hsu, K., H. V. Gupta, X. Gao, S. Sorooshian, and B. Imam (2002), Selforganizing linear output (SOLO): An artificial neural network suitable for hydrologic modeling and analysis, Water Resour. Res., 38(12), 1302, doi: 10.1029/2001WR000795.

Huff, F. A., 1993: 100-Year Rainstorms in the Midwest: Design Characteristics. Illinois State Water Survey, 20 pp. (Circular 176.) 
Huffman, G. J., R. F. Adler, B. Rudolf, U. Schneider, and P. R. Keehn, 1995: Global precipitation estimates based on a technique for combining satellite-based estimates, rain gauge analysis, and NWP model precipitation information. J. Climate, 8, 1284-1295.

Huffman, G. J., Adler, R. F., Bolvin, D. T., Gu, G., Nelkin, E. J., Bowman, K. P., Hong, Y., Stocker, E. F., and Wolff, D. B.: The TRMM Multi-satellite Precipitation Analysis: Quasi- global, multi-year, combined-sensor precipitation estimates at fine scale, J. Hydrometeor., 8, 38-55, 2007.

Huuskonen, A., 2006: EUMETNET OPERA: Operational Programme for the Exchange of Weather Radar Information. Proceedings of ERAD 2006, 3, 371-373

Joyce, R.J., Janowiak, J.E., Arkin, P.A. and XIE, P., 2004, CMORPH: A method that produces global precipitation estimates from passive microwave and infrared data at high spatial and temporal resolution. Journal of Hydrometeorology, 5, pp. 487-503.D

Kummerow, C., and L. Giglio (1995), A method for combining passive microwave and infrared rainfall observations, J. Atmos. Oceanic Tech- nol., 12, 33 - 45.

Kummerow, C., W. Barnes, T. Kozu, J. Shiue, and J. Simpson, 1998: The tropical rainfall measuring mission (TRMM) sensor package. J. Atmos. Oceanic Technol., $15,809-817$.

Lin, Y. and K. E. Mitchell, 2005: The NCEP Stage II/IV hourly precipitation analyses: development and applications. Preprints, 19th Conf. on Hydrology, American Meteorological Society, San Diego, CA, 9-13 January 2005, Paper 1.2. 
Lobl, E, 2001. Joint advanced microwave scanning radiometer (AMSR) science team meeting, Earth Observer 13(3): 3-9.

Metropolis N. and Ulam S., 1949: The Monte Carlo Method, Journal of the American Statistical Association, Vol. 44, No. 247. (Sep., 1949), pp. 335-341.

National Snow and Ice Data Center (NSIDC), 2007b. Instrument description: Advanced Microwave Scanning Radiometer (AMSR-E), URL: http://nsidc.org/ (Updated: 25 June 2007, date last accessed: 27 July 2007).

Pereira Fo., A. J. and K. C. Crawford, 1999: Mesoscale precipitation fields. Part I: Statistical analysis and hydrologic response, J. Appl. Meteor., 38, 82-101.

Rabinovich, S.: Measurement Errors and Uncertainties: Theory and Practice, book, Springer, 2005

Sorooshian, S., K.-L. Hsu, X. Gao, H. V. Gupta, B. Imam, and D. Braithwaite, 2000: Evaluation of PERSIANN system satellite-based estimates of tropical rainfall. Bull. Amer. Meteor. Soc., 81, 2035-2046.

Tsintikidis, J. L. Haferman, E. N. Anagnostou, W. F. Krajewski, and T. F. Smith, "A neural network approach to estimating rainfall from spaceborne microwave data," IEEE Trans. Geosci. Remote Sensing, vol. 35, pp. 1079-1093, Sept. 1997.

Wang, P. K., and D. E. Zhang, 1988: An introduction to some historical governmental weather records of China. Bull. Am. Meteorol. Soc., 69, 753-758. 
Weng, F., and N. C. Grody, 1994: Retrieval of cloud liquid water using the Special Sensor Microwave Imager (SSM/I). J. Geophys. Res., 99, 25 535-25 551.

Yates, D. N., T. T. Warner, and G. H. Leavesley, 2000: Prediction of a flash flood in complex terrain. Part II: A comparison of flood discharge simulations using rainfall input from radar, a dynamic model, and an automated algorithmic system. J. Appl. Meteor., 39, 815-825. 


\section{Appendix A}

The spatial correlation coefficient is introduced in Chapter 3 to describe the spatial change of the rainfall rate distribution. This quantity is convenient when the pixel resolution is fixed, as it would be in satellite applications. The drawback of correlation coefficient is that pixel size is implied. Other studies have therefore used the correlation length to describe the homogeneity of the rainfall filed.

Table 21. Spatial correlation coefficient and length for a grid size of $100 \times 100 \mathrm{~km}$

\begin{tabular}{|c|c|c|c|}
\hline Pixel resolution $(\mathrm{km})$ & $\mathbf{2 4}$ & $\mathbf{1 2}$ & $\mathbf{8}$ \\
\hline Spatial correlation coefficient & 0.599 & 0.624 & 0.635 \\
\hline Spatial correlation length $(\mathrm{km})$ & 26.4 & 23.3 & 18.6 \\
\hline
\end{tabular}

The correlation length is defined as the distance at which a correlation coefficient value drops by a factor of $\boldsymbol{e}$ compared to its initial value (i.e. no shift). Table 21 compares the correlation coefficients and correlation lengths to each of the correlation coefficients shown in Table 1 . Here, although the 8km pixel has higher correlation coefficients than the larger pixel, it is cleat that the correlation length is actually smaller for the higher resolution field. 
Table 22. Correlation length vs. correlation coefficient

\begin{tabular}{|c|c|c|c|c|c|c|c|c|c|c|c|c|c|}
\hline \multicolumn{4}{|c|}{ Spatial correlation length $(\mathrm{km})$} & 5 & 10 & 15 & 20 & 25 & 30 & 35 & 40 & 45 & 50 \\
\hline \multirow{6}{*}{ 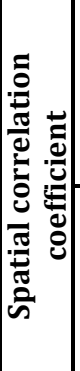 } & \multirow{3}{*}{$\begin{array}{c}\text { Grid size } \\
\text { 100x100km }\end{array}$} & \multirow{3}{*}{ 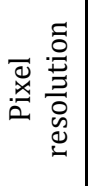 } & $8 \mathrm{~km}$ & 0.028 & 0.343 & 0.658 & 0.973 & 1.0 & 1.0 & 1.0 & 1.0 & 1.0 & 1.0 \\
\hline & & & $12 \mathrm{~km}$ & -0.115 & 0.146 & 0.407 & 0.668 & 0.929 & 1.0 & 1.0 & 1.0 & 1.0 & 1.0 \\
\hline & & & $24 \mathrm{~km}$ & -0.569 & -0.309 & -0.049 & 0.210 & 0.47 & 0.73 & 0.99 & 1.0 & 1.0 & 1.0 \\
\hline & \multirow{3}{*}{$\begin{array}{c}\text { Grid size } \\
\text { 250x250km }\end{array}$} & \multirow{3}{*}{ 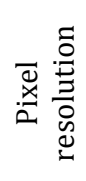 } & $8 \mathrm{~km}$ & 0.094 & 0.258 & 0.422 & 0.585 & 0.749 & 0.913 & 1.0 & 1.0 & 1.0 & 1.0 \\
\hline & & & $12 \mathrm{~km}$ & 0.017 & 0.159 & 0.301 & 0.443 & 0.586 & 0.728 & 0.871 & 1.0 & 1.0 & 1.0 \\
\hline & & & $24 \mathrm{~km}$ & -0.161 & -0.055 & 0.056 & 0.164 & 0.273 & 0.382 & 0.491 & 0.6 & 0.709 & 0.818 \\
\hline
\end{tabular}

To give a better sense of the relationship between the spatial coefficient and the spatial correlation length, Table 22 shows averages calculated for the entire OPERA data set, for the grid sizes of $250 \times 250 \mathrm{~km}$ and $100 \times 100 \mathrm{~km}$ and for pixel resolutions of $8 \mathrm{~km}, 12 \mathrm{~km}$ and $24 \mathrm{~km}$. This table provides convenient conversion for the spatial correlation coefficient if the spatial correlation length is known, and vice versa.

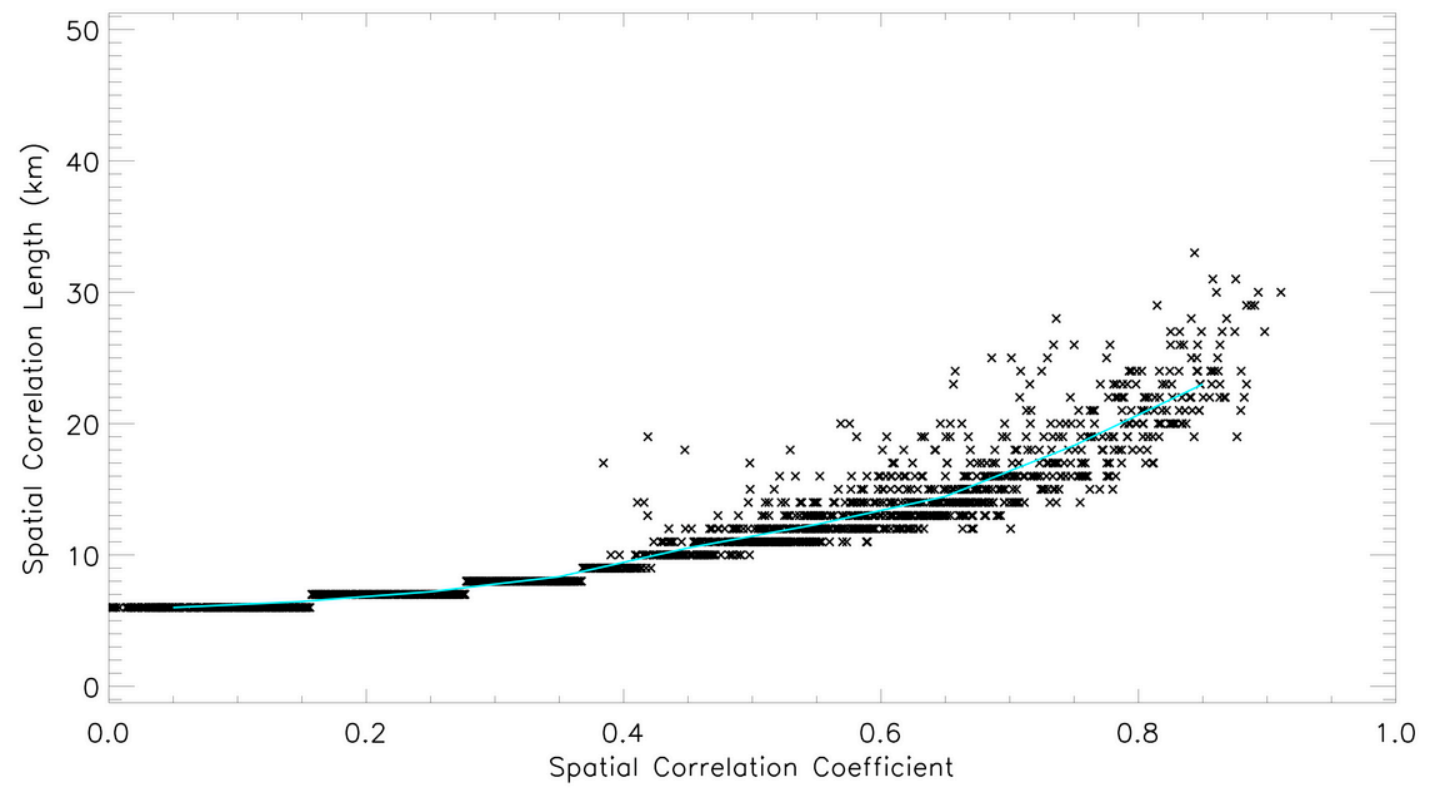

Figure 19. Spatial correlation coefficient vs. length (grid size $100 \mathrm{~km} ; 8 \mathrm{~km}$ pixel resolution) 
Figure 19 shows this relationship for a 100x100km grid size with an $8 \mathrm{~km}$ pixel resolution. The diagram is based on approximately $5 \%$ of all of the data available in the OPERA data set. The line shown in Figure 19 defines the values in Table 22 for the corresponding grid size and pixel resolution. The exponential relationship between the length and the coefficient can be also found in Pereira et al. (1999). The difference between their result and the one seen here is due to the fact that their study was focused to specific area with the pixel resolution of only $2 \mathrm{~km}$. Therefore, their spatial correlation coefficient with approximate value of 0.98 corresponds to the length of approximately $22 \mathrm{~km}$, while here that length is approximately 1.5 times greater. Otherwise the results show the same behavior.

Table 23. temporal correaltion coefficient for separation times of 30 and $45 \mathrm{~min}$

\begin{tabular}{|c|c|c|c|c|}
\hline \multirow{2}{*}{ Field size (km) } & \multirow{2}{*}{ Time separation (min) } & \multicolumn{3}{|c|}{ Pixel size (km) } \\
\cline { 2 - 5 } & & $\mathbf{2 4}$ & $\mathbf{1 2}$ & $\mathbf{8}$ \\
\hline \multirow{2}{*}{$\mathbf{5 0 0} \times \mathbf{5 0 0}$} & $\mathbf{3 0}$ & 0.616 & 0.505 & 0.424 \\
\cline { 2 - 5 } & $\mathbf{4 5}$ & 0.528 & 0.431 & 0.343 \\
\hline \multirow{2}{*}{$\mathbf{2 5 0} \times \mathbf{2 5 0}$} & $\mathbf{3 0}$ & 0.552 & 0.434 & 0.389 \\
\cline { 2 - 5 } & $\mathbf{4 5}$ & 0.455 & 0.357 & 0.318 \\
\hline \multirow{2}{*}{$\mathbf{1 0 0} \times \mathbf{1 0 0}$} & $\mathbf{3 0}$ & 0.540 & 0.390 & 0.342 \\
\cline { 2 - 5 } & $\mathbf{4 5}$ & 0.452 & 0.323 & 0.288 \\
\hline
\end{tabular}

Similarly to the spatial correlation case, temporal correlation length is calculated as the time at which the initial value of the temporal correlation coefficient drops by a factor of $\boldsymbol{e}$. Figure 20 shows that longer spatial correlation lengths correspond to longer temporal correlation lengths, implying that more uniform (stratiform) raining systems tend to change at a slower rate than nonuniform (convective) ones. 


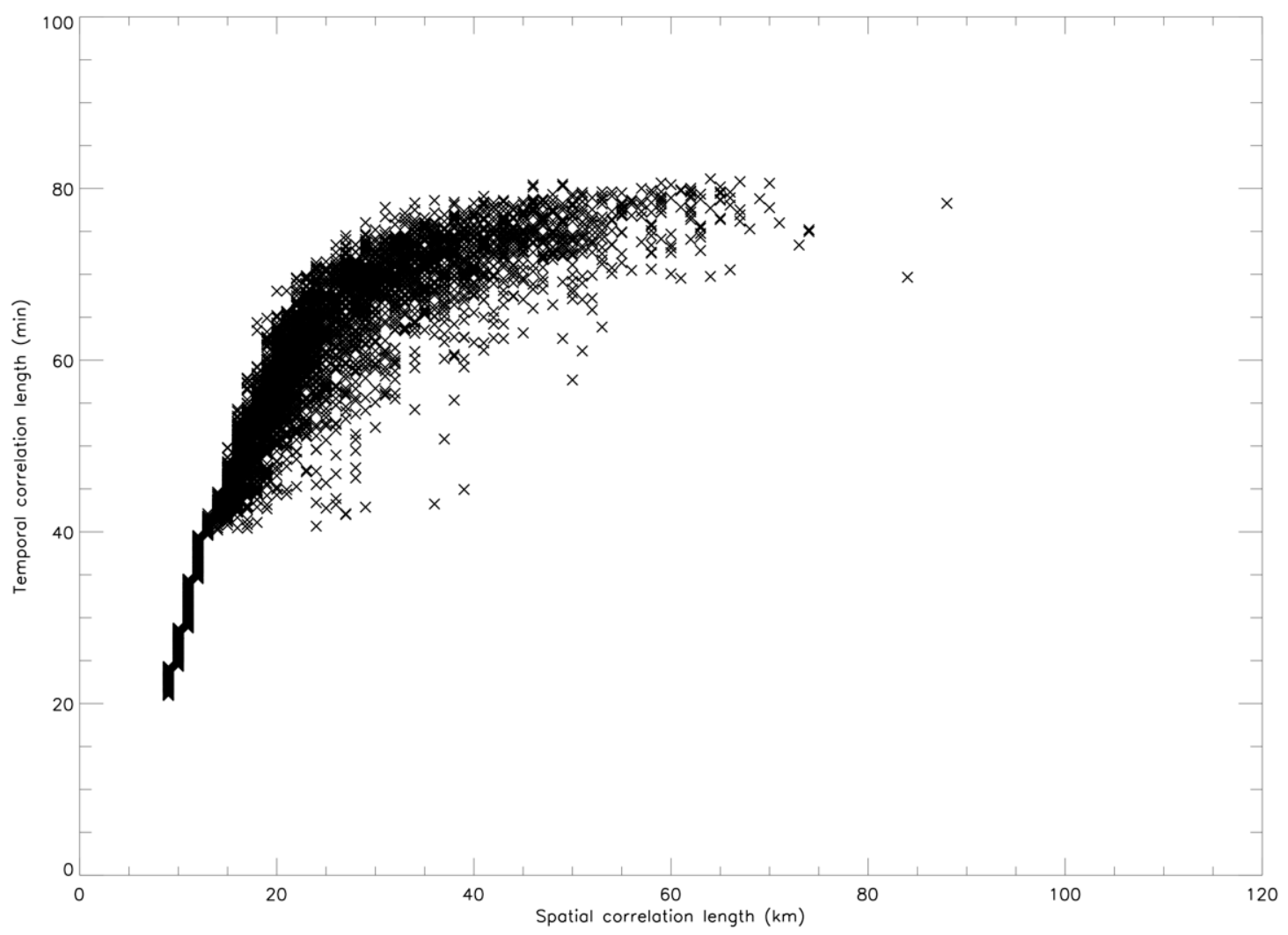

Figure 20. Spatial-Temporal length (grid size 250km; pixel resolution $12 \mathrm{~km}$ )

The same dependence of temporal and spatial correlation lengths can be found in Bell et al. (1990b). Although they have found different values for correlation lengths (much longer than seen here), the shapes of the relationship curves are the same. The differences in the lengths are due to the different manner in which calculations have been done (the parameters they have used to obtain those relations are based on observations taken in less than a month) and the fact they have used much smaller and more specific area.

Table 24. Spatial-Temporal length (grid size $250 \mathrm{~km}$; pixel resolution $12 \mathrm{~km}$ )

\begin{tabular}{|c|c|c|c|c|c|c|c|c|c|c|}
\hline Spatial correlation length (km) & 5 & 10 & 15 & 20 & 25 & 30 & 35 & 40 & 45 & 50 \\
\hline Temporal correlation length (min) & 31 & 38 & 44 & 50 & 56 & 62 & 68 & 74 & 80 & 86 \\
\hline
\end{tabular}




\section{Appendix B}

\section{Combining the results of measurements}

Rabinovich 2005, provides the foundation for combining measurements with various uncertainties. Here, only the combination of two measurement sets of known variances is described.

\section{Theoretical principles}

Consider L groups of measurements of the same quantity A. Estimates of the measured quantity $\mathrm{x}_{1}, \ldots, \mathrm{x}_{\mathrm{L}}$ were made from the measurements of each group, and

$$
E\left[\bar{x}_{1}\right]=\cdots=E\left[\bar{x}_{L}\right]=A
$$

The variances of the measurements in each group $\sigma_{1}{ }^{2}, \ldots, \sigma_{\mathrm{L}}{ }^{2}$ and the number of measurements in each group $\mathrm{n}_{1}, \ldots, \mathrm{n}_{\mathrm{L}}$ are known.

The goal is finding an estimate of the measured quantity based on data from all groups of measurements. This estimate is denoted as $\stackrel{\bar{x}}{x}$ and is called the combined average or weighted mean. 
We shall seek $\bar{x}$ as a linear function of $\bar{x}_{j}$ i.e., as their weighted mean,

$$
\bar{x}=\sum_{j=1}^{L} g_{j} \bar{x}_{j}
$$

Therefore the problem reduces to finding the weights $g_{j}$. As $E\left[\bar{x}_{j}\right]=A$ and $E\left[\bar{x}_{j}\right]=A$, we obtain

$$
E[\bar{x}]=E\left[\sum_{j=1}^{L} g_{j} \bar{x}_{j}\right]=\sum_{j=1}^{L} g_{j} E\left[\bar{x}_{j}\right]
$$

Therefore,

$$
\sum_{j=1}^{L} g_{j}=1
$$

Next, we require that $\overline{\bar{x}}$ be an efficient estimate of $\mathrm{A}$; i.e. $\mathrm{V}[\overline{\bar{x}}]$ must be minimum. For this reason we find an expression for $\mathrm{V}[\overline{\bar{x}}]$, using next formula:

$$
V[\overline{\bar{x}}]=V\left[\sum_{j=1}^{L} g_{j} \bar{x}_{j}\right]=\sum_{j=1}^{L} g_{j}^{2} V\left[\bar{x}_{j}\right]=g_{1}^{2} \sigma^{2}\left(\bar{x}_{1}\right)+g_{2}^{2} \sigma^{2}\left(\bar{x}_{2}\right)+\cdots+g_{L}^{2} \sigma^{2}\left(\bar{x}_{L}\right)
$$

Using the condition that the sum of all weights must be equal to 1 , we write $\mathrm{g}_{\mathrm{L}}=1-\mathrm{g}_{1}-\mathrm{g}_{2}-\cdots-\mathrm{g}_{\mathrm{L}-1}$. We shall now find the condition under which the derivative of $\mathrm{V}[$ $\overline{\bar{x}}$ ] with respect to $g_{j}$ is equal to 0 . It turns out that the weights of the arithmetic means of the groups of measurements must satisfy (for details see Rabinovich 2005): 


$$
g_{1}: g_{2}: \cdots: g_{L}=\frac{1}{\sigma^{2}\left(\bar{x}_{1}\right)}: \frac{1}{\sigma^{2}\left(\bar{x}_{2}\right)}: \cdots: \frac{1}{\sigma^{2}\left(\bar{x}_{L}\right)}
$$

To find weight, $g_{j}$, it is necessary to know either the variances of the arithmetic means or the ratio of the variances. If we have the variances, $\sigma^{2}\left(\overline{x_{j}}\right)$, then we can set $g_{j}^{\prime}=\frac{1}{\sigma^{2}\left(\overline{x_{j}}\right)}$. We then obtain:

$$
g_{j}=\frac{g_{j}^{\prime}}{\sum_{j=1}^{L} g_{j}^{\prime}}
$$

This defines $\bar{x}$.

According to this study, groups of measurements are data sets from different satellites, while what has been defined as measurement accuracy is the standard deviation of the arithmetic mean of such a data set. Thus, the squared accuracy is the variance as used here to define the weight $g_{j}$. Note that in Chapter 4 the symbol, $g_{j}^{\prime}$, is replaced by $\boldsymbol{w}_{\boldsymbol{i}}$.

Combining the results of measurements containing both systematic and random errors

Assume that $\boldsymbol{n}$ instruments measure the same quantity A. Each instrument gives the result, $\boldsymbol{x}_{\boldsymbol{j}}$, with error, $\boldsymbol{q}_{\boldsymbol{j}}$ :

$$
x_{j}=A+q_{j} \quad, j=1,2, \ldots, n
$$


To combine the series of values of $\mathrm{x}$ in a well-founded manner and obtain a more accurate estimate of the measured quantity, one must have certain information about the errors, $\boldsymbol{q}_{\boldsymbol{j}}$. Here, the error, $\boldsymbol{q}_{\boldsymbol{j}}$, is the sum of the conditionally constant error, $v_{j}$, and random error, $\psi_{j}$ :

$$
\mathrm{q}_{\mathrm{j}}=v_{\mathrm{j}}+\psi_{\mathrm{j}}
$$

If this is the case, the weights, $\mathbf{g}_{j}$, of the measurements being combined should be calculated using the following formula:

$$
g_{j}=\frac{\frac{1}{S^{2}\left(v_{j}\right)+S^{2}\left(\psi_{j}\right)}}{\sum_{j=1}^{n} \frac{1}{S^{2}\left(v_{j}\right)+S^{2}\left(\psi_{j}\right)}}
$$

Where $S^{2}\left(v_{j}\right)$ and $S^{2}\left(\psi_{j}\right)$ are estimates of variances of conditionally constant errors and the random error of the same measurement result.

Regarding this study, $S^{2}\left(v_{j}\right)$ and $S^{2}\left(\psi_{j}\right)$ are proportional to temporal variability and measurement error, respectively. 


\section{Appendix C}

\section{Monte Carlo Method}

The Monte Carlo Method (Metropolis and Ulam, 1949) is any method that solves a problem by generating suitable random numbers and observing the fraction of numbers obeying some property or properties. The method is useful for obtaining numerical solutions to problems, which are too complex to solve analytically. In this particular case the problem is as follows.

Inaccuracy of the measurement influences the accuracy of the spatial correlation coefficient calculated in Equation 2, which is then used to define the temporal variability. Rather than looking for the propagation of the $\boldsymbol{x}$ and $\boldsymbol{y}$ vectors' errors in Equation 1, the Monte Carlo method is used to define the uncertainty of the spatial correlation coefficient, by comparing accurate fields to their uncertain duplicates. OPERA data with simulated errors (as described in Chapter 2) are used to produce those uncertain duplicates for 10 different uncertainty levels (given in Table 25) for all combinations of grid sizes and pixel resolutions. Results are given as corrections that have to be added to uncertain spatial correlation coefficients. Table 25 gives an example of the spatial correlation coefficient's corrections for the grid size of $250 \mathrm{~km}$ with a $12 \mathrm{~km}$ pixel resolution. 
Table 25. Spatial correlation coefficient correction (grid size $250 \mathrm{~km} ; 12 \mathrm{~km}$ pixel resolution)

\begin{tabular}{|c|c|c|c|c|c|c|c|c|c|c|c|c|}
\hline & \multicolumn{11}{|c|}{ Spatial correlation coefficient interval } \\
\hline & & {$[-0.1,0)$} & {$[0,0.1$} & $0.1,0.2$ & {$[0.2,0.3)$} & {$[0.3,0.4)$} & {$[0.4,0.5)$} & {$[0.5,0.6)$} & {$[0.6,0.7)$} & {$[0.7,0.8)$} & {$[0.8,0.9]$} & {$[0.9,1.0]$} \\
\hline \multirow{10}{*}{ 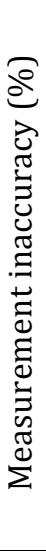 } & 10 & 0.00 & 0.00 & 0.00 & 0.00 & 0.00 & 0.00 & 0.00 & 0.00 & 0.00 & 0.00 & 0.00 \\
\hline & 20 & 0.00 & 0.00 & 0.00 & 0.00 & -0.01 & -0.01 & -0.01 & -0.01 & -0.01 & -0.02 & 0.00 \\
\hline & 30 & 0.00 & 0.00 & -0.01 & -0.01 & -0.02 & -0.02 & -0.03 & -0.03 & -0.04 & -0.04 & 0.00 \\
\hline & 40 & 0.00 & -0.01 & -0.01 & -0.02 & -0.03 & -0.04 & -0.04 & -0.05 & -0.06 & -0.06 & 0.00 \\
\hline & 50 & 0.00 & -0.01 & -0.02 & -0.03 & -0.04 & -0.05 & -0.06 & -0.07 & -0.08 & -0.09 & 0.00 \\
\hline & 60 & 0.00 & -0.01 & -0.02 & -0.04 & -0.05 & -0.07 & -0.08 & -0.10 & -0.11 & -0.12 & 0.00 \\
\hline & 70 & 0.00 & -0.01 & -0.03 & -0.05 & -0.07 & -0.09 & -0.11 & -0.12 & -0.14 & -0.15 & 0.00 \\
\hline & 80 & 0.00 & -0.02 & -0.04 & -0.06 & -0.09 & -0.11 & -0.14 & -0.16 & -0.17 & -0.19 & 0.00 \\
\hline & 90 & -0.01 & -0.02 & -0.05 & -0.08 & -0.11 & -0.14 & -0.16 & -0.19 & -0.21 & -0.22 & -0.01 \\
\hline & 99 & -0.01 & -0.03 & -0.05 & -0.09 & -0.12 & -0.16 & -0.19 & -0.21 & -0.23 & -0.25 & -0.01 \\
\hline
\end{tabular}




\section{Appendix D}

\begin{tabular}{|c|c|c|c|c|c|c|c|c|c|c|c|}
\hline \multicolumn{12}{|c|}{$\begin{array}{l}\text { RMS error improvement (\%) with 0min separation time } \\
\text { Grid size } 250 \mathrm{~km} \text { pixel resolution } 12 \mathrm{~km}\end{array}$} \\
\hline \multirow{2}{*}{\multicolumn{2}{|c|}{$\begin{array}{l}\text { \# of events: } \\
15,000\end{array}$}} & \multicolumn{10}{|c|}{ Uncertainty of sensor \#1 (\%) } \\
\hline & & $\mathbf{0}$ & 10 & 20 & 30 & 40 & 50 & 60 & 70 & 80 & 90 \\
\hline \multirow{10}{*}{ 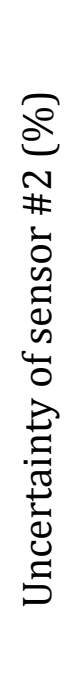 } & 0 & 0 & 0 & -0.01 & 0.07 & -0.01 & 0.29 & 0.76 & 0.60 & 0.6 & 1.61 \\
\hline & 10 & 0 & 0 & -0.01 & 0.03 & -0.03 & 0.23 & 0.71 & 0.55 & 0.56 & 1.56 \\
\hline & 20 & -0.01 & -0.01 & 0 & 0.07 & 0.04 & 0.32 & 0.79 & 0.68 & 0.69 & 1.61 \\
\hline & 30 & 0.07 & 0.03 & 0.07 & 0 & -0.09 & 0.15 & 0.47 & 0.40 & 0.43 & 1.22 \\
\hline & 40 & -0.01 & -0.03 & 0.04 & -0.09 & 0 & 0.10 & 0.46 & 0.35 & 0.39 & 1.22 \\
\hline & 50 & 0.29 & 0.23 & 0.32 & 0.15 & 0.1 & 0 & 0.03 & 0.05 & -0.18 & 0.61 \\
\hline & 60 & 0.76 & 0.71 & 0.79 & 0.47 & 0.46 & 0.03 & 0 & 0.06 & 0.02 & 0.11 \\
\hline & 70 & 0.60 & 0.55 & 0.68 & 0.40 & 0.35 & 0.05 & 0.06 & 0 & -0.26 & -0.13 \\
\hline & 80 & 0.60 & 0.56 & 0.69 & 0.43 & 0.39 & -0.18 & 0.02 & -0.26 & 0 & -0.38 \\
\hline & 90 & 1.61 & 1.56 & 1.61 & 1.22 & 1.22 & 0.61 & 0.11 & -0.13 & -0.38 & 0 \\
\hline
\end{tabular}




\begin{tabular}{|c|c|c|c|c|c|c|c|c|c|c|c|}
\hline \multicolumn{12}{|c|}{$\begin{array}{c}\text { Absolute error improvement (\%) with 0min separation time } \\
\text { Grid size } 250 \mathrm{~km} \text { pixel resolution } 12 \mathrm{~km}\end{array}$} \\
\hline \multirow{2}{*}{\multicolumn{2}{|c|}{$\begin{array}{l}\text { \# of events: } \\
15,000\end{array}$}} & \multicolumn{10}{|c|}{ Uncertainty of sensor \#1 (\%) } \\
\hline & & 0 & 10 & 20 & 30 & 40 & 50 & 60 & 70 & 80 & 90 \\
\hline \multirow{10}{*}{ 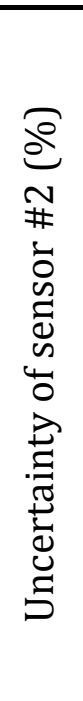 } & $\mathbf{0}$ & 0 & 0.16 & 0.34 & 0.62 & 0.83 & 1.03 & 1.51 & 1.96 & 2.68 & 3.06 \\
\hline & 10 & 0.16 & 0 & 0.09 & 0.30 & 0.50 & 0.69 & 1.16 & 1.62 & 2.35 & 2.71 \\
\hline & 20 & 0.34 & $0.0 \mathrm{C}$ & 0 & 0.11 & 0.26 & 0.43 & 0.84 & 1.31 & 1.97 & 2.28 \\
\hline & 30 & 0.62 & 0.30 & 0.11 & 0 & 0.01 & 0.13 & 0.38 & 0.76 & 1.33 & 1.70 \\
\hline & 40 & 0.83 & 0.50 & 0.26 & 0.01 & 0 & -0.07 & 0.14 & 0.44 & 0.89 & 1.26 \\
\hline & 50 & 1.03 & $0.6 \mathrm{c}$ & 0.43 & 0.13 & -0.07 & 0 & -0.01 & 0.08 & 0.41 & 0.73 \\
\hline & 60 & 1.51 & 1.16 & 0.84 & 0.38 & 0.14 & -0.01 & 0 & -0.02 & 0.26 & 0.38 \\
\hline & 70 & 1.96 & 1.62 & 1.31 & 0.76 & 0.44 & 0.08 & -0.02 & 0 & -0.12 & -0.10 \\
\hline & 80 & 2.68 & 2.35 & 1.97 & 1.33 & 0.89 & 0.41 & 0.26 & -0.12 & 0 & -0.28 \\
\hline & 90 & 3.06 & 2.71 & 2.28 & 1.70 & 1.26 & 0.73 & 0.38 & -0.10 & -0.28 & 0 \\
\hline
\end{tabular}

\begin{tabular}{|c|c|c|c|c|c|c|c|c|c|c|c|}
\hline & & RMS & $\mathrm{Gl}$ & d size & $\begin{array}{l}\text { nent } \\
50 \mathrm{~km}\end{array}$ & xel re & $\begin{array}{l}60 \mathrm{~min} \\
\text { olution }\end{array}$ & $12 \mathrm{~km}$ & Ilon & & \\
\hline$\#$ of $\mathrm{e}$ & & & & & Uncert & ainty 0 & sensor & $\# 1$ (\%) & & & \\
\hline & & 0 & 10 & 20 & 30 & 40 & 50 & 60 & 70 & 80 & 90 \\
\hline & 0 & 26.04 & 25.75 & 24.07 & 21.04 & 16.53 & 11.88 & 8.02 & 3.46 & 0.25 & -1.77 \\
\hline 0 & 10 & 25.75 & 25.60 & 24.32 & 21.64 & 17.42 & 13.03 & 9.09 & 4.63 & 1.32 & -0.85 \\
\hline & 20 & 24.07 & 24.32 & 24.09 & 22.64 & 19.55 & 15.71 & 12.06 & 7.48 & 4.01 & 1.91 \\
\hline t & 30 & 21.04 & 21.64 & 22.64 & 22.57 & 20.93 & 18.13 & 14.66 & 10.35 & 6.71 & 4.32 \\
\hline d & 40 & 16.53 & 17.42 & 19.55 & 20.93 & 21.36 & 20.31 & 17.84 & 14.32 & 10.90 & 8.66 \\
\hline 0 & 50 & 11.88 & 13.03 & 15.71 & 18.13 & 20.31 & 20.94 & 19.68 & 17.76 & 14.57 & 12.84 \\
\hline. & 60 & 8.02 & 9.09 & 12.06 & 14.66 & 17.84 & 19.68 & 19.83 & 18.85 & 16.72 & 15.24 \\
\hline 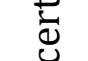 & 70 & 3.46 & 4.63 & 7.48 & 10.35 & 14.32 & 17.76 & 18.85 & 20.35 & 19.21 & 19.08 \\
\hline รี & 80 & 0.25 & 1.32 & 4.01 & 6.71 & 10.90 & 14.57 & 16.72 & 19.21 & 19.51 & 20.01 \\
\hline & 90 & -1.77 & -0.85 & 1.91 & 4.32 & 8.66 & 12.84 & 15.24 & 19.08 & 20.01 & 20.49 \\
\hline
\end{tabular}




\begin{tabular}{|c|c|c|c|c|c|c|c|c|c|c|c|}
\hline \multicolumn{12}{|c|}{$\begin{array}{l}\text { Absolute error improvement (\%) with } 60 \mathrm{~min} \text { separation time } \\
\text { Grid size } 250 \mathrm{~km} \text { pixel resolution } 12 \mathrm{~km}\end{array}$} \\
\hline \multirow{2}{*}{\multicolumn{2}{|c|}{$\begin{array}{l}\text { \# of events: } \\
15,000\end{array}$}} & \multicolumn{10}{|c|}{ Uncertainty of sensor \#1 (\%) } \\
\hline & & 0 & 10 & 20 & 30 & 40 & 50 & 60 & 70 & 80 & 90 \\
\hline \multirow{10}{*}{ 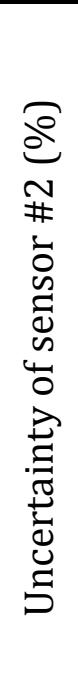 } & 0 & 33.03 & 32.15 & 29.19 & 25.08 & 19.96 & 15.61 & 11.78 & 7.90 & 5.75 & 3.86 \\
\hline & 10 & 32.15 & 31.51 & 29.13 & 25.40 & 20.50 & 16.24 & 12.38 & 8.44 & 6.20 & 4.23 \\
\hline & 20 & 29.19 & 29.13 & 28.31 & 26.11 & 22.21 & 18.40 & 14.57 & 10.56 & 8.19 & 6.13 \\
\hline & 30 & 25.08 & 25.40 & 26.11 & 25.84 & 23.59 & 20.60 & 17.06 & 13.08 & 10.53 & 8.17 \\
\hline & 40 & 19.96 & 20.50 & 22.21 & 23.59 & 23.46 & 22.16 & 19.66 & 16.31 & 13.78 & 11.53 \\
\hline & 50 & 15.61 & 16.24 & 18.40 & 20.60 & 22.16 & 22.56 & 21.13 & 18.89 & 16.62 & 14.64 \\
\hline & 60 & 11.78 & 12.38 & 14.57 & 17.06 & 19.66 & 21.13 & 21.12 & 20.06 & 18.64 & 16.91 \\
\hline & 70 & 7.90 & 8.44 & 10.56 & 13.08 & 16.31 & 18.89 & 20.06 & 20.90 & 20.27 & 19.60 \\
\hline & 80 & 5.75 & 6.20 & 8.19 & 10.53 & 13.78 & 16.62 & 18.64 & 20.27 & 20.53 & 20.34 \\
\hline & 90 & 3.86 & 4.23 & 6.13 & 8.17 & 11.53 & 14.64 & 16.91 & 19.6 & 20.34 & 20.62 \\
\hline
\end{tabular}

\begin{tabular}{|c|c|c|c|c|c|c|c|c|c|c|c|}
\hline \multicolumn{12}{|c|}{$\begin{array}{c}\text { RMS error improvement (\%) with } 120 \mathrm{~min} \text { separation time } \\
\text { Grid size } 250 \mathrm{~km} \text { pixel resolution } 12 \mathrm{~km}\end{array}$} \\
\hline \multirow{2}{*}{\multicolumn{2}{|c|}{$\begin{array}{l}\text { \# of events: } \\
\quad 15,000\end{array}$}} & \multicolumn{10}{|c|}{ Uncertainty of sensor \#1 (\%) } \\
\hline & & 0 & 10 & 20 & 30 & 40 & 50 & 60 & 70 & 80 & 90 \\
\hline \multirow{10}{*}{ 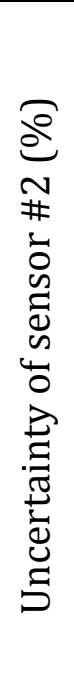 } & 0 & 45.30 & 45.20 & 44.18 & 40.86 & 35.40 & 25.99 & 18.53 & 12.18 & 4.41 & 0.56 \\
\hline & 10 & 45.20 & 45.24 & 44.58 & 41.75 & 36.72 & 27.62 & 20.32 & 14.02 & 6.15 & 2.32 \\
\hline & 20 & 44.18 & 44.58 & 45.05 & 43.55 & 39.84 & 31.93 & 25.00 & 18.88 & 11.22 & 7.27 \\
\hline & 30 & 40.86 & 41.75 & 43.55 & 44.15 & 42.58 & 36.52 & 30.94 & 25.27 & 17.75 & 13.75 \\
\hline & 40 & 35.40 & 36.72 & 39.84 & 42.58 & 44.02 & 40.50 & 36.81 & 32.31 & 25.25 & 21.68 \\
\hline & 50 & 25.99 & 27.62 & 31.93 & 36.52 & 40.50 & 41.37 & 39.86 & 37.09 & 32.43 & 29.59 \\
\hline & 60 & 18.53 & 20.32 & 25.00 & 30.94 & 36.81 & 39.86 & 40.81 & 40.11 & 37.49 & 35.21 \\
\hline & 70 & 12.18 & 14.02 & 18.88 & 25.27 & 32.31 & 37.09 & 40.11 & 39.65 & 38.52 & 36.30 \\
\hline & 80 & 4.41 & 6.15 & 11.22 & 17.75 & 25.25 & 32.43 & 37.49 & 38.52 & 39.50 & 38.51 \\
\hline & 90 & 0.56 & 2.32 & 7.27 & 13.75 & 21.68 & 29.59 & 35.21 & 36.30 & 38.51 & 37.02 \\
\hline
\end{tabular}




\begin{tabular}{|c|c|c|c|c|c|c|c|c|c|c|c|}
\hline \multicolumn{12}{|c|}{$\begin{array}{l}\text { Absolute error improvement }(\%) \text { with } 120 \mathrm{~min} \text { separation time } \\
\text { Grid size } 250 \mathrm{~km} \text { pixel resolution } 12 \mathrm{~km}\end{array}$} \\
\hline \multirow{2}{*}{\multicolumn{2}{|c|}{$\begin{array}{l}\text { \# of events: } \\
15,000\end{array}$}} & \multicolumn{10}{|c|}{ Uncertainty of sensor \#1 (\%) } \\
\hline & & 0 & 10 & 20 & 30 & 40 & 50 & 60 & 70 & 80 & 90 \\
\hline \multirow{10}{*}{ 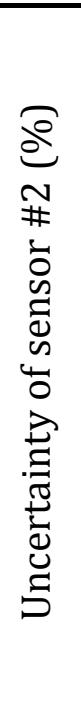 } & 0 & 47.54 & 47.03 & 45.52 & 42.09 & 36.92 & 30.65 & 24.06 & 18.82 & 13.44 & 9.83 \\
\hline & 10 & 47.03 & 46.62 & 45.45 & 42.47 & 37.62 & 31.65 & 25.16 & 19.95 & 14.47 & 10.86 \\
\hline & 20 & 45.52 & 45.45 & 45.23 & 43.41 & 39.70 & 34.47 & 28.33 & 23.27 & 17.80 & 14.14 \\
\hline & 30 & & 42.47 & 43.41 & 43.46 & 41.65 & 37.96 & 32.77 & 28.09 & 22.55 & 18.95 \\
\hline & 40 & 36.92 & 37.62 & 39.70 & 41.65 & 42.19 & 40.41 & 36.73 & 33.03 & 27.91 & 24.69 \\
\hline & 50 & 30.65 & 31.65 & 34.47 & 37.96 & 40.41 & 41.04 & 39.29 & 36.75 & 32.97 & 30.20 \\
\hline & 60 & 24.06 & 25.16 & 28.33 & 32.77 & 36.73 & 39.29 & 39.69 & 38.73 & 36.33 & 34.38 \\
\hline & 70 & 18.82 & 19.95 & 23.27 & 28.09 & 33.03 & 36.75 & 38.73 & 39.07 & 37.78 & 36.48 \\
\hline & 80 & 13.44 & 14.47 & 17.80 & 22.55 & 27.91 & 32.97 & 36.33 & 37.78 & 37.86 & 37.72 \\
\hline & 90 & 9.83 & 10.86 & 14.14 & 18.95 & 24.69 & 30.20 & 34.38 & 36.48 & 37.72 & 37.6 \\
\hline
\end{tabular}

\begin{tabular}{|c|c|c|c|c|c|c|c|c|c|c|c|}
\hline \multicolumn{12}{|c|}{$\begin{array}{l}\text { RMS error improvement (\%) with } 180 \mathrm{~min} \text { separation time } \\
\text { Grid size } 250 \mathrm{~km} \text { pixel resolution } 12 \mathrm{~km}\end{array}$} \\
\hline \multirow{2}{*}{\multicolumn{2}{|c|}{$\begin{array}{l}\text { \# of events: } \\
15,000\end{array}$}} & \multicolumn{10}{|c|}{ Uncertainty of sensor \#1 (\%) } \\
\hline & & 0 & 10 & 20 & 30 & 40 & 50 & 60 & 70 & 80 & 90 \\
\hline \multirow{10}{*}{ 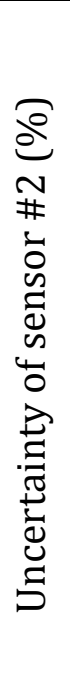 } & 0 & 30.10 & 30.03 & 29.21 & 27.81 & 23.47 & 18.14 & 11.64 & 5.59 & 0.28 & -3.93 \\
\hline & 10 & 30.03 & 30.05 & 29.36 & 28.35 & 24.30 & 19.33 & 12.90 & 7.10 & 1.66 & -2.40 \\
\hline & 20 & 29.21 & 29.36 & 29.22 & 29.16 & 25.95 & 21.93 & 15.99 & 10.30 & 5.16 & 1.22 \\
\hline & 30 & 27.81 & 28.35 & 29.16 & 30.95 & 29.37 & 26.81 & 22.07 & 17.18 & 12.16 & 8.85 \\
\hline & 40 & 23.47 & 24.30 & 25.95 & 29.37 & 29.23 & 28.87 & 25.90 & 22.21 & 17.67 & 15.31 \\
\hline & 50 & 18.14 & 19.33 & 21.93 & 26.81 & 28.87 & 30.58 & 30.23 & 27.39 & 23.42 & 22.24 \\
\hline & 60 & 11.64 & 12.9 & 15.99 & 22.07 & 25.9 & 30.23 & 30.98 & 30.18 & 27.71 & 27.09 \\
\hline & 70 & 5.59 & 7.10 & 10.30 & 17.18 & 22.21 & 27.39 & 30.18 & 30.48 & 29.03 & 28.93 \\
\hline & 80 & 0.28 & 1.66 & 5.16 & 12.16 & 17.67 & 23.42 & 27.71 & 29.03 & 28.39 & 29.68 \\
\hline & 90 & -3.93 & -2.40 & 1.22 & 8.85 & 15.31 & 22.24 & 27.09 & 28.93 & 29.68 & 31.44 \\
\hline
\end{tabular}




\begin{tabular}{|c|c|c|c|c|c|c|c|c|c|c|c|}
\hline \multicolumn{12}{|c|}{$\begin{array}{c}\text { Absolute error improvement (\%) with } \mathbf{1 8 0} \text { min separation time } \\
\text { Grid size } 250 \mathrm{~km} \text { pixel resolution } 12 \mathrm{~km}\end{array}$} \\
\hline \multirow{2}{*}{\multicolumn{2}{|c|}{$\begin{array}{l}\text { \# of events: } \\
\quad 15,000\end{array}$}} & \multicolumn{10}{|c|}{ Uncertainty of sensor \#1 (\%) } \\
\hline & & $\mathbf{0}$ & 10 & 20 & 30 & 40 & 50 & 60 & 70 & 80 & 90 \\
\hline \multirow{10}{*}{ 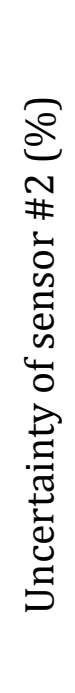 } & $\mathbf{0}$ & 36.00 & 35.72 & 34.73 & 32.50 & 28.33 & 23.82 & 18.27 & 13.37 & 8.77 & 5.08 \\
\hline & 10 & 35.72 & 35.46 & 34.65 & 32.71 & 28.84 & 24.58 & 19.12 & 14.33 & 9.68 & 6.02 \\
\hline & 20 & 34.73 & 34.65 & 34.47 & 33.56 & 30.51 & 26.91 & 21.89 & 17.28 & 12.62 & 9.07 \\
\hline & 30 & 32.50 & 32.71 & 33.56 & 34.31 & 32.78 & 30.49 & 26.32 & 22.28 & 17.75 & 14.47 \\
\hline & 40 & 28.33 & 28.84 & 30.51 & 32.78 & 33.03 & 32.54 & 29.85 & 26.76 & 22.65 & 19.86 \\
\hline & 50 & 23.82 & 24.58 & 26.91 & 30.49 & 32.54 & 33.64 & 32.77 & 30.79 & 27.25 & 25.46 \\
\hline & 60 & 18.27 & 19.12 & 21.89 & 26.32 & 29.85 & 32.77 & 33.06 & 32.53 & 30.21 & 29.04 \\
\hline & 70 & 13.37 & 14.33 & 17.28 & 22.28 & 26.76 & 30.79 & 32.53 & 33.36 & 32.04 & 31.34 \\
\hline & 80 & 8.77 & 9.68 & 12.62 & 17.75 & 22.65 & 27.25 & 30.21 & 32.04 & 31.21 & 31.90 \\
\hline & 90 & 5.08 & 6.02 & 9.07 & 14.47 & 19.86 & 25.46 & 29.04 & 31.34 & 31.90 & 33.05 \\
\hline
\end{tabular}




\section{Appendix E}

\begin{tabular}{|c|c|c|c|c|c|c|c|c|c|c|c|}
\hline \multicolumn{12}{|c|}{$\begin{array}{l}\text { RMS error improvement (\%) with random separation time } \\
\text { Grid size } 100 \mathrm{~km} \text { pixel resolution } 24 \mathrm{~km}\end{array}$} \\
\hline \multirow{2}{*}{\multicolumn{2}{|c|}{$\begin{array}{l}\text { \# of events: } \\
15,000\end{array}$}} & \multicolumn{10}{|c|}{ Uncertainty of sensor \#1 (\%) } \\
\hline & & $\mathbf{0}$ & 10 & 20 & 30 & 40 & 50 & 60 & 70 & 80 & 90 \\
\hline \multirow{10}{*}{ 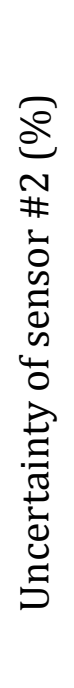 } & 0 & 13.78 & 13.76 & 13.77 & 13.86 & 12.47 & 11.86 & 11.78 & 9.44 & 9.42 & 7.88 \\
\hline & 10 & 13.76 & 13.73 & 13.78 & 13.92 & 12.57 & 12.02 & 12.08 & 9.91 & 9.78 & 8.29 \\
\hline & 20 & 13.77 & $13.7 \varepsilon$ & 13.50 & 13.94 & 12.51 & 11.89 & 12.02 & 9.75 & 9.65 & 8.30 \\
\hline & 30 & 13.86 & 13.92 & 13.94 & 13.96 & 13.08 & 12.75 & 13.25 & 10.85 & 10.71 & 8.89 \\
\hline & 40 & 12.47 & 12.57 & 12.51 & 13.08 & 12.51 & 11.92 & 12.18 & 9.75 & 9.95 & 8.43 \\
\hline & 50 & 11.86 & 12.02 & 11.89 & 12.75 & 11.92 & 9.73 & 12.00 & 8.94 & 8.58 & 8.22 \\
\hline & 60 & 11.78 & 12.08 & 12.02 & 13.25 & 12.18 & 12.00 & 12.25 & 10.29 & 9.72 & 8.32 \\
\hline & 70 & 9.44 & 9.91 & 9.75 & 10.85 & 9.75 & 8.94 & 10.29 & 7.04 & 7.73 & 6.41 \\
\hline & 80 & 9.42 & 9.78 & 9.65 & 10.71 & 9.95 & 8.58 & 9.72 & 7.73 & 6.63 & 5.79 \\
\hline & 90 & 7.88 & 8.29 & 8.30 & 8.89 & 8.43 & 8.22 & 8.32 & 6.41 & 5.79 & 4.68 \\
\hline
\end{tabular}




\begin{tabular}{|c|c|c|c|c|c|c|c|c|c|c|c|}
\hline \multicolumn{12}{|c|}{$\begin{array}{l}\text { Absolute error improvement (\%) with random separation time } \\
\text { Grid size } 100 \mathrm{~km} \text { pixel resolution } 24 \mathrm{~km}\end{array}$} \\
\hline \multirow{2}{*}{\multicolumn{2}{|c|}{$\begin{array}{l}\text { \# of events: } \\
15,000\end{array}$}} & \multicolumn{10}{|c|}{ Uncertainty of sensor \#1 (\%) } \\
\hline & & 0 & 10 & 20 & 30 & 40 & 50 & 60 & 70 & 80 & 90 \\
\hline \multirow{10}{*}{ 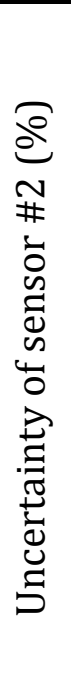 } & 0 & 21.64 & 21.16 & 20.53 & 20.10 & 18.73 & 17.63 & 17.07 & 15.64 & 15.14 & 14.26 \\
\hline & 10 & 21.16 & 20.58 & 20.06 & 19.67 & 18.34 & 17.20 & 16.74 & 15.40 & 14.87 & 13.90 \\
\hline & 20 & 20.53 & 20.06 & 19.22 & 19.10 & 17.68 & 16.59 & 16.11 & 14.77 & 14.16 & 13.40 \\
\hline & 30 & 20.10 & 19.67 & 19.10 & 18.57 & 17.66 & 16.59 & 16.33 & 15.00 & 14.28 & 13.02 \\
\hline & 40 & 18.73 & 18.34 & 17.68 & 17.66 & 16.76 & 15.71 & 15.20 & 14.04 & 13.47 & 12.64 \\
\hline & 50 & 17.63 & 17.20 & 16.59 & 16.59 & 15.71 & 13.46 & 14.15 & 12.80 & 11.91 & 11.17 \\
\hline & 60 & 17.07 & 16.74 & 16.11 & 16.33 & 15.20 & 14.15 & 13.51 & 12.86 & 11.69 & 10.39 \\
\hline & 70 & 15.64 & 15.40 & 14.77 & 15.00 & 14.04 & 12.8 & 12.86 & 10.22 & 10.80 & 9.53 \\
\hline & 80 & 15.14 & 14.87 & 14.16 & 14.28 & 13.47 & 11.91 & 11.69 & 10.80 & 9.62 & 8.28 \\
\hline & 90 & 14.26 & 13.90 & 13.40 & 13.02 & 12.64 & 11.17 & 10.39 & 9.53 & 8.28 & 6.76 \\
\hline
\end{tabular}

\begin{tabular}{|c|c|c|c|c|c|c|c|c|c|c|c|}
\hline \multicolumn{12}{|c|}{$\begin{array}{l}\text { RMS error improvement (\%) with random separation time } \\
\text { Grid size } 100 \mathrm{~km} \text { pixel resolution } 12 \mathrm{~km}\end{array}$} \\
\hline \multirow{2}{*}{\multicolumn{2}{|c|}{$\begin{array}{l}\text { \# of events: } \\
15,000\end{array}$}} & \multicolumn{10}{|c|}{ Uncertainty of sensor \#1 (\%) } \\
\hline & & $\mathbf{0}$ & 10 & 20 & 30 & 40 & 50 & 60 & 70 & 80 & 90 \\
\hline \multirow{10}{*}{ 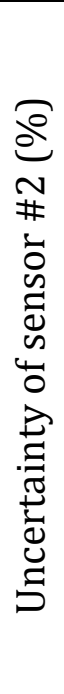 } & $\mathbf{0}$ & 10.98 & 10.94 & 10.76 & 10.01 & 9.44 & 8.32 & 6.64 & 6.41 & 4.47 & 4.70 \\
\hline & 10 & 10.94 & 10.91 & 10.83 & 10.22 & 9.73 & 8.65 & 7.01 & 6.87 & 5.02 & 5.12 \\
\hline & 20 & 10.76 & 10.83 & 11.14 & 10.91 & 10.65 & 9.70 & 8.40 & 7.92 & 6.34 & 6.43 \\
\hline & 30 & 10.01 & 10.22 & 10.91 & 11.28 & 11.26 & 10.75 & 9.88 & 9.34 & 7.71 & 7.70 \\
\hline & 40 & 9.44 & 9.73 & 10.65 & 11.26 & 11.38 & 11.26 & 10.62 & 10.08 & 8.75 & 8.53 \\
\hline & 50 & 8.32 & 8.65 & 9.700 & 10.75 & 11.26 & 11.33 & 11.08 & 10.78 & 9.40 & 9.37 \\
\hline & 60 & 6.64 & 7.01 & 8.40 & 9.88 & 10.62 & 11.08 & 11.39 & 10.57 & 10.53 & 9.41 \\
\hline & 70 & 6.41 & 6.87 & 7.92 & 9.34 & 10.08 & 10.78 & 10.57 & 9.77 & 9.03 & 8.92 \\
\hline & 80 & 4.47 & 5.02 & 6.34 & 7.71 & 8.75 & 9.40 & 10.53 & 9.03 & 8.87 & 8.41 \\
\hline & 90 & 4.70 & 5.12 & 6.43 & 7.7 & 8.53 & 9.37 & 9.41 & 8.92 & 8.41 & 7.54 \\
\hline
\end{tabular}




\begin{tabular}{|c|c|c|c|c|c|c|c|c|c|c|c|}
\hline \multicolumn{12}{|c|}{$\begin{array}{l}\text { Absolute error improvement }(\%) \text { with random separation time } \\
\text { Grid size } 100 \mathrm{~km} \text { pixel resolution } 12 \mathrm{~km}\end{array}$} \\
\hline \multirow{2}{*}{\multicolumn{2}{|c|}{$\begin{array}{l}\text { \# of events: } \\
15,000\end{array}$}} & \multicolumn{10}{|c|}{ Uncertainty of sensor \#1 (\%) } \\
\hline & & 0 & 10 & 20 & 30 & 40 & 50 & 60 & 70 & 80 & 90 \\
\hline \multirow{10}{*}{ 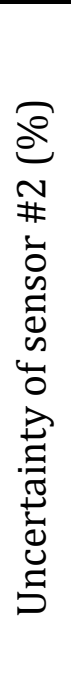 } & 0 & 19.57 & 19.15 & 18.52 & 17.29 & 16.09 & 14.39 & 13.07 & 12.02 & 10.66 & 10.33 \\
\hline & 10 & 19.15 & 18.74 & 18.27 & 17.22 & 16.10 & 14.49 & 13.18 & 12.19 & 10.95 & 10.44 \\
\hline & 20 & 18.52 & 18.27 & 18.30 & 17.71 & 16.96 & 15.56 & 14.41 & 13.31 & 12.08 & 11.67 \\
\hline & 30 & 17.29 & 17.22 & 17.71 & 17.69 & 17.48 & 16.58 & 15.74 & 14.67 & 13.43 & 13.01 \\
\hline & 40 & 16.09 & 16.10 & 16.96 & 17.48 & 17.61 & 17.19 & 16.71 & 15.86 & 14.76 & 14.34 \\
\hline & 50 & 14.39 & 14.49 & 15.56 & 16.58 & 17.19 & 17.15 & 17.10 & 16.48 & 15.33 & 15.05 \\
\hline & 60 & 13.07 & 13.18 & 14.41 & 15.74 & 16.71 & 17.10 & 17.11 & 16.70 & 16.13 & 15.76 \\
\hline & 70 & 12.02 & 12.19 & 13.31 & 14.67 & 15.86 & 16.48 & 16.70 & 15.85 & 15.29 & 15.14 \\
\hline & 80 & 10.66 & 10.95 & 12.08 & 13.43 & 14.76 & 15.33 & 16.13 & 15.29 & 14.41 & 14.54 \\
\hline & 90 & 10.33 & 10.44 & 11.67 & 13.01 & 14.34 & 15.05 & 15.76 & 15.14 & 14.54 & 13.58 \\
\hline
\end{tabular}

\begin{tabular}{|c|c|c|c|c|c|c|c|c|c|c|c|}
\hline \multicolumn{12}{|c|}{$\begin{array}{c}\text { RMS error improvement (\%) with random separation time } \\
\text { Grid size } 100 \mathrm{~km} \text { pixel resolution } 8 \mathrm{~km}\end{array}$} \\
\hline \multirow{2}{*}{\multicolumn{2}{|c|}{$\begin{array}{l}\text { \# of events: } \\
15,000\end{array}$}} & \multicolumn{10}{|c|}{ Uncertainty of sensor \#1 (\%) } \\
\hline & & 0 & 10 & 20 & 30 & 40 & 50 & 60 & 70 & 80 & 90 \\
\hline \multirow{10}{*}{ 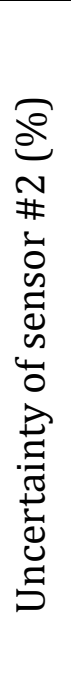 } & 0 & 10.00 & 9.98 & 9.81 & 9.28 & 8.16 & 6.12 & 5.26 & 3.79 & 3.06 & 3.15 \\
\hline & 10 & 9.98 & 10.00 & 9.90 & 9.51 & 8.50 & 6.58 & 5.74 & 4.43 & 3.62 & 3.74 \\
\hline & 20 & 9.81 & 9.9 & 10.04 & 10.18 & 9.44 & 7.93 & 7.27 & 6.15 & 5.36 & 5.45 \\
\hline & 30 & 9.28 & 9.51 & 10.18 & 10.88 & 10.75 & 9.93 & 9.25 & 8.52 & 7.57 & 7.57 \\
\hline & 40 & 8.16 & 8.5 & 9.44 & 10.75 & 11.16 & 10.73 & 10.30 & 9.86 & 9.11 & 9.15 \\
\hline & 50 & 6.12 & 6.58 & 7.93 & 9.93 & 10.73 & 11.04 & 10.97 & 11.18 & 10.26 & 10.59 \\
\hline & 60 & 5.26 & 5.74 & 7.27 & 9.25 & 10.30 & 10.97 & 11.09 & 11.50 & 11.00 & 11.20 \\
\hline & 70 & 3.79 & 4.43 & 6.15 & 8.52 & 9.86 & 11.18 & 11.50 & 11.86 & 11.73 & 11.84 \\
\hline & 80 & 3.06 & 3.62 & 5.36 & 7.57 & 9.11 & 10.26 & 11.00 & 11.73 & 11.50 & 11.72 \\
\hline & 90 & 3.15 & 3.74 & 5.45 & 7.57 & 9.15 & 10.59 & 11.20 & 11.84 & 11.72 & 11.71 \\
\hline
\end{tabular}




\begin{tabular}{|c|c|c|c|c|c|c|c|c|c|c|c|}
\hline \multicolumn{12}{|c|}{$\begin{array}{l}\text { Absolute error improvement }(\%) \text { with random separation time } \\
\qquad \text { Grid size } 100 \mathrm{~km} \text { pixel resolution } 8 \mathrm{~km}\end{array}$} \\
\hline \multirow{2}{*}{\multicolumn{2}{|c|}{$\begin{array}{l}\text { \# of events: } \\
15,000\end{array}$}} & \multicolumn{10}{|c|}{ Uncertainty of sensor \#1 (\%) } \\
\hline & & 0 & 10 & 20 & 30 & 40 & 50 & 60 & 70 & 80 & 90 \\
\hline \multirow{10}{*}{ 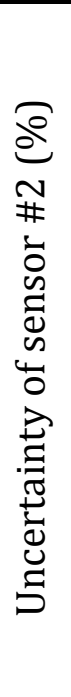 } & 0 & 19.35 & 19.03 & 18.44 & 17.43 & 15.77 & 13.85 & 12.22 & 10.88 & 9.69 & 9.38 \\
\hline & 10 & 19.03 & 18.77 & 18.34 & 17.51 & 15.94 & 14.09 & 12.51 & 11.2 & 10.06 & 9.70 \\
\hline & 20 & 18.44 & 18.34 & 18.35 & 18.15 & 17.03 & 15.54 & 14.09 & 12.88 & 11.78 & 11.39 \\
\hline & 30 & 17.43 & 17.51 & 18.15 & 18.69 & 18.22 & 17.35 & 16.17 & 15.10 & 14.21 & 13.74 \\
\hline & 40 & 15.77 & 15.94 & 17.03 & 18.22 & 18.55 & 18.26 & 17.50 & 16.74 & 16.14 & 15.57 \\
\hline & 50 & 13.85 & 14.09 & 15.54 & 17.35 & 18.26 & 18.76 & 18.48 & 18.31 & 17.77 & 17.52 \\
\hline & 60 & 12.22 & 12.51 & 14.09 & 16.17 & 17.50 & 18.48 & 18.51 & 18.72 & 18.55 & 18.32 \\
\hline & 70 & 10.88 & 11.2 & 12.88 & 15.10 & 16.74 & 18.31 & 18.72 & 18.81 & 19.04 & 18.88 \\
\hline & 80 & 9.69 & 10.06 & 11.78 & 14.21 & 16.14 & 17.77 & 18.55 & 19.04 & 19.24 & 19.20 \\
\hline & 90 & 9.38 & 9.70 & 11.39 & 13.74 & 15.57 & 17.52 & 18.32 & 18.88 & 19.20 & 18.8 \\
\hline
\end{tabular}

\begin{tabular}{|c|c|c|c|c|c|c|c|c|c|c|c|}
\hline \multicolumn{12}{|c|}{$\begin{array}{l}\text { RMS error improvement (\%) with random separation time } \\
\text { Grid size } 250 \mathrm{~km} \text { pixel resolution } 24 \mathrm{~km}\end{array}$} \\
\hline \multirow{2}{*}{\multicolumn{2}{|c|}{$\begin{array}{l}\text { \# of events: } \\
15,000\end{array}$}} & \multicolumn{10}{|c|}{ Uncertainty of sensor \#1 (\%) } \\
\hline & & $\mathbf{0}$ & 10 & 20 & 30 & 40 & 50 & 60 & 70 & 80 & 90 \\
\hline \multirow{10}{*}{ 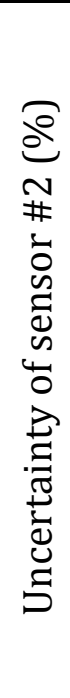 } & $\mathbf{0}$ & 11.56 & 11.52 & 11.01 & 9.86 & 8.12 & 6.54 & 4.84 & 3.83 & 3.03 & 2.46 \\
\hline & 10 & 11.52 & 11.54 & 11.24 & 10.17 & 8.49 & 6.92 & 5.24 & 4.28 & 3.39 & 2.68 \\
\hline & 20 & 11.01 & 11.24 & 11.32 & 10.69 & 9.40 & 7.99 & 6.42 & 5.48 & 4.38 & 3.60 \\
\hline & 30 & 9.86 & 10.17 & 10.69 & 10.57 & 10.04 & 9.12 & 7.72 & 6.82 & 5.73 & 5.02 \\
\hline & 40 & 8.12 & 8.49 & 9.40 & 10.04 & 10.02 & 9.38 & 8.64 & 8.11 & 6.76 & 6.28 \\
\hline & 50 & 6.54 & 6.92 & 7.99 & 9.12 & 9.38 & 9.09 & 9.00 & 8.86 & 7.83 & 7.38 \\
\hline & 60 & 4.84 & 5.24 & 6.42 & 7.72 & 8.64 & 9.00 & 9.41 & 9.50 & 8.49 & 7.96 \\
\hline & 70 & 3.83 & 4.28 & 5.48 & 6.82 & 8.11 & 8.86 & 9.50 & 9.66 & 8.75 & 8.65 \\
\hline & 80 & 3.03 & 3.39 & 4.38 & 5.73 & 6.76 & 7.83 & 8.49 & 8.75 & 8.15 & 7.83 \\
\hline & 90 & 2.46 & 2.68 & 3.60 & 5.02 & 6.28 & 7.38 & 7.96 & 8.65 & 7.83 & 8.30 \\
\hline
\end{tabular}




\begin{tabular}{|c|c|c|c|c|c|c|c|c|c|c|c|}
\hline \multicolumn{12}{|c|}{$\begin{array}{l}\text { Absolute error improvement (\%) with random separation time } \\
\text { Grid size } 250 \mathrm{~km} \text { pixel resolution } 24 \mathrm{~km}\end{array}$} \\
\hline \multirow{2}{*}{\multicolumn{2}{|c|}{$\begin{array}{l}\text { \# of events: } \\
15,000\end{array}$}} & \multicolumn{10}{|c|}{ Uncertainty of sensor \#1 (\%) } \\
\hline & & 0 & 10 & 20 & 30 & 40 & 50 & 60 & 70 & 80 & 90 \\
\hline \multirow{10}{*}{ 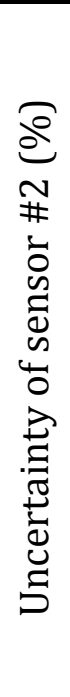 } & 0 & 21.75 & 20.93 & 19.15 & 16.70 & 14.37 & 11.97 & 10.32 & 8.59 & 8.08 & 7.51 \\
\hline & 10 & 20.93 & 20.29 & 18.91 & 16.66 & 14.44 & 11.98 & 10.32 & 8.60 & 7.99 & 7.30 \\
\hline & 20 & 19.15 & 18.91 & 18.34 & 16.84 & 15.03 & 12.66 & 10.99 & 9.37 & 8.53 & 7.72 \\
\hline & 30 & 16.70 & 16.66 & 16.84 & 16.32 & 15.40 & 13.57 & 12.08 & 10.42 & 9.56 & 8.71 \\
\hline & 40 & 14.37 & 14.44 & 15.03 & 15.40 & 15.29 & 14.02 & 13.10 & 11.77 & 10.75 & 9.67 \\
\hline & 50 & 11.97 & 11.98 & 12.66 & 13.57 & 14.02 & 13.46 & 13.14 & 12.19 & 11.19 & 10.52 \\
\hline & 60 & 10.32 & 10.32 & 10.99 & 12.08 & 13.10 & 13.14 & 13.07 & 12.54 & 11.81 & 10.82 \\
\hline & 70 & 8.59 & 8.60 & 9.37 & 10.42 & 11.77 & 12.19 & 12.54 & 12.15 & 11.73 & 11.24 \\
\hline & 80 & 8.08 & 7.99 & 8.53 & 9.56 & 10.75 & 11.19 & 11.81 & 11.73 & 10.95 & 10.64 \\
\hline & 90 & 7.51 & 7.30 & 7.72 & 8.71 & 9.67 & 10.52 & 10.82 & 11.24 & 10.64 & 10.08 \\
\hline
\end{tabular}

\begin{tabular}{|c|c|c|c|c|c|c|c|c|c|c|c|}
\hline \multicolumn{12}{|c|}{$\begin{array}{l}\text { RMS error improvement (\%) with random separation time } \\
\text { Grid size } 250 \mathrm{~km} \text { pixel resolution } 12 \mathrm{~km}\end{array}$} \\
\hline \multirow{2}{*}{\multicolumn{2}{|c|}{$\begin{array}{l}\text { \# of events: } \\
15,000\end{array}$}} & \multicolumn{10}{|c|}{ Uncertainty of sensor \#1 (\%) } \\
\hline & & 0 & 10 & 20 & 30 & 40 & 50 & 60 & 70 & 80 & 90 \\
\hline \multirow{10}{*}{ 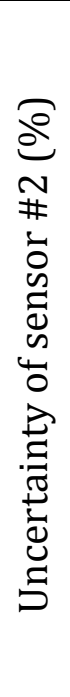 } & 0 & 15.26 & 15.17 & 14.41 & 13.05 & 10.76 & 8.17 & 5.29 & 3.14 & 0.31 & -0.84 \\
\hline & 10 & 15.17 & 15.15 & 14.58 & 13.42 & 11.25 & 8.76 & 5.93 & 3.76 & 0.90 & -0.28 \\
\hline & 20 & 14.41 & 14.58 & 14.54 & 13.95 & 12.36 & 10.25 & 7.57 & 5.44 & 2.51 & 1.34 \\
\hline & 30 & 13.05 & 13.42 & 13.95 & 14.16 & 13.40 & 12.00 & 9.59 & 7.74 & 4.91 & 3.68 \\
\hline & 40 & 10.76 & 11.25 & 12.36 & 13.4 & 13.74 & 13.19 & 11.71 & 10.09 & 7.65 & 6.36 \\
\hline & 50 & 8.17 & 8.76 & 10.25 & 12.00 & 13.19 & 13.67 & 12.99 & 11.94 & 10.11 & 9.05 \\
\hline & 60 & 5.29 & 5.93 & 7.57 & 9.59 & 11.71 & 12.99 & 13.33 & 12.91 & 11.96 & 10.93 \\
\hline & 70 & 3.14 & 3.76 & 5.44 & 7.74 & 10.09 & 11.94 & 12.91 & 13.26 & 12.7 & 12.14 \\
\hline & 80 & 0.31 & 0.90 & 2.51 & 4.91 & 7.65 & 10.11 & 11.96 & 12.70 & 12.96 & 12.67 \\
\hline & 90 & -0.84 & -0.28 & 1.34 & 3.68 & 6.36 & 9.05 & 10.93 & 12.14 & 12.67 & 12.39 \\
\hline
\end{tabular}




\begin{tabular}{|c|c|c|c|c|c|c|c|c|c|c|c|}
\hline \multicolumn{12}{|c|}{$\begin{array}{l}\text { Absolute error improvement (\%) with random separation time } \\
\qquad \text { Grid size } 250 \mathrm{~km} \text { pixel resolution } 12 \mathrm{~km}\end{array}$} \\
\hline \multirow{2}{*}{\multicolumn{2}{|c|}{$\begin{array}{l}\text { \# of events: } \\
15,000\end{array}$}} & \multicolumn{10}{|c|}{ Uncertainty of sensor \#1 (\%) } \\
\hline & & 0 & 10 & 20 & 30 & 40 & 50 & 60 & 70 & 80 & 90 \\
\hline \multirow{10}{*}{ 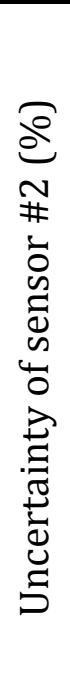 } & 0 & 22.94 & 22.24 & 20.41 & 18.00 & 14.86 & 11.89 & 9.27 & 6.87 & 4.91 & 3.77 \\
\hline & 10 & 22.24 & 21.74 & 20.30 & 18.16 & 15.13 & 12.20 & 9.57 & 7.11 & 5.12 & 3.92 \\
\hline & 20 & 20.41 & 20.30 & 19.81 & 18.55 & 16.20 & 13.62 & 11.04 & 8.60 & 6.46 & 5.19 \\
\hline & 30 & 18.00 & 18.16 & 18.55 & 18.49 & 17.14 & 15.27 & 12.94 & 10.60 & 8.44 & 7.04 \\
\hline & 40 & 14.86 & 15.13 & 16.20 & 17.14 & 17.13 & 16.32 & 14.72 & 12.73 & 10.67 & 9.39 \\
\hline & 50 & 11.89 & 12.20 & 13.62 & 15.27 & 16.32 & 16.64 & 15.87 & 14.55 & 12.91 & 11.72 \\
\hline & 60 & 9.27 & 9.57 & 11.04 & 12.94 & 14.72 & 15.87 & 15.93 & 15.43 & 14.30 & 13.41 \\
\hline & 70 & 6.87 & 7.11 & 8.60 & 10.60 & 12.73 & 14.55 & 15.43 & 15.86 & 15.28 & 14.93 \\
\hline & 80 & 4.91 & 5.12 & 6.46 & 8.44 & 10.67 & 12.91 & 14.30 & 15.28 & 15.14 & 15.18 \\
\hline & 90 & 3.77 & 3.92 & 5.19 & 7.04 & 9.39 & 11.72 & 13.41 & 14.93 & 15.18 & 15.41 \\
\hline
\end{tabular}

\begin{tabular}{|c|c|c|c|c|c|c|c|c|c|c|c|}
\hline & & 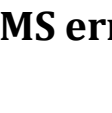 & $\begin{array}{r}\mathbf{r} \text { imp } \\
\text { Gri }\end{array}$ & $\begin{array}{l}\text { rovem } \\
\text { d size }\end{array}$ & $\begin{array}{l}\text { ent (\%) } \\
50 \mathrm{~km}\end{array}$ & $\begin{array}{l}\text { with } \\
\text { ixel re }\end{array}$ & olutios & $8 \mathrm{~km}$ & 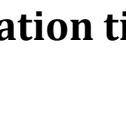 & & \\
\hline \# of & ints: & & & & Uncerta & 11718y or & sensor & $\# 1(\%)$ & & & \\
\hline & & 0 & 10 & 20 & 30 & 40 & 50 & 60 & 70 & 80 & 90 \\
\hline & 0 & 14.34 & 14.25 & 13.76 & 12.35 & 10.87 & 8.49 & 5.84 & 3.95 & 0.85 & -0.15 \\
\hline 8 & 10 & 14.25 & 14.22 & 13.86 & 12.61 & 11.24 & 8.93 & 6.36 & 4.47 & 1.30 & 0.30 \\
\hline$\underbrace{N}_{\sim}$ & 20 & 13.76 & 13.86 & 13.88 & 13.09 & 12.08 & 10.14 & 7.75 & 5.94 & 2.81 & 1.69 \\
\hline 0 & 30 & 12.35 & 12.61 & 13.09 & 13.06 & 12.73 & 11.51 & 9.65 & 8.08 & 5.02 & 3.88 \\
\hline d & 40 & 10.87 & 11.24 & 12.08 & 12.73 & 13.06 & 12.56 & 11.26 & 9.99 & 7.04 & 5.97 \\
\hline 4 & 50 & 8.49 & 8.93 & 10.14 & 11.51 & 12.56 & 13.00 & 12.67 & 11.99 & 9.64 & 8.57 \\
\hline. & 60 & 5.84 & 6.36 & 7.75 & 9.65 & 11.26 & 12.67 & 12.94 & 12.83 & 11.18 & 10.58 \\
\hline 离 & 70 & 3.95 & 4.47 & 5.94 & 8.08 & 9.99 & 11.99 & 12.83 & 13.24 & 12.31 & 11.54 \\
\hline$\Xi$ & 80 & 0.85 & 1.30 & 2.81 & 5.02 & 7.04 & 9.64 & 11.18 & 12.31 & 12.18 & 11.83 \\
\hline & 90 & -0.15 & 0.30 & 1.69 & 3.88 & 5.97 & 8.57 & 10.58 & 11.54 & 11.83 & 11.70 \\
\hline
\end{tabular}




\begin{tabular}{|c|c|c|c|c|c|c|c|c|c|c|c|}
\hline \multicolumn{12}{|c|}{$\begin{array}{l}\text { Absolute error improvement }(\%) \text { with random separation time } \\
\qquad \text { Grid size } 250 \mathrm{~km} \text { pixel resolution } 8 \mathrm{~km}\end{array}$} \\
\hline \multirow{2}{*}{\multicolumn{2}{|c|}{$\begin{array}{l}\text { \# of events: } \\
15,000\end{array}$}} & \multicolumn{10}{|c|}{ Uncertainty of sensor \#1 (\%) } \\
\hline & & 0 & 10 & 20 & 30 & 40 & 50 & 60 & 70 & 80 & 90 \\
\hline \multirow{10}{*}{ 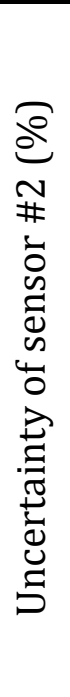 } & $\mathbf{0}$ & 22.95 & 22.32 & 20.81 & 18.32 & 15.66 & 12.67 & 9.93 & 7.67 & 5.30 & 3.75 \\
\hline & 10 & 22.32 & 21.89 & 20.73 & 18.49 & 15.97 & 13.04 & 10.30 & 8.04 & 5.62 & 4.02 \\
\hline & 20 & 20.81 & 20.73 & 20.38 & 18.97 & 16.99 & 14.39 & 11.76 & 9.45 & 6.99 & 5.24 \\
\hline & 30 & 18.32 & 18.49 & 18.97 & 18.77 & 17.82 & 16.04 & 13.79 & 11.59 & 9.10 & 7.26 \\
\hline & 40 & 15.66 & 15.97 & 16.99 & 17.82 & 17.97 & 17.26 & 15.60 & 13.76 & 11.39 & 9.56 \\
\hline & 50 & 12.67 & 13.04 & 14.39 & 16.04 & 17.26 & 17.68 & 17.08 & 15.89 & 13.99 & 12.33 \\
\hline & 60 & 9.93 & 10.3 & 11.76 & 13.79 & 15.60 & 17.08 & 17.29 & 16.82 & 15.61 & 14.35 \\
\hline & 70 & 7.67 & 8.04 & 9.45 & 11.59 & 13.76 & 15.89 & 16.82 & 16.93 & 16.52 & 15.62 \\
\hline & 80 & 5.30 & 5.62 & 6.99 & 9.10 & 11.39 & 13.99 & 15.61 & 16.52 & 16.77 & 16.44 \\
\hline & 90 & 3.75 & 4.02 & 5.24 & 7.26 & 9.56 & 12.33 & 14.35 & 15.62 & 16.44 & 16.67 \\
\hline
\end{tabular}

\begin{tabular}{|c|c|c|c|c|c|c|c|c|c|c|c|}
\hline \multicolumn{12}{|c|}{$\begin{array}{l}\text { RMS error improvement (\%) with random separation time } \\
\text { Grid size } 500 \mathrm{~km} \text { pixel resolution } 24 \mathrm{~km}\end{array}$} \\
\hline \multirow{2}{*}{\multicolumn{2}{|c|}{$\begin{array}{l}\text { \# of events: } \\
\quad 3,500\end{array}$}} & \multicolumn{10}{|c|}{ Uncertainty of sensor \#1 (\%) } \\
\hline & & 0 & 10 & 20 & 30 & 40 & 50 & 60 & 70 & 80 & 90 \\
\hline \multirow{10}{*}{ 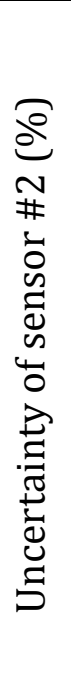 } & 0 & 16.47 & 16.28 & 15.57 & 14.2 & 12.34 & 10.22 & 7.59 & 6.17 & 3.86 & 3.01 \\
\hline & 10 & 16.28 & 16.17 & 15.6 & 14.36 & 12.59 & 10.52 & 7.87 & 6.52 & 4.23 & 3.36 \\
\hline & 20 & 15.57 & 15.60 & 15.51 & 14.72 & 13.33 & 11.56 & 9.15 & 7.80 & 5.51 & 4.54 \\
\hline & 30 & 14.20 & 14.36 & 14.72 & 14.47 & 13.50 & 12.10 & 9.95 & 8.66 & 6.59 & 5.60 \\
\hline & 40 & 12.34 & 12.59 & 13.33 & 13.50 & 13.01 & 12.04 & 10.35 & 9.32 & 7.54 & 6.36 \\
\hline & 50 & 10.22 & 10.52 & 11.56 & 12.10 & 12.04 & 11.46 & 10.35 & 9.60 & 8.12 & 7.00 \\
\hline & 60 & 7.59 & 7.87 & 9.15 & 9.95 & 10.35 & 10.35 & 10.15 & 9.80 & 8.88 & 8.02 \\
\hline & 70 & 6.17 & 6.52 & 7.80 & 8.66 & 9.32 & 9.60 & 9.80 & 9.60 & 9.25 & 8.43 \\
\hline & 80 & 3.86 & 4.23 & 5.51 & 6.59 & 7.54 & 8.12 & 8.88 & 9.25 & 9.47 & 8.91 \\
\hline & 90 & 3.01 & 3.36 & 4.54 & 5.60 & 6.36 & 7.00 & 8.02 & 8.43 & 8.91 & 8.14 \\
\hline
\end{tabular}




\begin{tabular}{|c|c|c|c|c|c|c|c|c|c|c|c|}
\hline \multicolumn{12}{|c|}{$\begin{array}{l}\text { Absolute error improvement (\%) with random separation time } \\
\text { Grid size } 500 \mathrm{~km} \text { pixel resolution } 24 \mathrm{~km}\end{array}$} \\
\hline \multirow{2}{*}{\multicolumn{2}{|c|}{$\begin{array}{l}\text { \# of events: } \\
\quad 3,500\end{array}$}} & \multicolumn{10}{|c|}{ Uncertainty of sensor \#1 (\%) } \\
\hline & & 0 & 10 & 20 & 30 & 40 & 50 & 60 & 70 & 80 & 90 \\
\hline \multirow{10}{*}{ 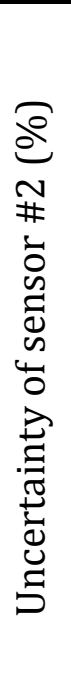 } & 0 & 24.81 & 23.94 & 22.16 & 19.74 & 16.74 & 14.33 & 11.67 & 10.59 & 8.70 & 7.81 \\
\hline & 10 & 23.94 & 23.20 & 21.69 & 19.47 & 16.59 & 14.21 & 11.53 & 10.43 & 8.55 & 7.63 \\
\hline & 20 & 22.16 & 21.69 & 20.95 & 19.41 & 16.97 & 14.74 & 12.20 & 10.99 & 9.01 & 8.01 \\
\hline & 30 & 19.74 & 19.47 & 19.41 & 18.62 & 16.89 & 15.09 & 12.78 & 11.44 & 9.58 & 8.43 \\
\hline & 40 & 16.74 & 16.59 & 16.97 & 16.89 & 16.11 & 14.86 & 13.09 & 12.14 & 10.51 & 9.16 \\
\hline & 50 & 14.33 & 14.21 & 14.74 & 15.09 & 14.86 & 13.86 & 12.76 & 11.89 & 10.59 & 9.21 \\
\hline & 60 & 11.67 & 11.53 & 12.20 & 12.78 & 13.09 & 12.76 & 12.24 & 11.58 & 10.81 & 9.61 \\
\hline & 70 & 10.59 & 10.43 & 10.99 & 11.44 & 12.14 & 11.89 & 11.58 & 11.00 & 10.66 & 9.39 \\
\hline & 80 & 8.70 & 8.55 & 9.01 & 9.58 & 10.51 & 10.59 & 10.81 & 10.66 & 10.74 & 9.77 \\
\hline & 90 & 7.81 & 7.63 & 8.01 & 8.43 & 9.16 & 9.21 & 9.61 & 9.39 & 9.77 & 8.87 \\
\hline
\end{tabular}

\begin{tabular}{|c|c|c|c|c|c|c|c|c|c|c|c|}
\hline & & IS er & $\begin{array}{r}\text { or imp } \\
\text { Gri }\end{array}$ & $\begin{array}{l}\text { rovem } \\
\text { size } 5\end{array}$ & $\begin{array}{l}\text { ent }(\%) \\
00 \mathrm{~km} \mathrm{p}\end{array}$ & $\begin{array}{l}\text { with } \\
\text { xel res }\end{array}$ & $\begin{array}{l}\text { Indo } \\
\text { lutio }\end{array}$ & $\begin{array}{l}\text { separ } \\
2 \mathrm{~km}\end{array}$ & 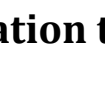 & & \\
\hline \# of & ents: & & & & Uncerta & inty of & ensor & $\neq 1(\%$ & & & \\
\hline & & 0 & 10 & 20 & 30 & 40 & 50 & 60 & 70 & 80 & 90 \\
\hline & 0 & 16.00 & 15.57 & 13.56 & 10.28 & 6.67 & 2.86 & 0.28 & -1.86 & -3.39 & -4.72 \\
\hline (2) & 10 & 15.57 & 15.37 & 13.86 & 10.89 & 7.42 & 3.60 & 0.96 & -1.26 & -2.88 & -4.29 \\
\hline$\underbrace{\sim}_{\sim}$ & 20 & 13.56 & 13.86 & 13.62 & 11.98 & 9.26 & 5.74 & 3.19 & 0.84 & -0.93 & -2.51 \\
\hline 0 & 30 & 10.28 & 10.89 & 11.98 & 12.01 & 10.7 & 8.13 & 5.83 & 3.51 & 1.59 & -0.16 \\
\hline 己્d & 40 & 6.67 & 7.42 & 9.26 & 10.7 & 10.78 & 9.56 & 7.90 & 5.91 & 4.08 & 2.25 \\
\hline 0 & 50 & 2.86 & 3.60 & 5.74 & 8.13 & 9.56 & 10.08 & 9.58 & 8.44 & 7.14 & 5.77 \\
\hline. & 60 & 0.28 & 0.96 & 3.19 & 5.83 & 7.90 & 9.58 & 9.81 & 9.31 & 8.34 & 7.49 \\
\hline 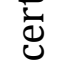 & 70 & -1.86 & -1.26 & 0.84 & 3.51 & 5.91 & 8.44 & 9.31 & 9.41 & 9.19 & 8.81 \\
\hline 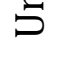 & 80 & -3.39 & -2.88 & -0.93 & 1.59 & 4.08 & 7.14 & 8.34 & 9.19 & 9.10 & 9.25 \\
\hline & 90 & -4.72 & -4.29 & -2.51 & -0.16 & 2.25 & 5.77 & 7.49 & 8.81 & 9.25 & 10.00 \\
\hline
\end{tabular}




\begin{tabular}{|c|c|c|c|c|c|c|c|c|c|c|c|}
\hline \multicolumn{12}{|c|}{$\begin{array}{c}\text { Absolute error improvement }(\%) \text { with random separation time } \\
\text { Grid size } 500 \mathrm{~km} \text { pixel resolution } 12 \mathrm{~km}\end{array}$} \\
\hline \multirow{2}{*}{\multicolumn{2}{|c|}{$\begin{array}{l}\text { \# of events: } \\
3,500\end{array}$}} & \multicolumn{10}{|c|}{ Uncertainty of sensor \#1 (\%) } \\
\hline & & $\mathbf{0}$ & 10 & 20 & 30 & 40 & 50 & 60 & 70 & 80 & 90 \\
\hline \multirow{10}{*}{ 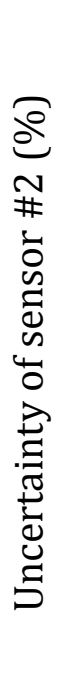 } & $\mathbf{0}$ & 24.37 & 22.84 & 19.03 & 14.46 & 10.19 & 6.72 & 3.88 & 2.15 & 0.70 & -0.33 \\
\hline & 10 & 22.84 & 22.04 & 19.16 & 14.95 & 10.79 & 7.27 & 4.36 & 2.51 & 0.96 & -0.14 \\
\hline & 20 & 19.03 & 19.16 & 18.43 & 15.92 & 12.48 & 9.13 & 6.24 & 4.22 & 2.49 & 1.17 \\
\hline & 30 & 14.46 & 14.95 & 15.92 & 15.56 & 13.80 & 11.20 & 8.50 & 6.47 & 4.48 & 2.98 \\
\hline & 40 & 10.19 & 10.79 & 12.48 & 13.80 & 13.76 & 12.46 & 10.54 & 8.83 & 6.89 & 5.28 \\
\hline & 50 & 6.72 & 7.27 & 9.13 & 11.20 & 12.46 & 12.48 & 11.69 & 10.57 & 9.04 & 7.56 \\
\hline & 60 & 3.88 & 4.36 & 6.24 & 8.50 & 10.54 & 11.69 & 11.78 & 11.38 & 10.22 & 9.26 \\
\hline & 70 & 2.15 & 2.51 & 4.22 & 6.47 & 8.83 & 10.57 & 11.38 & 11.52 & 11.11 & 10.48 \\
\hline & 80 & 0.70 & 0.96 & 2.49 & 4.48 & 6.89 & 9.04 & 10.22 & 11.11 & 11.00 & 10.93 \\
\hline & 90 & -0.33 & -0.14 & 1.17 & 2.98 & 5.28 & 7.56 & 9.26 & 10.48 & 10.93 & 11.14 \\
\hline
\end{tabular}

\begin{tabular}{|c|c|c|c|c|c|c|c|c|c|c|c|}
\hline \multicolumn{12}{|c|}{$\begin{array}{l}\text { RMS error improvement (\%) with random separation time } \\
\text { Grid size } 500 \mathrm{~km} \text { pixel resolution } 8 \mathrm{~km}\end{array}$} \\
\hline \multirow{2}{*}{\multicolumn{2}{|c|}{$\begin{array}{l}\text { \# of events: } \\
3,500\end{array}$}} & \multicolumn{10}{|c|}{ Uncertainty of sensor \#1 (\%) } \\
\hline & & 0 & 10 & 20 & 30 & 40 & 50 & 60 & 70 & 80 & 90 \\
\hline \multirow{10}{*}{ 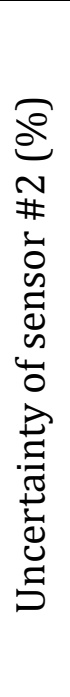 } & 0 & 12.99 & 12.7 & 11.44 & 9.07 & 6.47 & 3.71 & 1.15 & -0.51 & -2.05 & -3.64 \\
\hline & 10 & 12.70 & 12.55 & 11.57 & 9.45 & 6.96 & 4.23 & 1.67 & -0.04 & -1.63 & -3.27 \\
\hline & 20 & 11.44 & 11.57 & 11.43 & 10.20 & 8.26 & 5.78 & 3.33 & 1.50 & -0.20 & -1.94 \\
\hline & 30 & 9.07 & 9.45 & 10.20 & 10.19 & 9.21 & 7.45 & 5.43 & 3.59 & 1.91 & 0.20 \\
\hline & 40 & 6.47 & 6.96 & 8.26 & 9.21 & 9.27 & 8.33 & 6.95 & 5.41 & 3.85 & 2.15 \\
\hline & 50 & 3.71 & 4.23 & 5.78 & 7.45 & 8.33 & 8.30 & 7.80 & 6.61 & 5.46 & 4.05 \\
\hline & 60 & 1.15 & 1.67 & 3.33 & 5.43 & 6.95 & 7.80 & 7.94 & 7.33 & 6.85 & 5.79 \\
\hline & 70 & -0.51 & -0.04 & 1.50 & 3.59 & 5.41 & 6.61 & 7.33 & 7.25 & 7.08 & 6.43 \\
\hline & 80 & -2.05 & -1.63 & -0.20 & 1.91 & 3.85 & 5.46 & 6.85 & 7.08 & 7.67 & 7.55 \\
\hline & 90 & -3.64 & -3.27 & -1.94 & 0.20 & 2.15 & 4.05 & 5.79 & 6.43 & 7.55 & 7.75 \\
\hline
\end{tabular}




\begin{tabular}{|c|c|c|c|c|c|c|c|c|c|c|c|}
\hline \multicolumn{12}{|c|}{$\begin{array}{c}\text { Absolute error improvement (\%) with random separation time } \\
\text { Grid size } 500 \mathrm{~km} \text { pixel resolution } 8 \mathrm{~km}\end{array}$} \\
\hline \multirow{2}{*}{\multicolumn{2}{|c|}{$\begin{array}{l}\text { \# of events: } \\
3,500\end{array}$}} & \multicolumn{10}{|c|}{ Uncertainty of sensor \#1 (\%) } \\
\hline & & 0 & 10 & 20 & 30 & 40 & 50 & 60 & 70 & 80 & 90 \\
\hline \multirow{10}{*}{ 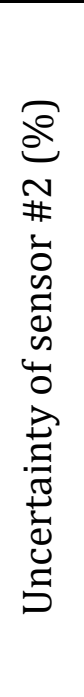 } & $\mathbf{0}$ & 22.97 & 21.72 & 18.61 & 14.50 & 10.80 & 7.48 & 4.84 & 2.73 & 1.28 & -0.06 \\
\hline & 10 & 21.72 & 20.97 & $\mid 18.57$ & 14.81 & 11.21 & 7.89 & 5.20 & 3.03 & 1.52 & 0.12 \\
\hline & 20 & 18.61 & 18.57 & 17.95 & 15.60 & 12.66 & 9.52 & 6.84 & 4.52 & 2.84 & 1.31 \\
\hline & 30 & 14.50 & 14.81 & 15.60 & 15.10 & 13.49 & 11.06 & 8.73 & 6.45 & 4.68 & 3.08 \\
\hline & 40 & 10.8 & 11.21 & 12.66 & 13.49 & 13.35 & 11.98 & 10.36 & 8.41 & 6.78 & 5.06 \\
\hline & 50 & 7.48 & 7.89 & 9.52 & 11.06 & 11.98 & 11.60 & 10.88 & 9.47 & 8.21 & 6.71 \\
\hline & 60 & 4.84 & 5.20 & 6.84 & 8.73 & 10.36 & 10.88 & 10.89 & 10.19 & 9.42 & 8.20 \\
\hline & 70 & 2.73 & 3.03 & 4.52 & 6.45 & 8.41 & 9.47 & 10.19 & 10.22 & 10.04 & 9.33 \\
\hline & 80 & 1.28 & 1.52 & 2.84 & 4.68 & 6.78 & 8.21 & 9.42 & 10.04 & 10.32 & 10.11 \\
\hline & 90 & -0.06 & 0.12 & 1.31 & 3.08 & 5.06 & 6.71 & 8.20 & 9.33 & 10.11 & 10.21 \\
\hline
\end{tabular}

